University of South Florida

DIGITAL COMMONS

@ UNIVERSITY OF SOUTH FLORIDA
Digital Commons @ University of

South Florida

$12-1-2004$

\title{
Analysis of Florida Transit Bus Accidents
}

CUTR

Follow this and additional works at: https://digitalcommons.usf.edu/cutr_nctr

\section{Recommended Citation}

"Analysis of Florida Transit Bus Accidents," National Center for Transit Research (NCTR) Report No. CUTRNCTR-RR-2003-16, Center for Urban Transportation Research, University of South Florida, 2004.

DOI: https://doi.org/10.5038/CUTR-NCTR-RR-2003-16

Available at: https://scholarcommons.usf.edu/cutr_nctr/20

This Technical Report is brought to you for free and open access by the National Center for Transit Research (NCTR) Archive (2000-2020) at Digital Commons @ University of South Florida. It has been accepted for inclusion in Research Reports by an authorized administrator of Digital Commons @ University of South Florida. For more information, please contact digitalcommons@usf.edu. 


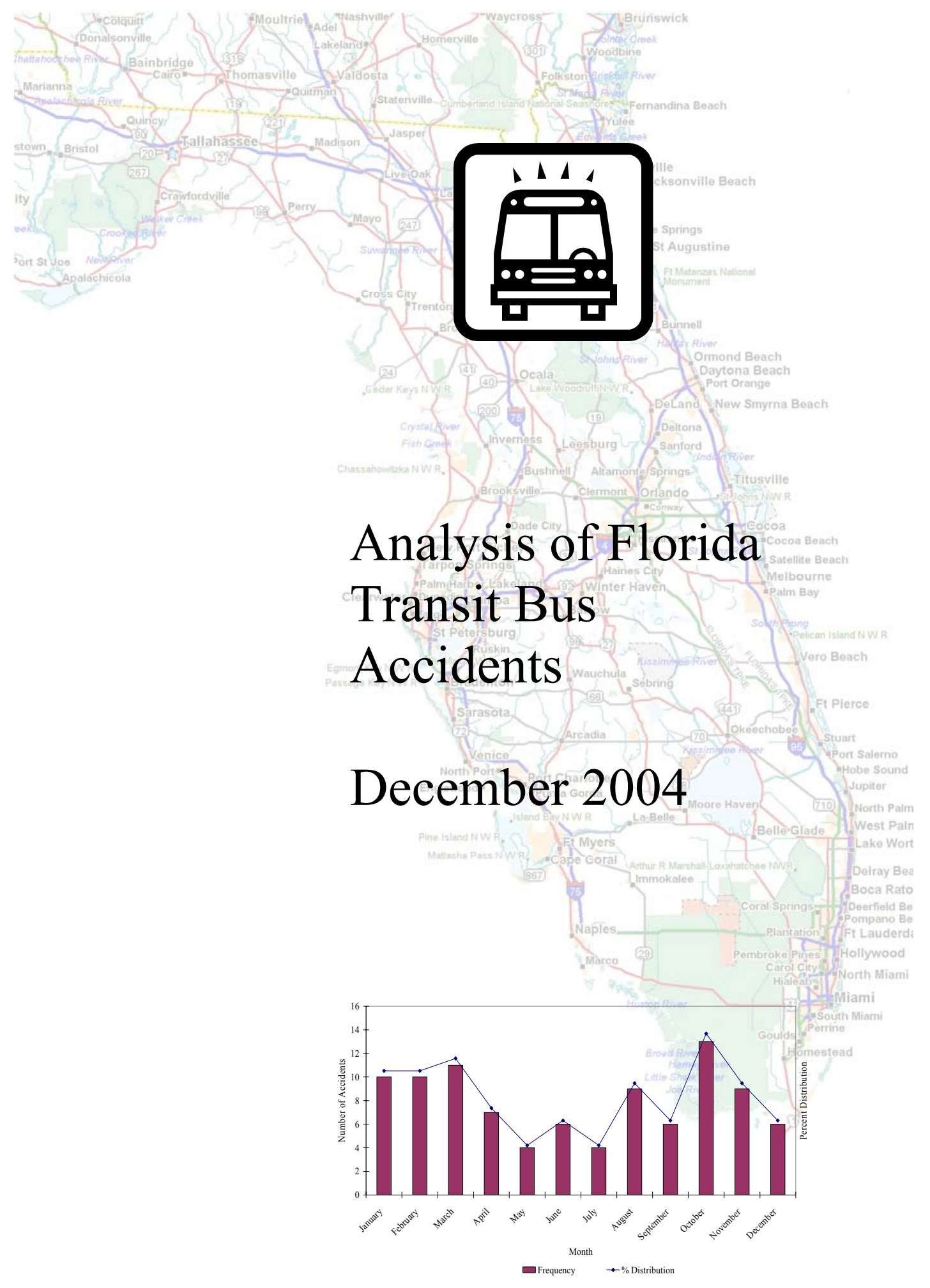


TECHNICAL REPORT STANDARD TITLE PAGE

\begin{tabular}{|c|c|c|c|}
\hline $\begin{array}{l}\text { 1.Report No. } \\
527-11\end{array}$ & \multicolumn{2}{|c|}{ 2. Government Accession No. } & 3.Recipient's Catalog No. \\
\hline \multirow{3}{*}{\multicolumn{3}{|c|}{$\begin{array}{l}\text { 4.Title and Subtitle } \\
\text { Analysis of Florida Transit Bus Accidents }\end{array}$}} & \multirow{2}{*}{$\begin{array}{l}\text { 5.Report Date } \\
\text { December } 2004\end{array}$} \\
\hline & & & \\
\hline & & & 6.Performing Organization Code \\
\hline \multirow{2}{*}{\multicolumn{3}{|c|}{$\begin{array}{l}\text { 7.Author(s) } \\
\text { Deborah Buchacz Sapper \& Oliver Page }\end{array}$}} & \multirow{2}{*}{ 8.Performing Organization Report } \\
\hline & & & \\
\hline \multirow{2}{*}{\multicolumn{3}{|c|}{$\begin{array}{l}\text { 9.Performing Organization Name and Address } \\
\text { National Center for Transit Research } \\
\text { Center for Urban Transportation Research } \\
\text { University of South Florida } \\
\text { 4202 E. Fowler Avenue, CUT } 100 \\
\text { Tampa, FL 33620-5375 }\end{array}$}} & 10. Work Unit No. \\
\hline & & & $\begin{array}{l}\text { 11.Contract or Grant No. } \\
\text { DTRS98-G-0032 }\end{array}$ \\
\hline \multirow{2}{*}{\multicolumn{3}{|c|}{$\begin{array}{l}\text { 12.Sponsoring Agency Name and Address } \\
\text { Office of Research and Special Programs } \\
\text { U.S. Department of Transportation, Washington, D.C. } 20690\end{array}$}} & $\begin{array}{l}\text { 13. Type of Report and Period } \\
\text { Covered }\end{array}$ \\
\hline & & & 14.Sponsoring Agency Code \\
\hline \multicolumn{4}{|l|}{ 15.Supplementary Notes } \\
\hline \multicolumn{4}{|l|}{ 16.Abstract } \\
\hline \multicolumn{4}{|c|}{$\begin{array}{l}\text { The safe operation of public transit vehicles is of utmost importance to the transit agency, its' employees and } \\
\text { passengers. Most transit agencies have hundreds of accidents per year. While each accident may be reviewed } \\
\text { carefully as an individual incident, at many Florida transit systems there has been very little formal analysis of } \\
\text { all accidents on an aggregate basis, and a tool to identify the effectiveness of capital and operational safety } \\
\text { campaigns. The FDOT Research Ideas project on System Safety Plans and Accident Tracking Analysis } \\
\text { completed in 1999, recommended that all Florida transit systems begin collecting a core set of accident } \\
\text { characteristics to be monitored and analyzed on a statewide basis. This project uses this data to track and } \\
\text { analyze accident occurrences and causal factors for many of the medium-size transit systems in Florida. } \\
\text { In addition, a data-based tool has developed for medium transit systems to easily track and analyze their } \\
\text { accident data in aggregate over time is included in the Appendix A and the NCTR website. This will allow the } \\
\text { agency to be able to identify trends in occurrences and the effectiveness of safety programs. }\end{array}$} \\
\hline 17.Key Words & \multirow{2}{*}{\multicolumn{3}{|c|}{$\begin{array}{l}\text { 18.Distribution Statement } \\
\text { Available to the public through the National Technical Information } \\
\text { Service (NTIS),5285 Port Royal Road, Springfield, VA 22181 ph (703) } \\
487-4650 \text { http://www.ntis.gov , and through the NCTR web sit at } \\
\text { http://www.nctr.usf.edu/. }\end{array}$}} \\
\hline Public Transit, Safety, Accidents & & & \\
\hline 19.Security Classif. (of this report) & $\begin{array}{l}\text { 20.Security Classif. (of } \\
\text { this page) } \\
\text { Unclassified }\end{array}$ & $\begin{array}{l}\text { 21.No. of pages } \\
84\end{array}$ & 22. Price \\
\hline
\end{tabular}

Form DOT F 1700.7 (8-69) 


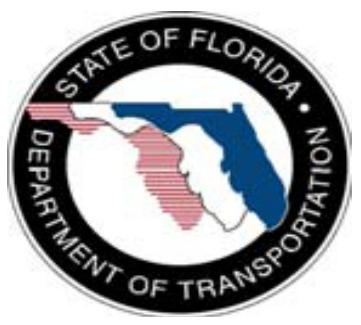

\title{
State of Florida Department of Transportation
}

Public Transit Office

605 Suwannee Street

Tallahassee, FL 32399-0450

(850) 414-4500

Project Manager:

Mike Johnson

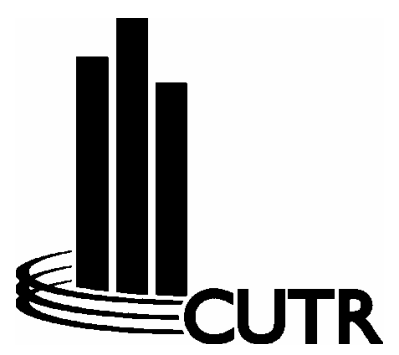

\author{
National Center for Transit Research \\ Center for Urban Transportation Research \\ University of South Florida \\ 4202 E. Fowler Avenue, CUT 100 \\ Tampa, FL 33620-5375
}

(813) 974-3120

Project Staff: Deborah Buchacz Sapper, Senior Research Associate Oliver Page, Graduate Research Assistant

The opinions, findings and conclusions expressed in this publication are those of the authors and not necessarily those of the U.S. Department of Transportation or the State of Florida Department of Transportation. 
TABLE OF CONTENTS

CHAPTER 1 INTRODUCTION

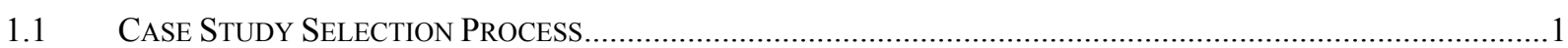

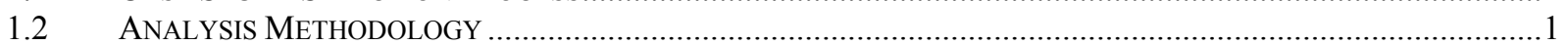

CHAPTER 2 GAINESVILLE REGIONAL TRANSIT SYSTEM ............................................................

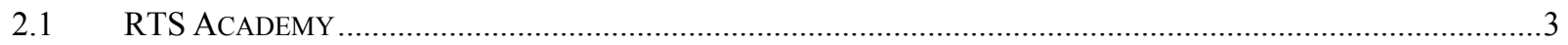

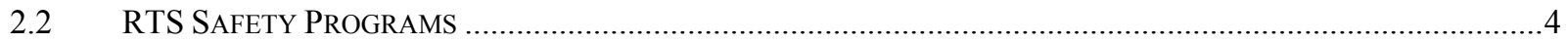

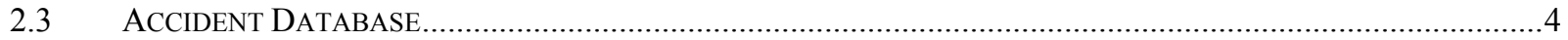

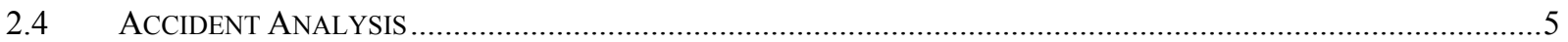

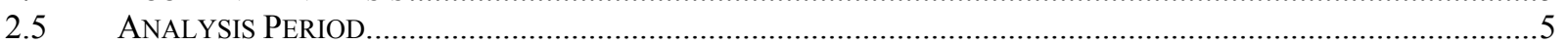

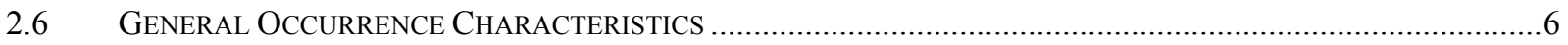

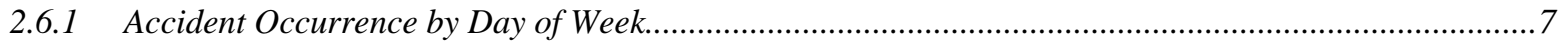

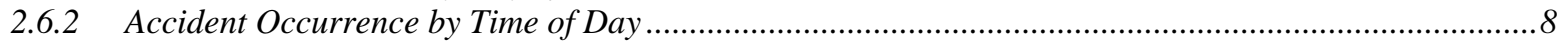

2.6.3 Accident Occurrence by Type of Weather.....................................................................................

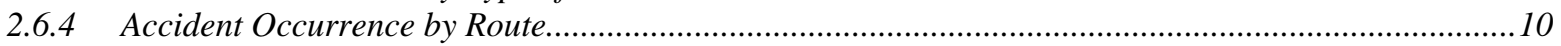

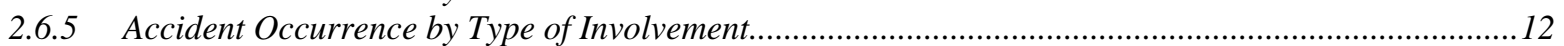

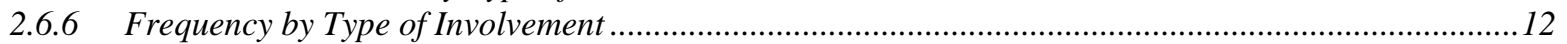

2.6.7 Accident Occurrence Identified by Preventability Status ................................................................13

2.6.8 Preventability Status and Accident Type ……...................................................................................

2.6.9 Type of Accident according to Time of Day ...........................................................................................13

2.6.10 Crash Occurrence by Years of Operator Experience ........................................................................14

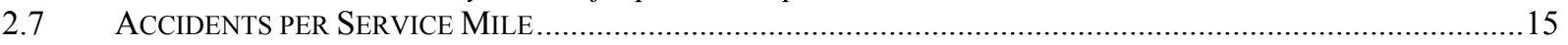

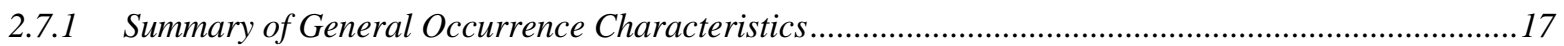

2.8 OTHER FACTORS INFLUENCING ACCIDENT POTENTIAL …...................................................................

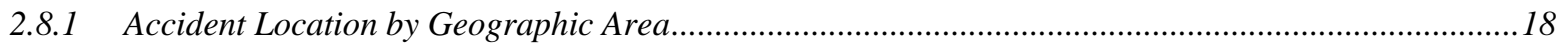

CHAPTER 3 SARASOTA COUNTY TRANSPORTATION AUTHORITY...............................................21

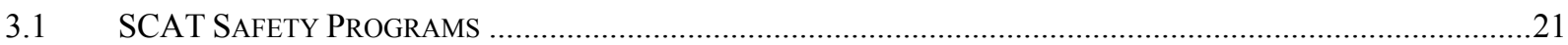

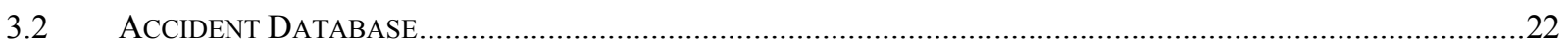

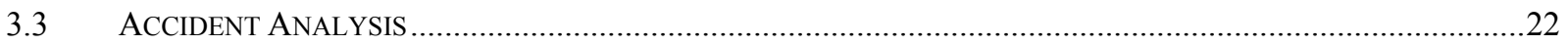

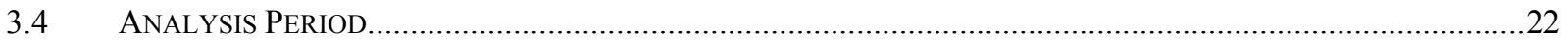

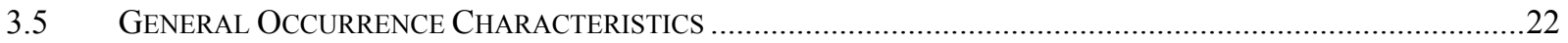

3.5.1 Crash Occurrence by Day of Week ...............................................................................................24

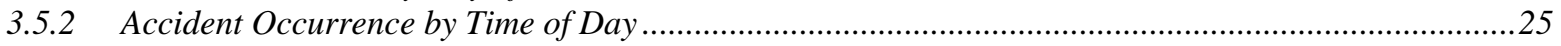

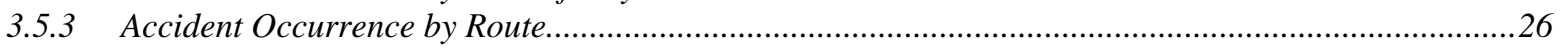

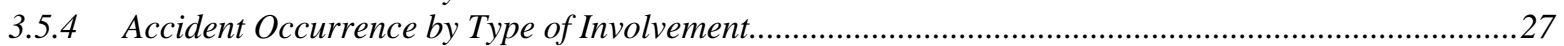

3.5.5 Type of Accident according to Time of Day..........................................................................................

3.5.6 Type of Accident according to Bus Route ........................................................................................28

3.5.7 Accident Occurrence by Type of Weather and Road Condition ...........................................................29

3.5.8 Accident Occurrence Identified By Preventability Status .....................................................................31

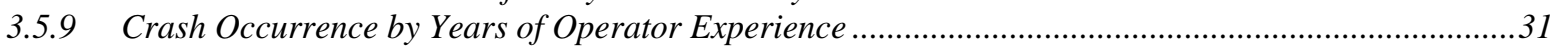

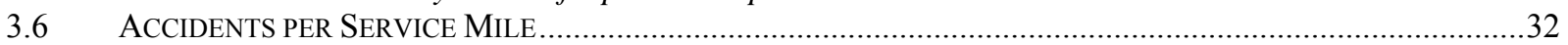

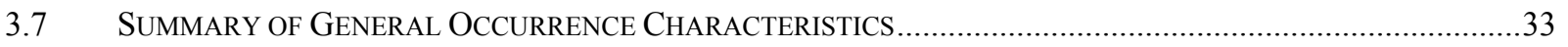

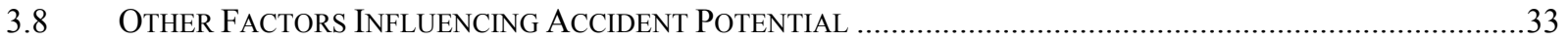

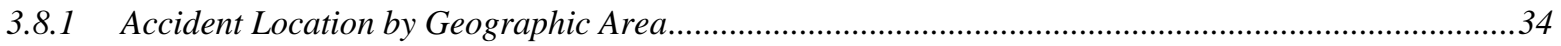

CHAPTER 4 VOLUSIA COUNTY PUBLIC TRANSIT SYSTEM .................................................................37

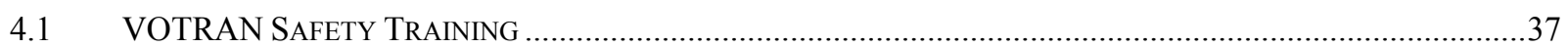

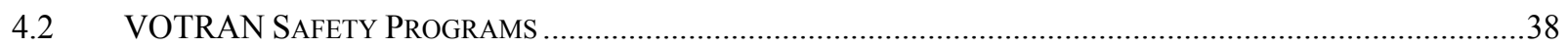

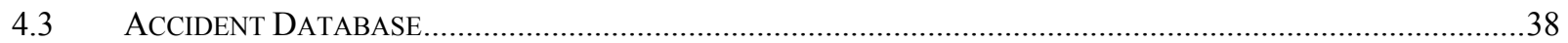

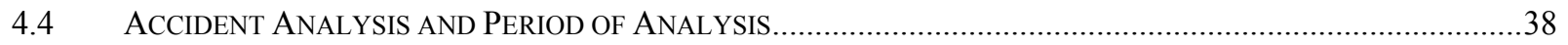

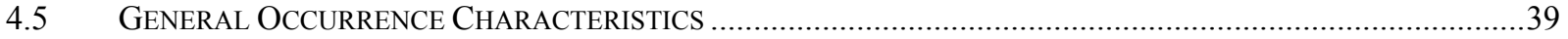

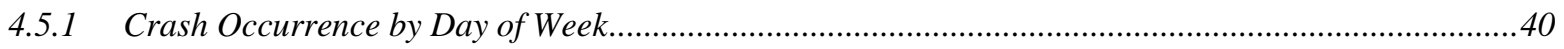

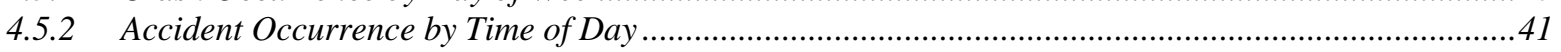

4.5.3 Accident Occurrence by Type of Weather.....................................................................................42 


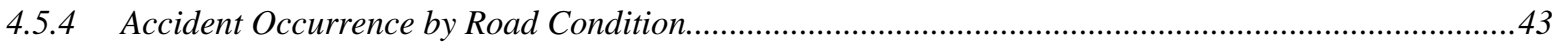

4.5.5 Accident Occurrence by Route..........................................................................................................

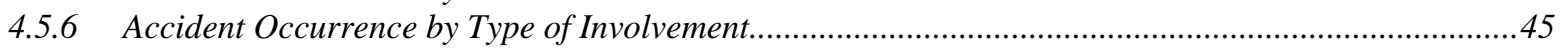

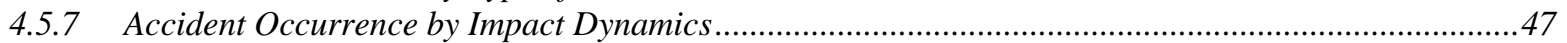

4.5.8 Accident Occurrence Identified by Preventability Status ......................................................................47

4.5.9 Crash Occurrence by Years of Operator Experience ……......................................................................48

4.6 SUMMARY OF GENERAL OCCURRENCE CHARACTERISTICS..................................................................49

4.7 OTHER FACTORS INFLUENCING ACCIDENT POTENTIAL …............................................................................49

CHAPTER 5 LEE COUNTY REGIONAL TRANSIT SYSTEM............................................................51

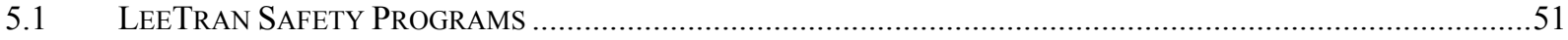

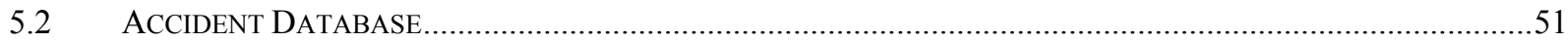

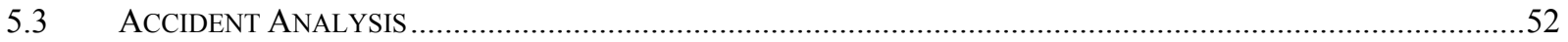

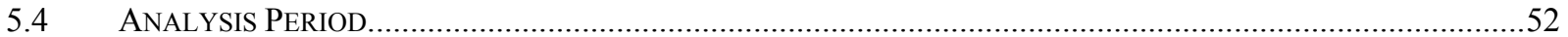

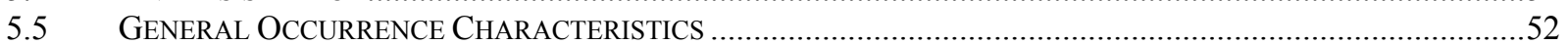

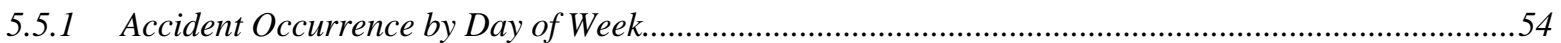

5.5.2 Accident Occurrence by Time of Day …………................................................................................5

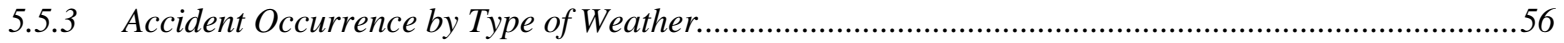

5.5.4 Accident Occurrence by Route..........................................................................................................56

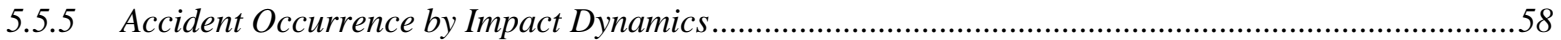

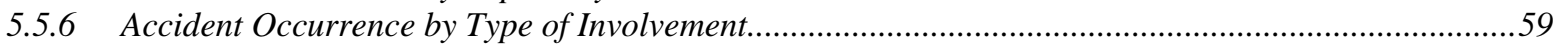

5.5.7 Accident Occurrence Identified by Preventability Status ..................................................................60

5.5.8 Crash Occurrence by Years of Operator Experience ......................................................................61

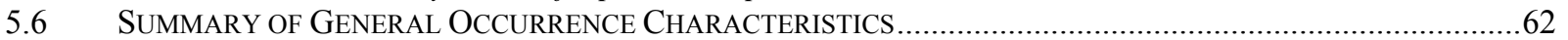

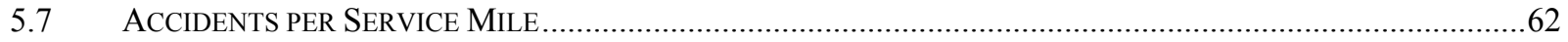

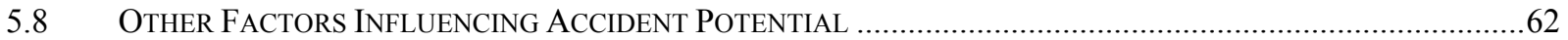

5.8.1 Accident Location by Geographic Area .......................................................................................63

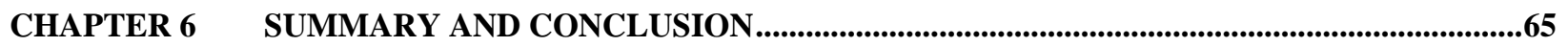

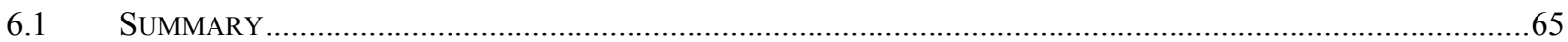

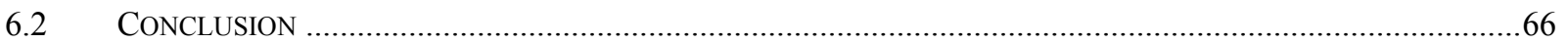

REFERENCES …….........................................................................................................................................69

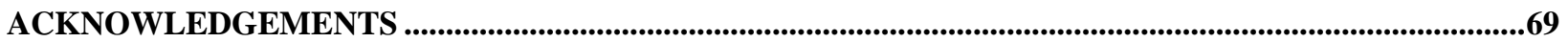

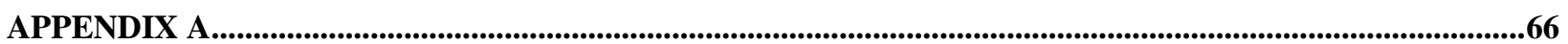




\section{LIST OF TABLES}

\section{GAINESVILLE REGIONAL TRANSIT SYSTEM}

Table 2.1 - RTS Academy Summer Training Course - June and July 2002 …................................... 5

Table 2.2 - Combined Frequency Distribution of Monthly Accidents................................................. 6

Table 2.3 - Combined Frequency Distribution of Day of Week Accidents ........................................... 7

Table 2.4 - Combined Frequency Distribution by Time of Day Accidents ........................................... 8

Table 2.5 - Accident Frequency Distribution by Type of Weather ....................................................... 9

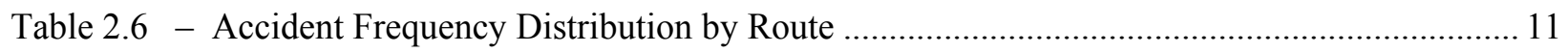

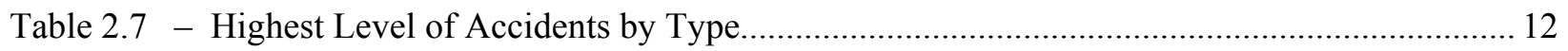

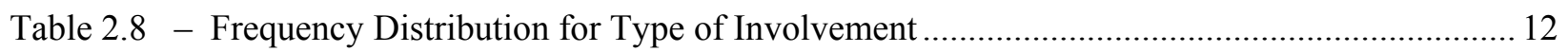

Table 2.9 - Accident Frequency and Distribution by Identified by Preventability Status........................ 13

Table 2.10 - Percentage of Accidents by Preventability Status by Accident Type .................................. 13

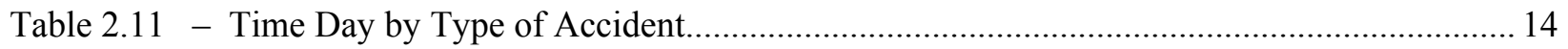

Table 2.12 - Frequency Distribution of Crashes and Operators by Operator Experience ......................... 15

\section{SARASOTA COUNTY TRANSPORTATION AUTHORITY}

Table 3.1 - Combined Frequency Distribution of Monthly Accidents................................................. 22

Table 3.2 - Combined Frequency Distribution of Day of Week Accidents .......................................... 23

Table 3.3 - Combined Frequency Distribution by Time of Day Accidents .......................................... 24

Table 3.4 - Accident Frequency Distribution by Route …................................................................. 25

Table 3.5 - Frequency Distribution for Type of Involvement …....................................................... 26

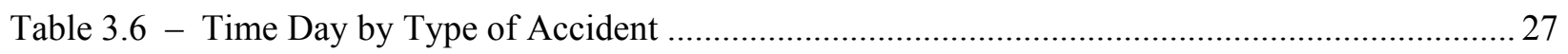

Table 3.7 - Accident Occurrence by Route and Type (Ranked) .......................................................2 28

Table 3.8 - Accident Occurrence by Type of Weather and Road Conditions .........................................29

Table 3.9 - Frequency Distribution of Accidents according to Years of Operator Experience................. 30

\section{VOLUSIA COUNTY PUBLIC TRANSIT SYSTEM}

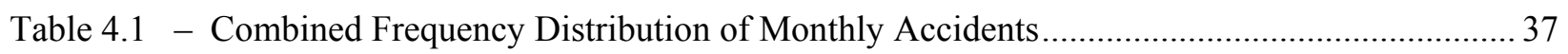

Table 4.2 - Combined Frequency Distribution of Day of Week Accidents .......................................... 38

Table 4.3 - Combined Frequency Distribution by Time of Day Accidents ........................................... 39

Table 4.4 - Accident Frequency Distribution by Type of Weather ..................................................... 40

Table 4.5 - Accident Frequency Distribution by Road Conditions ....................................................... 41

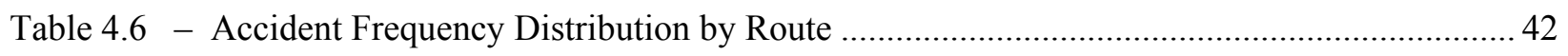

Table 4.7 - Frequency Distribution for Type of Involvement .......................................................... 43

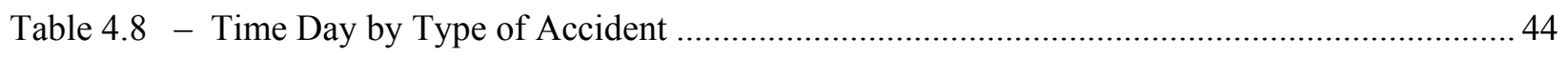

Table 4.9 - Accident Occurrence by Impact Dynamics .................................................................. 45

Table 4.10 - Accident Occurrence Identified by Preventability Status ................................................. 45

Table 4.11 - Accident Occurrence Identified by Preventability Status and Accident Type..................... 45

Table 4.12 - Crash Occurrence by Years of Operator Experience ........................................................... 46 


\section{LEE COUNTY REGIONAL TRANSIT SYSTEM}

Table 5.1 - Combined Frequency Distribution of Monthly Accidents.............................................. 50

Table 5.2 - Crash Occurrence by Day of Week............................................................................... 51

Table 5.3 - Combined Frequency Distribution by Time of Day ..........................................................52

Table 5.4 - Combined Frequency Distribution by Type of Weather.................................................... 53

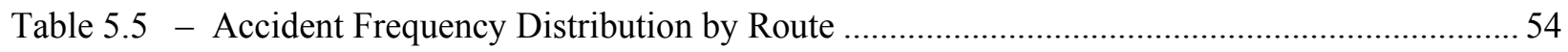

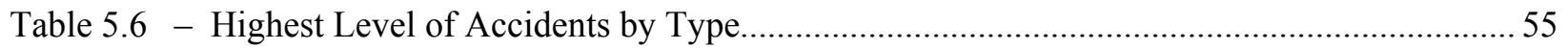

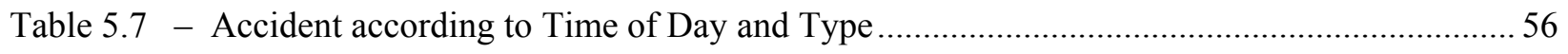

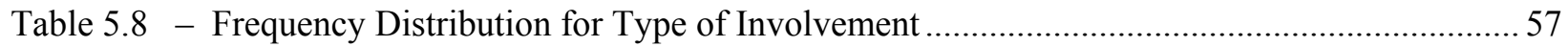

Table 5.9 - Accident Frequency and Distribution by Identified Preventability Status........................... 57

Table 5.10 - Percentage of Accidents by Preventability Status by Accident Type .................................. 57

Table 5.11 - Frequency Distribution of Crashes and Operators by Operator Experience ......................... 58

\section{LIST OF FIGURES}

\section{GAINESVILLE REGIONAL TRANSIT SYSTEM}

Figure 2.1 - Gainesville RTS Ridership Trends ...................................................................... 4

Figure 2.2 - Combined Frequency Distribution of Monthly Accidents ............................................... 7

Figure 2.3 - Combined Frequency Distribution of Day of Week Accidents ..................................... 8

Figure 2.4 - Combined Frequency Distribution by Time of Day Accidents ........................................ 9

Figure 2.5 - Accident Frequency Distribution by Type of Weather................................................... 10

Figure 2.6 - Accident Frequency Distribution by Route ..................................................................... 11

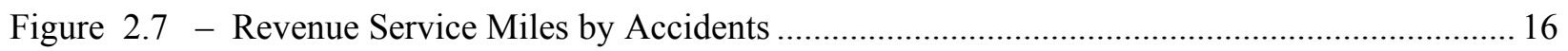

Figure 2.8 - Accidents per 100,000 Revenue Miles by Month ..................................................... 16

Figure 2.9 - Bus Accident Location - Gainesville ............................................................................ 19

\section{SARASOTA COUNTY TRANSPORTATION AUTHORITY}

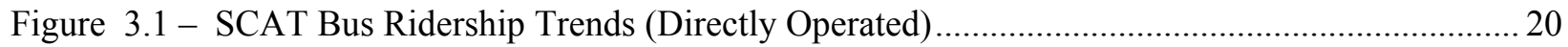

Figure 3.2 - Combined Frequency Distribution of Monthly Accidents ................................................. 22

Figure 3.3 - Combined Frequency Distribution of Day of Week Accidents .......................................... 23

Figure 3.4 - Combined Frequency Distribution by Time of Day Accidents ......................................... 24

Figure 3.5 - Accident Frequency Distribution by Route …............................................................. 25

Figure 3.6 - Accident Frequency Distribution by Type of Weather......................................................29

Figure 3.7- Revenue Miles per Month Supplied versus Number of Accidents.................................... 31

Figure 3.8 - Accidents per 100,000 Revenue Miles by Month .......................................................... 32

Figure 3.9 - Bus Accident Locations - Sarasota County.................................................................... 34 


\section{VOLUSIA COUNTY PUBLIC TRANSIT SYSTEM}

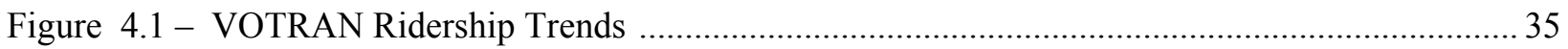

Figure 4.2 - Combined Frequency Distribution of Monthly Accidents ............................................... 38

Figure 4.3 - Combined Frequency Distribution of Day of Week Accidents ........................................... 39

Figure 4.4 - Combined Frequency Distribution by Time of Day Accidents ............................................ 40

Figure 4.5 - Accident Frequency Distribution by Type of Weather..................................................... 41

Figure 4.6 - Accident Frequency Distribution by Road Condition ..................................................... 42

Figure 4.7 - Accidents Frequency Distribution by Route................................................................ 43

\section{LEE COUNTY REGIONAL TRANSIT SYSTEM}

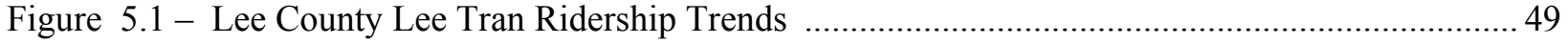

Figure 5.2 - Combined Frequency Distribution of Monthly Accidents ................................................ 50

Figure 5.3 - Combined Frequency Distribution of Day of Week Accidents .......................................... 51

Figure 5.4 - Combined Frequency Distribution by Time of Day ....................................................... 52

Figure 5.5 - Combined Frequency Distribution by Type of Weather .....................................................53

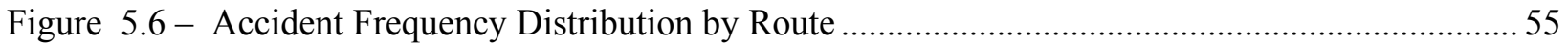

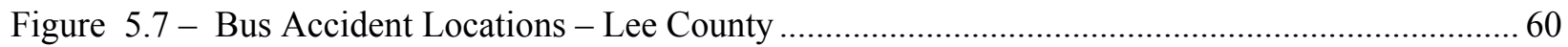




\section{CHAPTER 1 INTRODUCTION}

Through its National Center for Transit Research (NCTR), and under contract with the Florida Department of Transportation (FDOT), the Center for Urban Transportation (CUTR) was tasked to undertake a continued sampled review of bus transit accidents at selected Florida public transit systems. The purpose of this review is to analyze the change in accident data over time. The goal of the project is to show transit systems, through demonstration, the simplicity by which accident data can be analyzed, how to use the data to identify the success of safety campaigns, and how a small investment in analyses might have a great impact on reducing transit accidents, thereby lowering operating costs and insurance premiums. Through this research exercise transit systems in Florida will be more likely to analyze their data and reduce transit accidents at their property.

It is important to note that this evaluation is a follow up study to 1999 Florida Department of Transportation Research Idea project entitled "System Safety Program and Accident Tracking Analysis" as well as the "Analysis of Florida Transit Bus Crashes" project completed in 2001. This project followsup on the recommendations of those reports. The expectation of this project is to enable small and medium size agencies to track accident occurrences and trends and measure the effectiveness of safety campaigns.

\subsection{Case Study Selection Process}

CUTR commenced its investigation by researching medium Florida transit systems that had some type of safety program in place over the last couple of years. For this project, a safety program will be defined as a system-wide operator training that has been implemented to promote safety and reduce the number of accidents within a system.

After an initial evaluation of Florida's medium transit systems, and with guidance from FDOT, four systems were ultimately selected for this investigation: Gainesville Regional Transit System (RTS) in Gainesville; Sarasota County Transportation Authority (SCAT) in Sarasota; County of Volusia, dba VOTRAN in Daytona Beach and Lee County Regional Transit System (LeeTran) in Fort Myers. This reports documents the case study analysis of safety programs and accident tracking and analysis at RTS, SCAT, VOTRAN, and LeeTran.

\subsection{Analysis Methodology}

To begin the analysis of the safety program, the systems were contacted to discuss the project and scope and goals, encourage participation and identify a primary contact person for subsequent communication, information requests, and questions. Meetings were held with agency representatives at the outset of the effort to help establish data requirements for the evaluation. 
Following initial contact, CUTR staff worked with system contacts to collect information regarding their safety program, and accident data for a minimum period of 24 months were collected from system records and analyzed. After retrieval of the appropriate occurrence data, Microsoft Excel was utilized to sort the data and arrange it into a format suitable for analysis. The data collection effort was geared to ensure that each accident data record included the following variables: date, time of day, day of week, preventability status, location, vehicle number, route number; years of experience of the operator, weather conditions; and type of impact dynamics. The results of these analyses for each case study transit system are described in the following sections.

Also, provided in this report is a user friendly database and analysis tool that has been developed in Microsoft Access to help medium size transit systems to collect and analyze data. The database includes the variables collected in this project along with some additional variables such as: year and manufacturer of the vehicle, post accident testing and date of last training and type of training.

It should be noted that the following definitions apply for this project and it documentation. An accident is defined as a collision with another vehicle, pedestrian or fixed object and occurs when there is physical contact between the bus and another vehicle, pedestrian or fixed object. An incident is defined as an occurrence which can take place on the vehicle or without any contact with another vehicle (i.e., a passenger falls on the bus.) This study will focus on bus accidents. 


\section{CHAPTER 2 GAINESVILLE REGIONAL TRANSIT SYSTEM}

The City of Gainesville located in Alachua County, Florida ranked $21^{\text {st }}$ out of 67 counties in Florida with an estimated population of 223,578 people according to the 2003 United States Census population estimates. The 2003 population of Gainesville was approximately 117,182 people (52 percent of the county population). In addition to being the largest municipality in the county, Gainesville is also home to the oldest and largest university in the State of Florida, the University of Florida (UF) in 2004, Fall Semester enrollment at UF was approximately 48,000 students.

The Gainesville Regional Transit System (RTS) was established in 1975, and operated as a small urban transit system. Up until 1997, RTS was experiencing declining transit ridership and community support. This situation changed when Gainesville and the University of Florida entered into a partnership to allow student access to the RTS system. The University of Florida pays a student services fee to Gainesville, based on the number of student credit hours in a semester. Students can then ride RTS (free) by showing their student ID.

The current RTS system operates as a pulsed network, focused on the downtown city plaza and the UF transportation hub. According to the 2002 National Transit Database (NTD), the RTS service area is approximately 73 square miles, with a service area population of 140,000. The service area population fluctuates substantially during the year due to the incoming and outgoing student population. Fixed route service is provided 7 days a week (with reduced service on the weekends) and with a fleet of 85 directly operated buses. In 2002, over 7 million unlinked trips were made on RTS. This was an increase of 14 percent over the 2001 ridership figure. Growth in RTS ridership is illustrated in Figure 2.1

\subsection{RTS Academy}

The RTS Academy is a department within RTS tasked with bus training operators in a variety of components of bus driving and operations. The Academy is managed by one training supervisor (certified by the Transportation Safety Institute). The RTS Academy commenced training programs in the mid 1990's. All new operators (whether experienced or not) joining RTS are expected to complete the course at the Academy. Bus operators completing training in the RTS Academy have achieved a 98 percent success rate earning their Commercial Drivers License (CDL). 
Figure 2.1

Gainesville RTS Ridership Trends

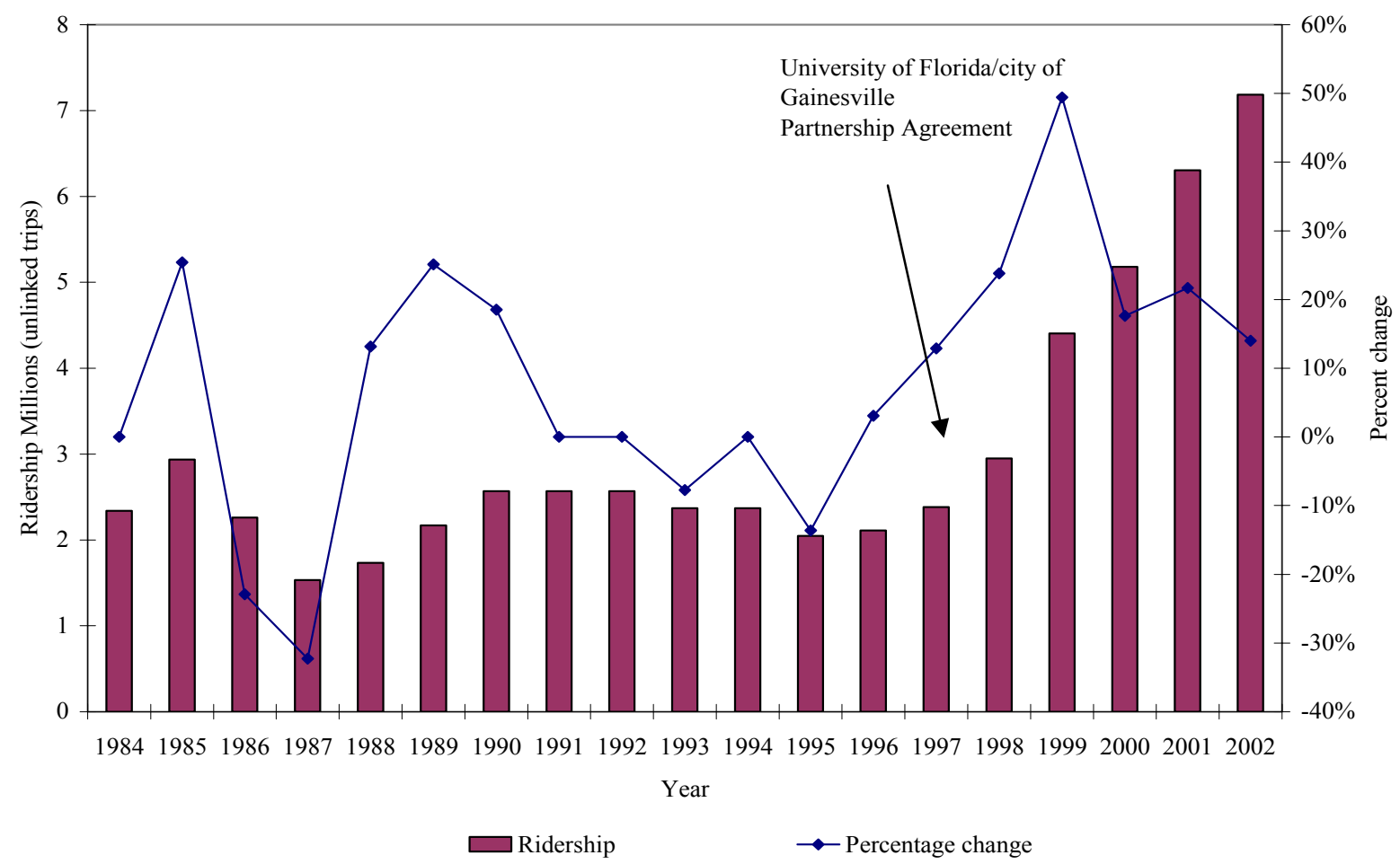

\subsection{RTS Safety Programs}

All operators joining RTS must complete an initial training program (6 weeks in duration), which assumes operators have no commercial driving background. Operators with a CDL usually can complete the course in approximately four weeks.

Following initial training, RTS requires operators to complete yearly "refresher" training. The refresher training course is offered during the summer months. These courses target the driving behavior and knowledge of senior operators but all RTS operators are expected to participate in the program. Eighty-six RTS bus operators participated in the 2002 summer refresher course. The primary facilitator of the course is the RTS training supervisor, but outside experts are invited to participate in the teaching of specialized subject areas. Each course lasts approximately 40 hours and updates operators on new routes, new driving techniques, hours of service and defensive driving techniques. Gainesville offers a 'Bicycle Friendly' environment, and one of the components of the refresher courses is to train and update operators in bicycle safety techniques and awareness. In this study, the summer training program took place during the months of June and July 2002. Curriculum details of the program are presented in Table 2.1

\subsection{Accident Database}

RTS records all accidents which involve their buses, even when a third party may have been involved. Through such data collection, basic accident statistics are captured and are subsequently used as 
management information. In-depth statistical analysis of the data was not performed due to the low number of accidents.

Table 2.1

RTS Academy Summer Training Course - June and July 2002

\begin{tabular}{|l|l|}
\hline Class Description & Time \\
\hline Farebox & $8: 00-9: 00$ AM \\
\hline GPD & $9: 00-11: 30$ AM \\
\hline Lunch & $11: 30$ AM - 12:30 PM \\
\hline Adult CPR & $12: 30-5: 00$ PM \\
\hline Pre and Post Trip & $8: 00-10: 00$ AM \\
\hline Day on the Range & $10: 00$ AM - 12:00 PM \\
\hline Lunch & $12: 00-1: 00$ PM \\
\hline Day on the Range Cont & $1: 00-5: 00$ PM \\
\hline Common Problems & $8: 00-10: 00$ AM \\
\hline Bicycle Accident Prevention & $10: 00$ AM- 12:00 PM \\
\hline Lunch & $12: 00-1: 00$ PM \\
\hline RTS Rules / Handbook & $1: 00-5: 00$ PM \\
\hline Americans with Disabilities Act ADA Regulations & $8: 00-9: 00$ AM \\
\hline Disability and Sensitivity & $9: 00-11: 30$ AM \\
\hline Lunch & $11: 30$ AM - 12:30 PM \\
\hline Customer Service & $12: 30-5: 00$ PM \\
\hline Preparing for The Fall & $8: 00-9: 00$ AM \\
\hline Drugs and Alcohol & $9: 00-11: 30$ AM \\
\hline Lunch & $11: 30$ AM- 12:30 PM \\
\hline Use of Radio & $12: 30-2: 30$ PM \\
\hline Most Common Accidents & $2: 30-5: 00$ PM \\
\hline
\end{tabular}

\subsection{Accident Analysis}

Accident data used in this study were obtained from RTS office in Gainesville. RTS staff collected and prepared the records, while CUTR staff captured and analyzed the data in Microsoft Excel. Any questions regarding clarification of records were answered by RTS staff.

\subsection{Analysis Period}

Safety refresher programs are conducted at RTS during the summer months. This is also the period where ridership is at its lowest when most students are away from the UF campus. Accident records were used for the 12 preceding and 12 months after the Safety Training course (taking place in June and July 2002). Thus, the total analysis time frame was from June 2001 to July 2003 (26 months). 


\subsection{General Occurrence Characteristics}

The number of accidents that occurred during the 26 month period of June 2001 through July 2003 is presented in Table 2.2 and Figure 2.2. Column 2 of Table 2.2 presents the number of accidents per month. The percentage distribution of these accidents is determined by the monthly accidents divided by the total number of accidents in the study period. Average accident frequency (per month) is derived by the number of accidents in a specific month, divided by the number of years for which those monthly accidents totals were submitted.

Table 2.2

Combined Frequency Distribution of Monthly Accidents

\begin{tabular}{|c|c|c|c|c|}
\hline Month & Number & \% Distribution & Average Frequency & Years of Data \\
\hline January & 8 & 10.4 & 4.0 & 2 \\
\hline February & 3 & 3.9 & 1.5 & 2 \\
\hline March & 8 & 10.4 & 4.0 & 2 \\
\hline April & 7 & 9.1 & 3.5 & 2 \\
\hline May & 3 & 3.9 & 1.5 & 2 \\
\hline June & 7 & 9.1 & 2.3 & 3 \\
\hline July & 9 & 11.7 & 3.0 & 2 \\
\hline August & 4 & 5.2 & 2.0 & 2 \\
\hline September & 10 & 13.0 & 5.0 & 2 \\
\hline October & 10 & 13.0 & 5.0 & 2 \\
\hline November & 1 & 1.3 & 0.5 & 3.5 \\
\hline December & 7 & 9.1 & & \\
\hline Total & $\mathbf{7 7}$ & $\mathbf{1 0 0 . 0}$ & & 2 \\
\hline
\end{tabular}

September and October experienced the highest number of accidents (based on average frequency). These two months were followed by January, March, December, April and July. The months with the lowest average frequency of accidents are November, February and May. 
Figure 2.2

\section{Combined Frequency Distribution of Monthly Accidents}

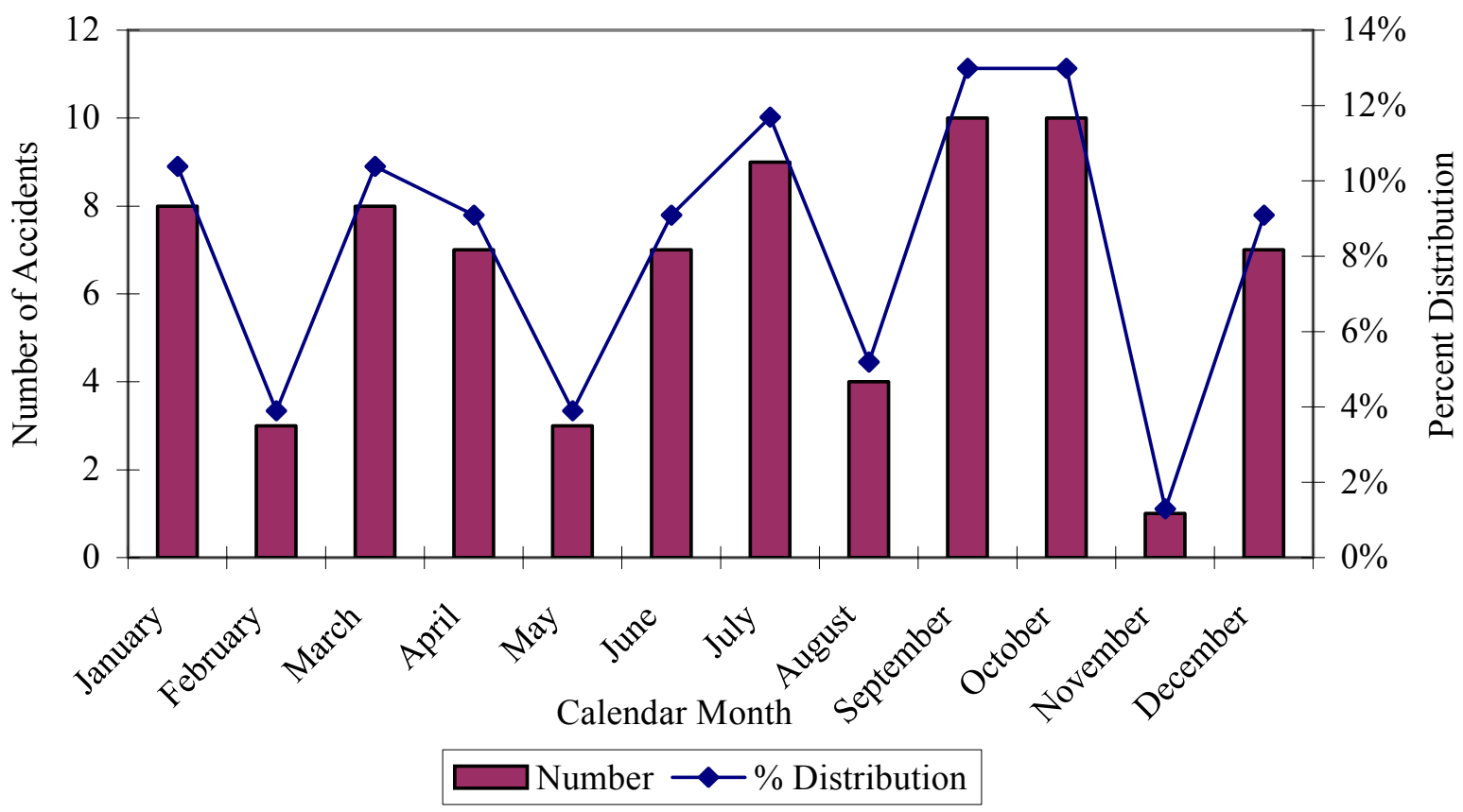

\subsubsection{Accident Occurrence by Day of Week}

Crash occurrence data by day of week is presented in Table 2.3 and in Figure 2.3. Table 2.3 presents data accident frequency by day of week. Overall, Tuesdays and Wednesdays were the days with the highest numbers of accidents. These two days were the days with the highest overall daily accident frequency (based on dividing the number of accidents occurring on a Monday by the number of Mondays in the study period). Reduced Sunday bus operation and less traffic may account for the significantly lower numbers of accidents occurring on this day.

Table 2.3

Combined Frequency Distribution of Day of Week Accidents

\begin{tabular}{|c|c|c|c|c|}
\hline Day of Week & Frequency & \% Distribution & Average Frequency & Days \\
\hline Sunday & 2 & 2.6 & 0.02 & 113 \\
\hline Monday & 14 & 18.2 & 0.12 & 113 \\
\hline Tuesday & 20 & 26.0 & 0.18 & 113 \\
\hline Wednesday & 18 & 23.4 & 0.16 & 113 \\
\hline Thursday & 5 & 6.5 & 0.04 & 113 \\
\hline Friday & 13 & 16.9 & 0.12 & 113 \\
\hline Saturday & 5 & 6.5 & 0.04 & 113 \\
\hline Total & $\mathbf{7 7}$ & $\mathbf{1 0 0 . 0}$ & $\mathbf{0 . 1 0}$ & $\mathbf{7 9 1}$ \\
\hline
\end{tabular}


Figure 2.3

\section{Combined Frequency Distribution of Day of Week Accidents}

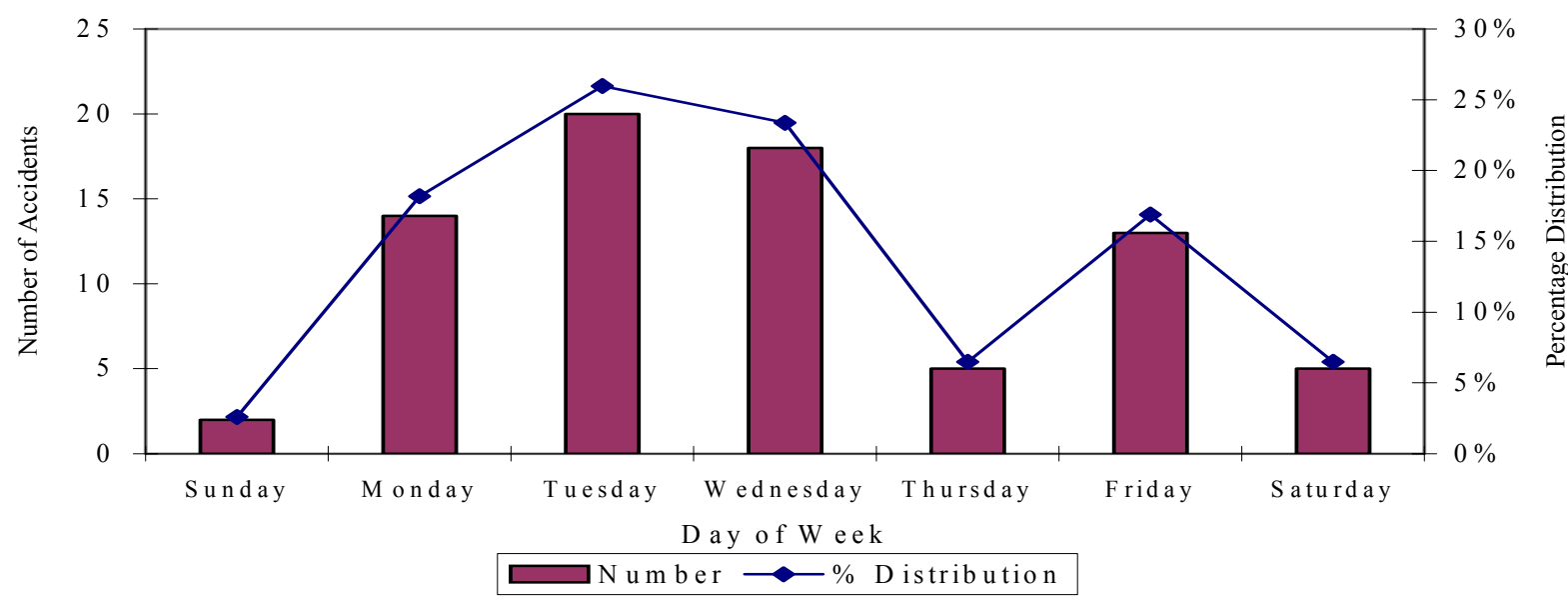

\subsubsection{Accident Occurrence by Time of Day}

Table 2.4 and Figure 2.4 present data on accident occurrence for various times of day that accidents occurred. The time periods with the highest number of accidents are between 2:00 p.m. - 2:59 p.m. and 4:00 p.m. - 4:59 p.m. The second busiest period for accident occurrence was during the off-peak period between 11:00 a.m.-11:59 a.m.

Table 2.4

Combined Frequency Distribution by Time of Day Accidents

\begin{tabular}{|l|c|c|l|c|c|}
\hline \multicolumn{1}{|c|}{ Time of Day } & Frequency & \% Distribution & \multicolumn{1}{|c|}{ Time of Day } & Frequency & \% Distribution \\
\hline 6:00 a.m. to 6:59a.m. & 0 & $0.0 \%$ & $4: 00$ p.m. to 4:59 p.m. & 9 & $11.7 \%$ \\
\hline 7:00 a.m. to 7:59a.m. & 3 & $3.9 \%$ & $5: 00$ p.m. to 5:59 p.m. & 6 & $7.8 \%$ \\
\hline 8:00 a.m. to 8:59a.m. & 1 & $1.3 \%$ & 6:00 p.m. to 6:59 p.m. & 5 & $6.5 \%$ \\
\hline 9:00a.m. to 9:59a.m & 6 & $7.8 \%$ & $7: 00$ p.m. to 7:59 p.m. & 2 & $2.6 \%$ \\
\hline 10:00 a.m. to 10:59 a.m. & 3 & $3.9 \%$ & $8: 00$ p.m. to 8:59 p.m. & 0 & $0.0 \%$ \\
\hline 11:00 a.m. to 11:59a.m. & 8 & $10.4 \%$ & $9: 00$ p.m. to 9:59 p.m. & 4 & $5.2 \%$ \\
\hline 12:00 p.m. to 12:59p.m. & 6 & $7.8 \%$ & $10: 00$ p.m. to $10: 59$ p.m. & 0 & $0.0 \%$ \\
\hline 1:00 p.m. to 1:59 p.m. & 6 & $7.8 \%$ & $11: 00$ p.m. to $11: 59$ p.m. & 0 & $0.0 \%$ \\
\hline 2:00 p.m. to 2:59 p.m. & 9 & $11.7 \%$ & $12: 00$ a.m. to 5:59 a.m. & 2 & $2.6 \%$ \\
\hline 3:00 p.m. to 3:59 p.m. & 6 & $7.8 \%$ & Missing & 1 & $1.3 \%$ \\
\hline
\end{tabular}


Figure 2.4

Combined Frequency Distribution by Time of Day Accidents
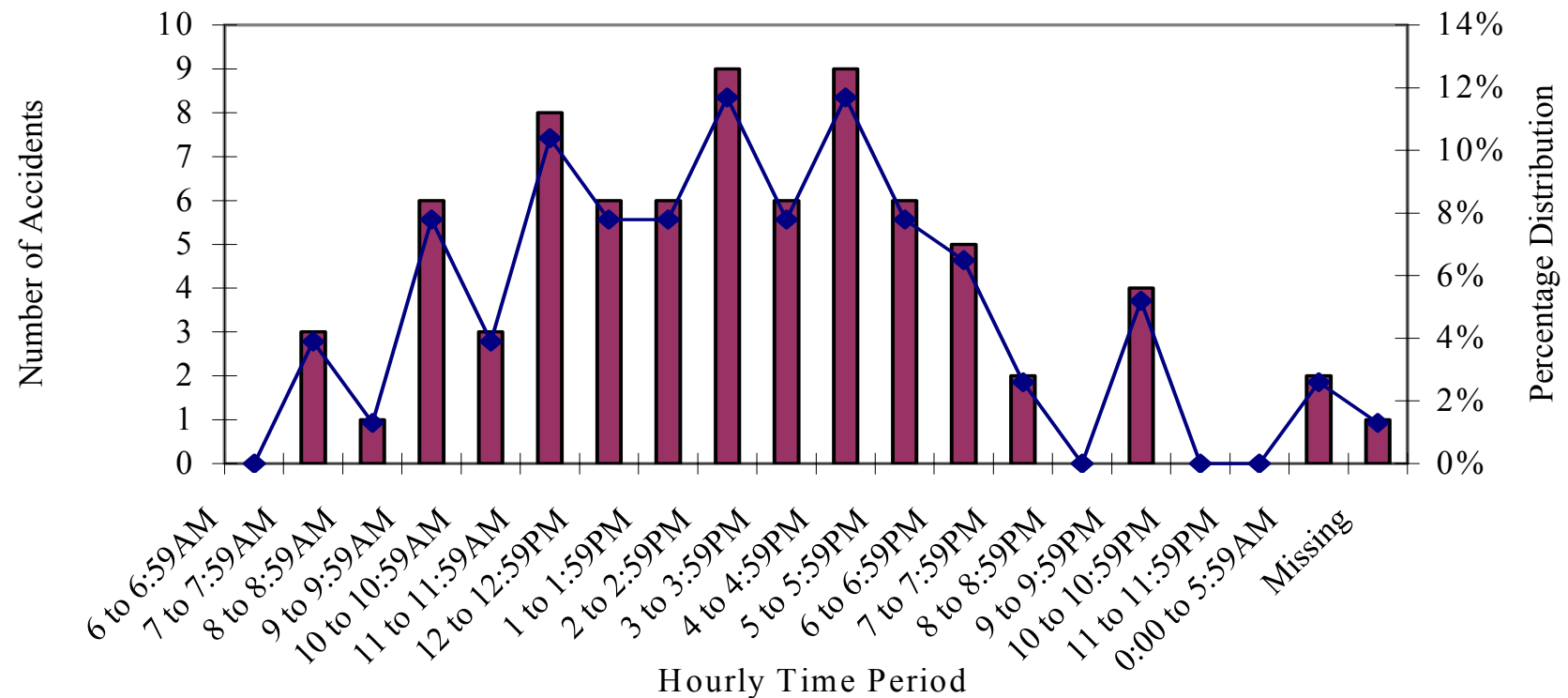

Hourly Time Period

$\square$ Number $\multimap \%$ Distribution

\subsubsection{Accident Occurrence by Type of Weather}

The frequency distribution for the weather conditions at the time of accident is presented in Table 2.5 and Figure 2.5. The majority (66 percent) of accidents occurred in clear/sunny weather.

Table 2.5

Accident Frequency Distribution by Type of Weather

\begin{tabular}{|l|c|c|}
\hline Weather & Frequency & \% Distribution \\
\hline Clear/Sunny & 51 & $66.23 \%$ \\
\hline Rain & 11 & $14.29 \%$ \\
\hline Dark/Night & 7 & $9.46 \%$ \\
\hline Dusk & 4 & $5.41 \%$ \\
\hline Cloudy & 3 & $4.05 \%$ \\
\hline Fog & 1 & $1.35 \%$ \\
\hline Dawn & 0 & $0.00 \%$ \\
\hline Missing & 0 & $0.00 \%$ \\
\hline Total & $\mathbf{7 7}$ & $\mathbf{1 0 0 \%}$ \\
\hline
\end{tabular}


Figure 2.5

\section{Accident Frequency Distribution by Type of Weather}

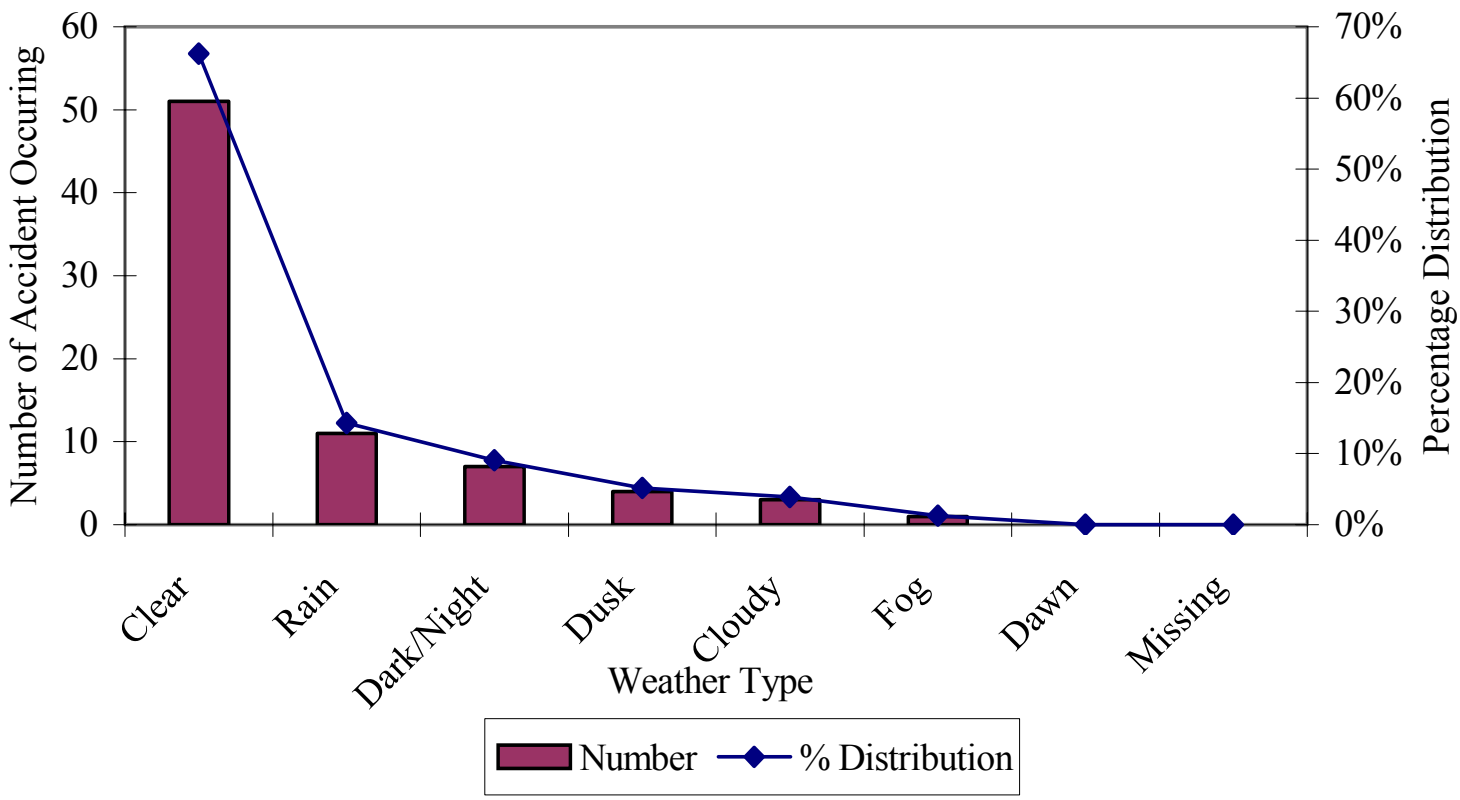

\subsubsection{Accident Occurrence by Route}

According to the National Transit Database, RTS operated a fleet of 83 buses in 2002. The number of bus routes operated does fluctuate on a month by month basis, partly influenced by the academic semester. Table 2.6 and Figure 2.6 show accident data by route.

Route 5 experienced the highest number of accidents with 7 accidents, followed by Routes 12, 13 and 75 (with 6 accidents each). These 4 routes accounted for approximately a third (25 out of 77) of all the accidents in the study period. Table 2.6 also presents the Z-statistic for each route. A Z-statistic greater than 1.40 can be used to identify routes that are more prone to crash occurrence relative to the other routes in the system. This information can assist in identifying potential problem routes within the system. Figure 2.6 shows accident frequency by route. 
Table 2.6

Accident Frequency Distribution by Route

\begin{tabular}{|c|c|c|c|}
\hline Route & Frequency & \% Distribution & Z-Statistic \\
\hline $\mathbf{1}$ & 3 & $3.90 \%$ & 0.140694 \\
\hline $\mathbf{2}$ & 2 & $2.60 \%$ & -0.42208 \\
\hline $\mathbf{5}$ & $\mathbf{7}$ & $\mathbf{9 . 0 9 \%}$ & $\mathbf{2 . 3 9 1 7 9 3}$ \\
\hline $\mathbf{7}$ & 3 & $3.90 \%$ & 0.140694 \\
\hline $\mathbf{8}$ & 4 & $5.19 \%$ & 0.703469 \\
\hline $\mathbf{9}$ & 4 & $5.19 \%$ & 0.703469 \\
\hline $\mathbf{1 0}$ & 4 & $5.19 \%$ & 0.703469 \\
\hline $\mathbf{1 1}$ & 1 & $1.30 \%$ & -0.98486 \\
\hline $\mathbf{1 2}$ & $\mathbf{6}$ & $7.79 \%$ & $\mathbf{1 . 8 2 9 0 1 8}$ \\
\hline $\mathbf{1 3}$ & $\mathbf{6}$ & $7.79 \%$ & $\mathbf{1 . 8 2 9 0 1 8}$ \\
\hline $\mathbf{1 5}$ & 2 & $2.60 \%$ & -0.42208 \\
\hline $\mathbf{1 6}$ & 3 & $3.90 \%$ & 0.140694 \\
\hline $\mathbf{2 0}$ & 2 & $2.60 \%$ & -0.42208 \\
\hline $\mathbf{2 4}$ & 3 & $3.90 \%$ & 0.140694 \\
\hline
\end{tabular}

\begin{tabular}{|c|c|c|c|}
\hline Route & Frequency & \% Distribution & Z-Statistic \\
\hline $\mathbf{3 5}$ & 3 & $3.90 \%$ & 0.140694 \\
\hline $\mathbf{4 3}$ & 1 & $1.30 \%$ & -0.98486 \\
\hline 75 & $\mathbf{6}$ & $7.79 \%$ & $\mathbf{1 . 8 2 9 0 1 8}$ \\
\hline $\mathbf{1 1 7}$ & 1 & $1.30 \%$ & -0.98486 \\
\hline $\mathbf{1 1 9}$ & 1 & $1.30 \%$ & -0.98486 \\
\hline $\mathbf{1 2 0}$ & 2 & $2.60 \%$ & -0.42208 \\
\hline $\mathbf{1 2 1}$ & 2 & $2.60 \%$ & -0.42208 \\
\hline $\mathbf{1 2 7}$ & 3 & $3.90 \%$ & 0.140694 \\
\hline $\mathbf{2 0 1}$ & 1 & $1.30 \%$ & -0.98486 \\
\hline $\mathbf{2 5 5}$ & 1 & $1.30 \%$ & -0.98486 \\
\hline $\mathbf{3 0 0}$ & 1 & $1.30 \%$ & -0.98486 \\
\hline $\mathbf{3 0 1}$ & 1 & $1.30 \%$ & -0.98486 \\
\hline $\mathbf{3 0 2}$ & 1 & $1.30 \%$ & -0.98486 \\
\hline na & 3 & $3.90 \%$ & 0.140694 \\
\hline Total & $\mathbf{7 7}$ & \multicolumn{3}{|c|}{$\mathbf{3 0 0 . 0 0 \%}$} \\
\hline
\end{tabular}

Figure 2.6

Accident Frequency Distribution by Route

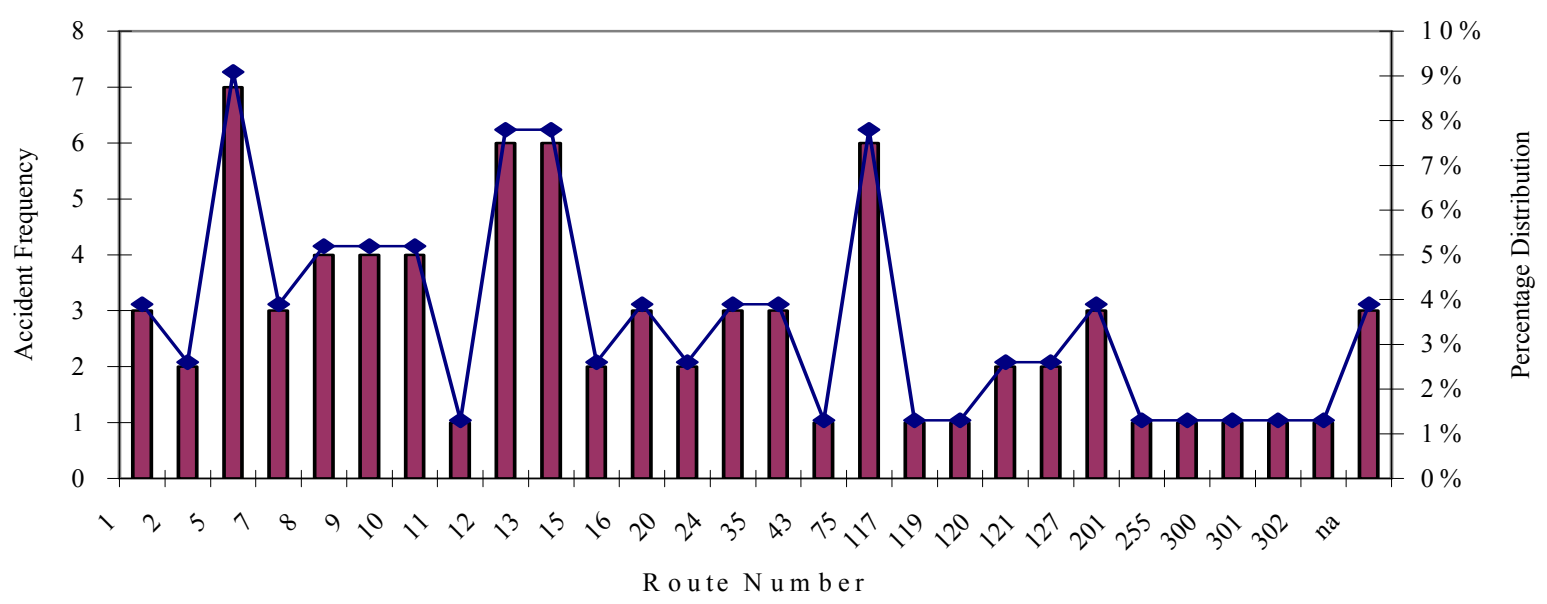

$\square$ Frequency $\longrightarrow$ D istribution 


\subsubsection{Accident Occurrence by Type of Involvement}

Table 2.7 presents the four routes with the highest level of accidents according to their accident type percentage. From this analysis, it is apparent that for two of the Routes 12 and 5, 50 percent of accidents were either rear end or angle. For Route 13, 85 percent of accidents that occurred were rear end. Route 5 was the only route out of those with high accident rates that had accidents in all three major categories; rear end, sideswipe and angle.

Table 2.7

Highest Level of Accidents by Type

\begin{tabular}{|c|c|c|c|c|}
\hline \multicolumn{1}{|l|}{ Route } & \% Rear End & \% Sideswipe & \% Angle & \% Other \\
\hline 5 & 14 & 14 & 58 & 14 \\
\hline 12 & 50 & - & 50 & - \\
\hline 13 & 83 & - & 17 & - \\
\hline 75 & 50 & - & 50 & - \\
\hline
\end{tabular}

\subsubsection{Frequency by Type of Involvement}

The frequency distribution for bus accident occurrence by type of involvement is presented in Table 2.8. The data clearly show that the majority ( 84 percent) of accidents occurred with other motor vehicles, followed by accidents with fixed objects, (e.g. tree) at 9 percent. Fortunately, accidents involving pedestrians amounted to zero. Recognizing the university nature of Gainesville and the potentially high level of student pedestrian activity (especially in locations such as the Hub), this is a great achievement.

Table 2.8

Frequency Distribution for Type of Involvement

\begin{tabular}{|l|c|c|}
\hline Type of Involvement & Frequency & Percent Distribution \\
\hline Motor Vehicle & 65 & 84 \\
\hline Fixed Object & 7 & 9 \\
\hline Pedestrian & 0 & 0 \\
\hline Another RTS Bus & 2 & 3 \\
\hline Parked vehicle & 2 & 3 \\
\hline Miscellaneous & 1 & 1 \\
\hline Total & $\mathbf{7 7}$ & $\mathbf{1 0 0}$ \\
\hline
\end{tabular}

Of the two accidents involving another RTS bus, one occurred at the RTS Administration facility. Other studies have shown that accidents involving vehicles from the same transit company tend to occur on the property of the transit company, (e.g. maintenance facilities, etc.). In these cases, individuals other than regular operators, (e.g. mechanics and fuelers) may have been operating the buses. 


\subsubsection{Accident Occurrence Identified by Preventability Status}

The frequency distribution for preventability status is presented in Table 2.9. Only two categories of preventability were recorded by RTS, preventable and non-preventable. The 61 percent of accidents as indicated in Table 2.9 were non preventable.

Table 2.9

Accident Frequency and Distribution by Identified by Preventability Status

\begin{tabular}{|l|c|c|}
\hline Preventability Status & Frequency & Percent Distribution \\
\hline Preventable & 30 & 39 \\
\hline Non-Preventable & 47 & 61 \\
\hline Total & $\mathbf{7 7}$ & $\mathbf{1 0 0}$ \\
\hline
\end{tabular}

\subsubsection{Preventability Status and Accident Type}

Table 2.10 presents the same information according to the four general accident categories. From Table 2.10 it is evident that the majority of rear end and angle type accidents were non-preventable, in these instances the other party was at fault. In the case of sideswipe and other type of accidents, the opposite was true. The bus operator was at fault or contributed to the accident.

Table 2 .10

Percentage of Accidents by Preventability Status by Accident Type

\begin{tabular}{|l|c|c|c|c|}
\hline Preventability Status & \% Rear End & \% Sideswipe & \% Angle & \% Other \\
\hline Preventable & 21 & 62 & 47 & 75 \\
\hline Non-Preventable & 79 & 38 & 53 & 25 \\
\hline Total & $\mathbf{1 0 0}$ & $\mathbf{1 0 0}$ & $\mathbf{1 0 0}$ & $\mathbf{1 0 0}$ \\
\hline
\end{tabular}

\subsubsection{Type of Accident according to Time of Day}

Table 2.11 represents time periods with the highest number of accidents according to type:

- Four rear end accidents occurred during the time period 4:00 p.m. to 4:59 p.m., which was also the period with the highest number of accidents overall..

- Two sideswipe type of accidents occurred during the time period 12:00 p.m. to 12:59 p.m.

- Six angle type of accidents occurred in time period 2:00 p.m. to 2:59 p.m. This time period also had the highest total number of accidents (9), together with the time period 4:00 p.m. - 4:59 p.m.

- Rear end impacts accounted for 42 percent of all accidents,

- Sideswipe 11 percent,

- Angle 42 percent

- Other 5 percent. 
Table 2.11

Time Day by Type of Accident

\begin{tabular}{|l|c|c|c|c|c|}
\hline Time of Day & $\begin{array}{c}\text { Rear } \\
\text { End }\end{array}$ & Sideswipe & Angle & Other & Total \\
\hline 6:00 a.m. to 6:59a.m. & - & - & - & - & - \\
\hline 7:00 a.m. to 7:59a.m. & 1 & 1 & 1 & - & 3 \\
\hline 8:00 a.m. to 8:59a.m. & 1 & - & - & - & 1 \\
\hline 9:00a.m. to 9:59a.m & 3 & 1 & 2 & - & 6 \\
\hline 10:00 a.m. to 10:59 a.m. & 2 & - & 1 & - & 3 \\
\hline 11:00 a.m. to 11:59a.m. & 3 & - & 5 & - & 8 \\
\hline 12:00 p.m. to 12:59p.m. & 3 & 2 & 1 & - & 6 \\
\hline 1:00 p.m. to 1:59 p.m. & 3 & 1 & 2 & - & 6 \\
\hline 2:00 p.m. to 2:59 p.m. & 2 & - & 6 & 1 & 9 \\
\hline 3:00 p.m. to 3:59 p.m. & 3 & - & 3 & - & 6 \\
\hline 4:00 p.m. to 4:59 p.m. & 4 & 1 & 4 & - & 9 \\
\hline 5:00 p.m. to 5:59 p.m. & 3 & - & 2 & 1 & 6 \\
\hline 6:00 p.m. to 6:59 p.m. & 1 & - & 3 & 1 & 5 \\
\hline 7:00 p.m. to 7:59 p.m. & 1 & 1 & - & - & 2 \\
\hline 8:00 p.m. to 8:59 p.m. & - & - & - & - & - \\
\hline 9:00 p.m. to 9:59 p.m. & 1 & 1 & 1 & 1 & 4 \\
\hline 10:00 p.m. to 10:59 p.m. & - & - & - & - & - \\
\hline 11:00 p.m. to 11:59 p.m. & - & - & - & - & - \\
\hline 12:00 a.m. to 5:59 a.m. & 1 & - & 1 & - & 2 \\
\hline Unknown & 1 & - & - & - & 1 \\
\hline Total & 33 & $\mathbf{3}$ & $\mathbf{4}$ & $\mathbf{7}$ \\
\hline
\end{tabular}

\subsubsection{Crash Occurrence by Years of Operator Experience}

Accident data collected by RTS also indicates the date of hire of the operator involved. From this information it is possible to calculate the years of experience of the operator at the time of the accident and then determine if length of driving experience has some relevance to accident potential. Table 2.12 presents frequency distributions of accidents with respect to length of operator service at the time of the accident. The first two columns show the distribution of all collision occurrences by operator experience categories. Columns 3 and 4 present data for preventable crashes only. The final column illustrates the distribution of RTS bus operators by level of experience based on July 2003 data.

In Table 2.12 operators with less than one year experience were responsible for 32 percent of the accidents in the study period. This group was followed by those with 3 years (18 percent) and 1 year (14 percent). Operators with 3 years or less RTS experience accounted for more than 66 percent of the accidents in the study period. Assessing preventable accidents only, the same categories of years of service; $\leq 1$ year were responsible for 40 percent, followed by 1 year with 23 percent and 3 years with 20 percent of accidents. Operators with 3 years or less accounted for more than 80 percent of the preventable accidents. 
Accident tendency of operators with 3 or less years of service was greater than that of their percentage makeup of RTS operators. In the all accidents category, operators with $\leq 3$ years of service accounted for 69 percent of accidents compared to being 62 percent of the RTS bus operator population (as of July 2003). In the preventable accidents category, the statistics were 86 percent to 62 percent. From these cursory observations, it is evident that RTS bus operators with 3 years or less of service, were involved in the majority of accidents (of either non preventable or preventable) and may benefit from additional training with respect to accident mitigation and prevention.

Table 2.12

Frequency Distribution of Crashes and Operators by Operator Experience

\begin{tabular}{|l|c|c|c|c|c|}
\hline $\begin{array}{l}\text { Years of } \\
\text { Experience }\end{array}$ & $\begin{array}{c}\text { Frequency } \\
\text { (All) }\end{array}$ & $\begin{array}{c}\text { Valid \% } \\
\text { Distribution }\end{array}$ & $\begin{array}{c}\text { Frequency } \\
\text { (Preventable) }\end{array}$ & $\begin{array}{c}\text { Valid \% } \\
\text { Distribution }\end{array}$ & $\begin{array}{c}\text { Operator \% } \\
\text { Distribution (2003) }\end{array}$ \\
\hline$<1 \mathrm{yr}$ & 25 & 32 & 12 & 40 & 28.5 \\
\hline 1 & 11 & 14 & 6 & 20 & 18.5 \\
\hline 2 & 4 & 5 & 1 & 3 & 3.8 \\
\hline 3 & 13 & 18 & 7 & 23 & 11.5 \\
\hline 4 & 7 & 9 & 2 & 7 & 12.3 \\
\hline 5 & 1 & 1 & - & - & 6.9 \\
\hline 6 & 2 & 2 & - & - & 0.8 \\
\hline 7 & - & 1 & - & - & 1.5 \\
\hline 8 & 1 & 1 & 1 & 3 & 0.8 \\
\hline 9 & - & - & - & - & 1.5 \\
\hline 10 & 3 & 4 & - & - & 3.1 \\
\hline 11 & - & - & - & - & - \\
\hline 12 & - & - & - & - & - \\
\hline 13 & - & - & - & - & 1.5 \\
\hline 14 & 1 & 1 & - & - & 7.5 \\
\hline 15 & 1 & 1 & - & - & Na \\
\hline 16 or more & 3 & 4 & 1 & 3 & \\
\hline Missing & 4 & 5 & - & - & \\
\hline Total & $\mathbf{7 7}$ & $\mathbf{1 0 0}$ & 30 & $\mathbf{1 0 0}$ & \\
\hline & & & & & \\
\hline
\end{tabular}

\subsection{Accidents per Service Mile}

The monthly totals of revenue service miles and the number of accidents are illustrated in Figure 2.7, clearly shows the peak and trough nature of the data. Revenue service miles provided by RTS, peaked during the months of October (early part of the Fall Semester) and April. The month with the lowest revenue service miles is June, which is also the period during which the RTS bus operator's refresher training courses are typically held. Figure 2.8 illustrates the accident totals per 100,000 revenue miles by month and cumulatively. 
Figure 2.7

Revenue Service Miles Provided and Number of Accidents

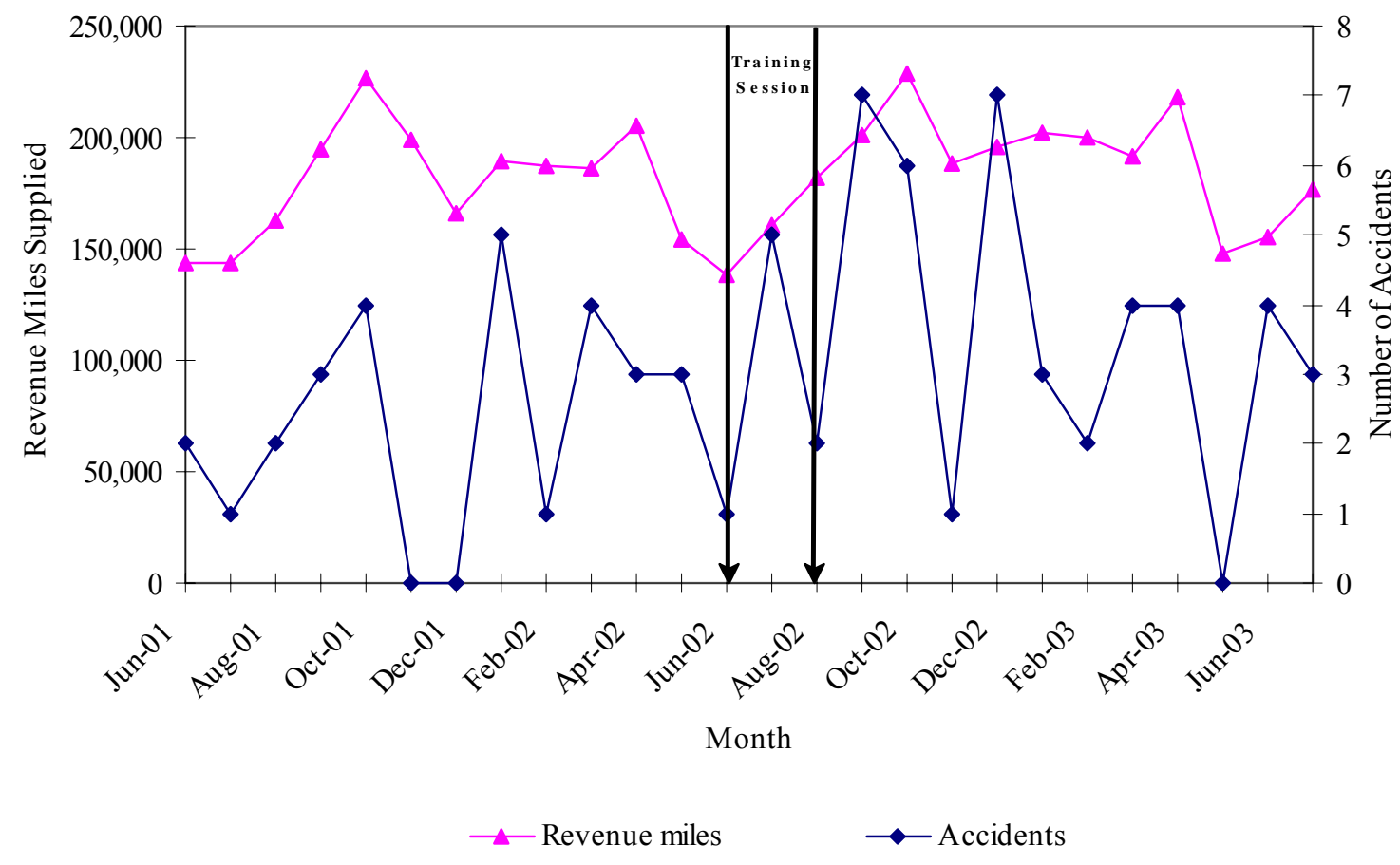

Figure 2.8

Accidents per 100,000 Revenue Miles by Month

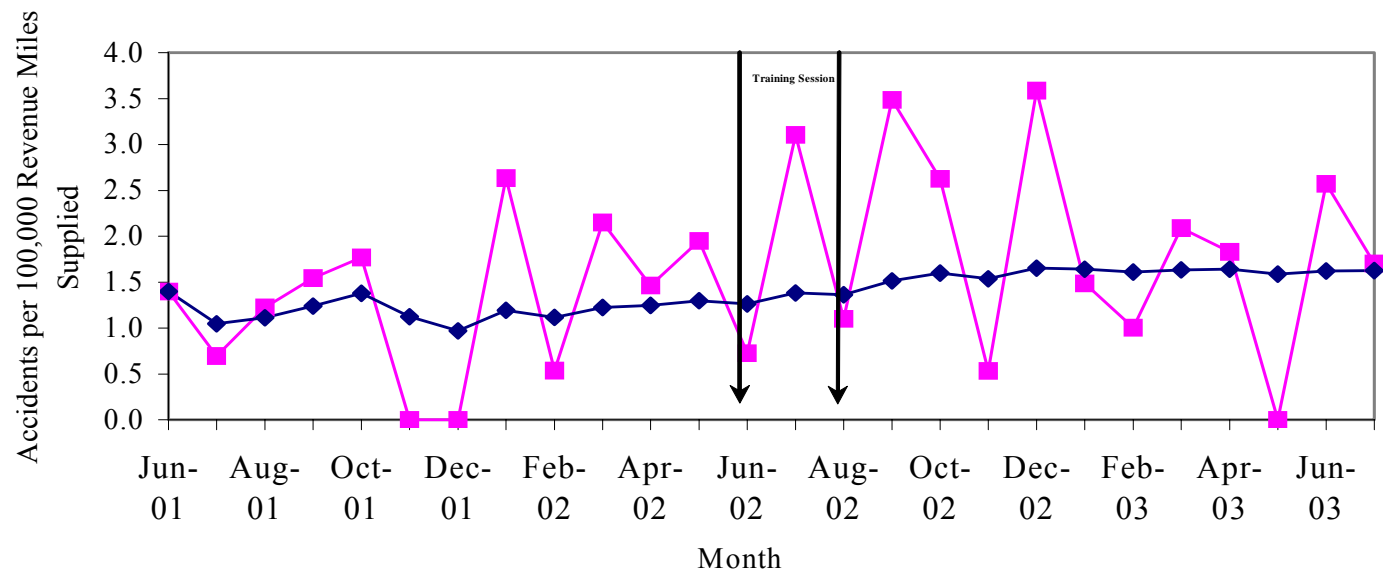

Accidents per 100,000 revenue miles $\longrightarrow$ Accidents per 100,000 Revenue Miles (Cummulative) 


\subsubsection{Summary of General Occurrence Characteristics}

Based on a review of the frequency distributions as contained in the preceding sections, it was determined that a 'typical' accident for a RTS bus operator during the study period:

- Occurred during the months of September or October

- Occurred on a Tuesday

- Occurred between the hours of 4:00 p.m. - 5:00 p.m.

- Occurred in clear weather

- Occurred on Route 5

- Involved another motor vehicle

- Either a rear end or angle type of accident

- Was non-preventable and

- Involved an operator with less than 3 years experience

\subsection{Other Factors Influencing Accident Potential}

Discussions with RTS officials revealed the additional information which has impacted the accident potential of RTS bus operators. These can be summarized as follows:

\section{- Seasonal Variation of Service Supply and Hiring}

RTS bus services are significantly reduced during the summer months, as the school and UF student population levels are generally small (major users of RTS services). At the start of the academic year, September and October are the busiest months for RTS. It is during this time, that RTS puts into service new operators which were hired during the summer months. These new operator gain their initial bus operating experience during the months of peak demand for RTS services.

\section{- Service Expansion and Penetration}

RTS in recent months has seen continuous expansion and penetration in Gainesville. Not only has there been an increase in route frequency but there has been a penetration into new parts of Gainesville that were not served beforehand. New operators, operating new routes in new areas, may be subjected initially to unfamiliar road and driving conditions, which in turn can impact on accident potential.

\section{- Operator Fatigue}

Many new RTS bus operators take advantage of the overtime and may work up to a maximum of 98 hours per pay period. Operators may want to drive a 13 hour day 6 days a week, some of whom start their day at 4 a.m. in the morning. With ongoing route expansion, opportunities for overtime are abundant, and newly hired operators may take advantage of these opportunities. 


\section{- Operator Hierarchy and Protocols}

New operators being lower down on the bus operator seniority list may also be more likely to operate on routes that may not be the easiest, in terms of hours worked, route length etc. In addition, when senior operators select their routes, often there are many routes still outstanding even after the younger operators have been accommodated. These additional routes, then fall under overtime, which the younger operators are encouraged into servicing.

\section{- Development in Gainesville}

Ongoing development within the City of Gainesville has resulted in a number of construction and development sites being created. Such sites have resulted in bus route diversions and delays, from time to time. Rescheduling and rerouting services to overcome these obstacles may also increase the potential for accidents.

\section{- Gainesville as a University City}

Gainesville being a university city has a large resident student population. Younger car drivers may manifest a higher level of driver aggression, and this may impact on the number of non-preventable accidents, e.g. rear-enders, RTS bus operators are exposed to.

\subsubsection{Accident Location by Geographic Area}

Geo-coding of accident data allows the identification of problem location on the RTS Network. Figure 2.9 is an example 31 accidents that have been manually geo-coded to a base map. This tool could be use to identify patterns in accident location that could be a result of roadway configuration and signalization, traffic congestion, and bus stop location. 
Figure 2.9

\section{Bus Accident Locations - Gainesville}

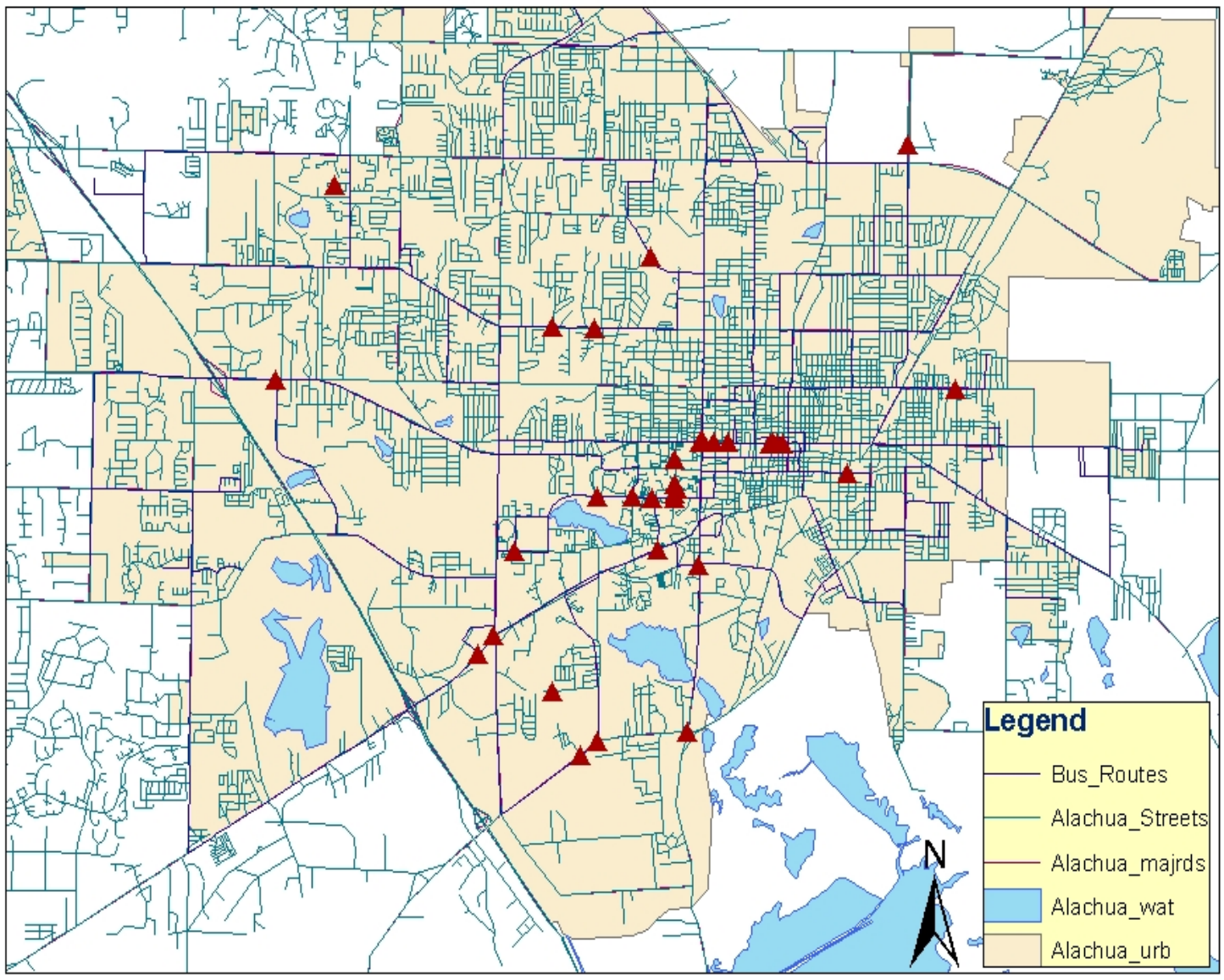

31 Accident Locations geocoded

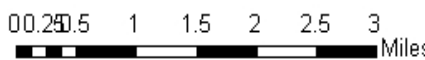




\section{CHAPTER 3 SARASOTA COUNTY TRANSPORTATION AUTHORITY}

On April 9, 1979, Sarasota County entered the public transit business by taking over a county operated bus system from Cities Transit, a private transit operator. This acquisition led to the formation of the Sarasota County Transportation Authority, informally known at Sarasota County Area Transit (SCAT). SCAT is an organizational member of the Sarasota County Government and is also governed by a fivemember Board of County Commissioners. SCAT serves the urbanized portion of Sarasota County (including the cities of Longboat Key, Sarasota, Venice, Englewood and North Port) via fixed-route and demand-response service. Since the County entered the public transit arena, bus patronage levels have dramatically increased from approximately 700,000 riders in the early 1980's to more than 1.8 million in the late 1990's. In SCAT's 20 years of service, more than 20 million passengers have taken advantage of SCAT's transit services.

According to the 2002 National Transit Database (NTD), SCAT service area encompasses approximately 159 square miles, with a service area population of 308,000. Fixed route service is provided 7 days a week with a fleet of 41 buses with reduced service on the weekends. In 2002, over 1.5 million unlinked trips were made on SCAT services. This was a 7 percent decrease the 2001 ridership figure (see Figure $3.1)$.

Figure 3.1

\section{SCAT Bus Ridership Trends (Directly Operated)}

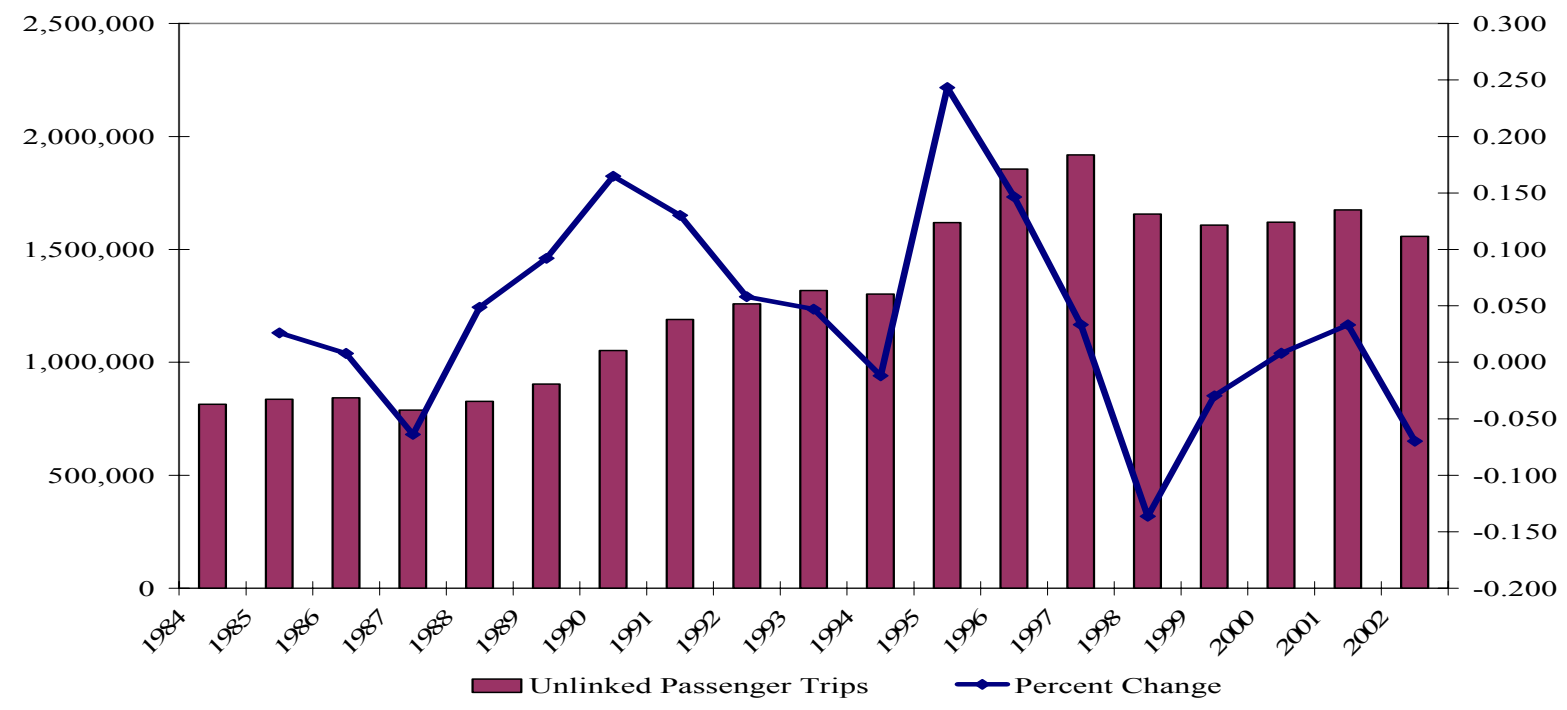

\subsection{SCAT Safety Programs}

During September 2001 to August 2003 limited remedial safety training was given to every bus operator at SCAT, this is in addition to the mandated induction course given at the commencement of hiring. 


\subsection{Accident Database}

SCAT records all accidents which involve buses even when a third party may have been involved. Data collected is placed in MS Excel format. Through such data collection, basic accident statistics are captured on a regular basis, which are subsequently used as management information. Basic analysis of the data by the SCAT Review Board tries to ascertain common safety problems and accident locations. This analysis leads to recommendations being made to management, to effect changes in order to remedy the problems identified. Detailed statistical analysis of the data is not regularly performed partly due to the low number of accidents.

\subsection{Accident Analysis}

Accident data records used in this study were obtained from SCAT offices in Sarasota. SCAT staff collected and prepared the records, while CUTR staff captured the data in MS Excel format. Questions requiring clarification of records input were answered by SCAT staff either on site or by telephone.

\subsection{Analysis Period}

The total accident analysis time frame was from September 2001 to August 2003 (24 months). Management determines when Remedial Safety Refresher Training Programs are held.

\subsection{General Occurrence Characteristics}

A total of 95 accidents occurred during the 24 month period of September 2001 through August 2003. Accident data is presented in Table 3.1 and Figure 3.2. Column 2 of Table 3.1 presents the number of accidents per month. The percentage distribution of these accidents is determined by the monthly accidents divided by the total number of accidents in the study period. Average frequency (per year) is derived by the number of accidents divided by the number of years for which those accidents were submitted. 
Table 3.1

Combined Frequency Distribution of Monthly Accidents

\begin{tabular}{|c|c|c|c|c|}
\hline Month & Number & \% Distribution & $\begin{array}{c}\text { Average } \\
\text { Frequency }\end{array}$ & Years of Data \\
\hline January & 10 & 11 & 5 & 2 \\
\hline February & 10 & 11 & 5 & 2 \\
\hline March & 11 & 12 & 5.5 & 2 \\
\hline April & 7 & 7.4 & 3.5 & 2 \\
\hline May & 4 & 4.2 & 2 & 2 \\
\hline June & 6 & 6.3 & 3 & 2 \\
\hline July & 4 & 4.2 & 2 & 2 \\
\hline August & 9 & 9.5 & 4.5 & 2 \\
\hline September & 6 & 6.3 & 3 & 2 \\
\hline October & 13 & 14 & 6.5 & 2 \\
\hline November & 9 & 9.5 & 4.5 & 2 \\
\hline December & 6 & 6.3 & 3 & 2 \\
\hline Total & $\mathbf{9 5}$ & $\mathbf{1 0 0 . 0}$ & & \\
\hline
\end{tabular}

Figure 3.2

Combined Frequency Distribution of Monthly Accidents

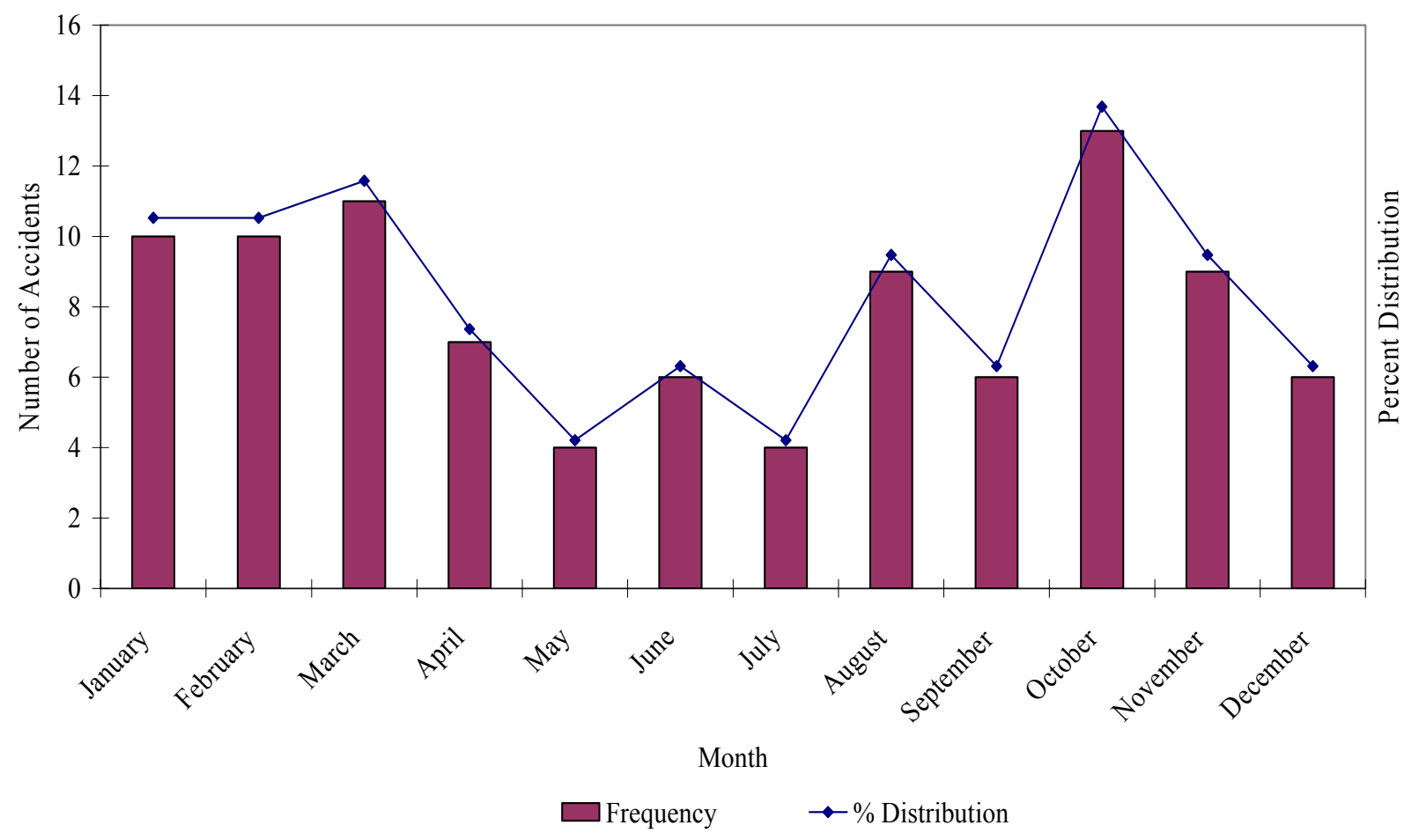


The highest number of accidents (13) occurred in the month of October with the average frequency also being the highest (6.5) followed by March, January and February. The months with the lowest average frequency of accidents were May and July followed by June, September and December. These months all experienced lighter traffic levels than the peak visitor seasons.

\subsubsection{Crash Occurrence by Day of Week}

Crash occurrence data by day of week is presented in Table 3.2 and in Figure 3.3. Table 3.2 also presents accident data frequency by day of week. Overall, Mondays and Thursdays were the days with the highest numbers of accidents with 19 each. The lack of Sunday bus operation coupled with lower levels of traffic, accounted for the one bus accident (over the entire study period) which occurred on this day.

Table 3.2

Combined Frequency Distribution of Day of Week Accidents

\begin{tabular}{|c|c|c|c|c|}
\hline Month & Frequency & \% Distribution & Average Frequency & Days \\
\hline Sunday & 1 & 1.05 & 0.010 & 105 \\
\hline Monday & 19 & 20.00 & 0.181 & 105 \\
\hline Tuesday & 14 & 14.74 & 0.135 & 104 \\
\hline Wednesday & 16 & 16.84 & 0.154 & 104 \\
\hline Thursday & 19 & 20.00 & 0.184 & 103 \\
\hline Friday & 13 & 13.68 & 0.125 & 104 \\
\hline Saturday & 13 & 13.68 & 0.124 & 105 \\
\hline Total & $\mathbf{9 5}$ & $\mathbf{1 0 0 . 0}$ & $\mathbf{0 . 1 3 0}$ & $\mathbf{7 3 0}$ \\
\hline
\end{tabular}

Figure 3.3

Combined Frequency Distribution of Day of Week

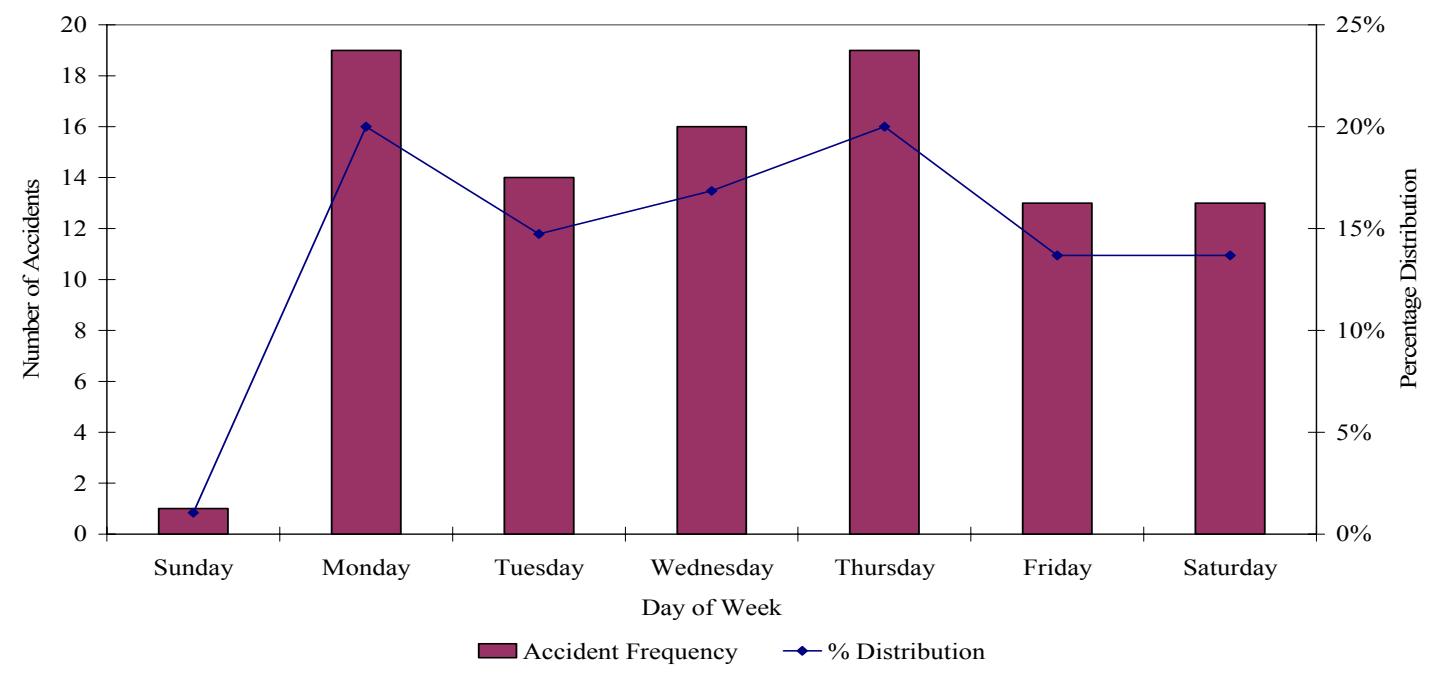




\subsubsection{Accident Occurrence by Time of Day}

Table 3.3 and Figure 3.4 present data on accident occurrence by time of day. The time period with the highest number of accidents is between 2:00 p.m. - 2:59 p.m. The second busiest period for accident occurs between 4:00 p.m. - 4:59 p.m. during the evening peak. SCAT does not operate evening service from 8:00 pm to midnight as a result the table shows 0 accidents for that time period. Table 3.3 presents data on accident type by time period.

Table 3.3

Combined Frequency Distribution by Time of Day Accidents

\begin{tabular}{|l|c|c|l|c|c|}
\hline Time of Day & Frequency & \% Distribution & Time of Day & Frequency & \% Distribution \\
\hline 6:00 a.m. to 6:59a.m. & 5 & $5.3 \%$ & $4: 00$ p.m. to 4:59 p.m. & 9 & $9.5 \%$ \\
\hline 7:00 a.m. to 7:59a.m. & 4 & $4.2 \%$ & $5: 00$ p.m. to 5:59 p.m. & 2 & $2.1 \%$ \\
\hline 8:00 a.m. to 8:59a.m. & 7 & $7.4 \%$ & $6: 00$ p.m. to 6:59 p.m. & 3 & $3.2 \%$ \\
\hline 9:00a.m. to 9:59a.m & 3 & $3.2 \%$ & 7:00 p.m. to 7:59 p.m. & 4 & $4.2 \%$ \\
\hline 10:00 a.m. to 10:59 a.m. & 6 & $6.3 \%$ & $8: 00$ p.m. to 8:59 p.m. & 0 & $0.0 \%$ \\
\hline 11:00 a.m. to 11:59a.m. & 6 & $6.3 \%$ & $9: 00$ p.m. to 9:59 p.m. & 0 & $0.0 \%$ \\
\hline 12:00 p.m. to 12:59p.m. & 6 & $6.3 \%$ & $10: 00$ p.m. to $10: 59$ p.m. & 0 & $0.0 \%$ \\
\hline 1:00 p.m. to 1:59 p.m. & 5 & $5.3 \%$ & $11: 00$ p.m. to $11: 59$ p.m. & 0 & $0.0 \%$ \\
\hline 2:00 p.m. to 2:59 p.m. & 11 & $11.6 \%$ & $12: 00$ a.m. to 5:59 a.m. & 2 & $2.1 \%$ \\
\hline 3:00 p.m. to 3:59 p.m. & 8 & $8.4 \%$ & Missing & 16 & $14.7 \%$ \\
\hline Total & \multicolumn{7}{|l|}{ 95 Accidents } \\
\hline
\end{tabular}

Figure 3.4

\section{Combined Frequency Distribution by Time of Day Accidents}

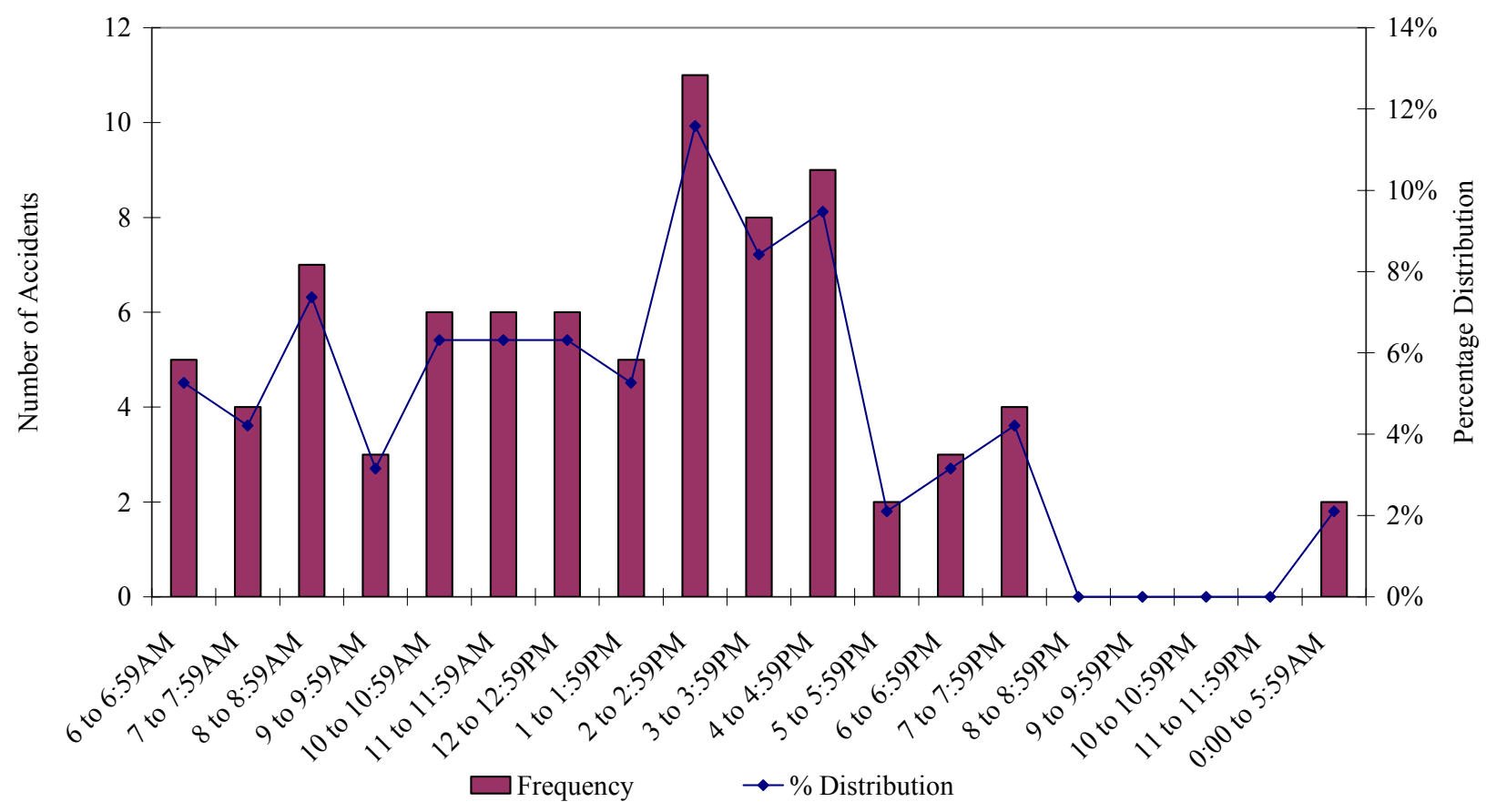




\subsubsection{Accident Occurrence by Route}

During the SCAT FY2002, SCAT operated a variety of routes with a fleet of 50 buses (NTD data). Over the study period the number of routes operated did not fluctuate on a month by month basis (SCAT generally operates the same schedule year round). Table 3.4 and Figure 3.5 present accident data by route.

Table 3.4

Accident Frequency Distribution by Route

\begin{tabular}{|c|c|c|c|}
\hline Route & Frequency & \% Distribution & Z-Statistic \\
\hline $\mathbf{1}$ & 4 & $4.2 \%$ & -0.029690 \\
\hline $\mathbf{2}$ & 3 & $3.2 \%$ & -0.257313 \\
\hline $\mathbf{3}$ & 2 & $2.1 \%$ & -0.484937 \\
\hline $\mathbf{4}$ & 2 & $2.1 \%$ & -0.484937 \\
\hline $\mathbf{5}$ & 6 & $6.3 \%$ & 0.425557 \\
\hline $\mathbf{6}$ & 6 & $6.3 \%$ & 0.425557 \\
\hline $\mathbf{7}$ & 3 & $3.2 \%$ & -0.257313 \\
\hline $\mathbf{8}$ & 6 & $6.3 \%$ & 0.425557 \\
\hline $\mathbf{9}$ & 2 & $2.1 \%$ & -0.484937 \\
\hline $\mathbf{1 0}$ & 0 & $0.0 \%$ & -0.940184 \\
\hline $\mathbf{1 1}$ & 2 & $2.1 \%$ & -0.484937 \\
\hline $\mathbf{1 2}$ & 3 & $3.2 \%$ & -0.257313 \\
\hline
\end{tabular}

\begin{tabular}{|c|c|c|c|}
\hline Route & Frequency & \% Distribution & Z-Statistic \\
\hline $\mathbf{1 3}$ & 0 & $0.0 \%$ & -0.940184 \\
\hline $\mathbf{1 4}$ & 3 & $3.2 \%$ & -0.257313 \\
\hline $\mathbf{1 5}$ & 7 & $7.4 \%$ & 0.653180 \\
\hline $\mathbf{1 6}$ & 2 & $2.1 \%$ & -0.484937 \\
\hline $\mathbf{1 7}$ & $\mathbf{1 5}$ & $\mathbf{1 5 . 8 \%}$ & $\mathbf{2 . 4 7 4 1 6 7}$ \\
\hline $\mathbf{1 8}$ & 0 & $0.0 \%$ & -0.940184 \\
\hline $\mathbf{1 9}$ & 3 & $3.2 \%$ & -0.257313 \\
\hline Garage & 1 & $1.1 \%$ & -0.712560 \\
\hline Charter & 2 & $2.1 \%$ & -0.484937 \\
\hline Trolley & 5 & $5.3 \%$ & 0.197933 \\
\hline Missing & 18 & $18.9 \%$ & 3.157038 \\
\hline Total & $\mathbf{9 5}$ & $\mathbf{1 0 0} \%$ & \\
\hline
\end{tabular}

The Route 17 experienced the highest number of accidents (15) accidents followed by Route 5 with 7 accidents. Route 17 accounted for 15 percent of all the accidents in the study period with a Z-Statistic of 2.47. A Z-statistic over 1.40 can be used to identify routes that are more prone to crash occurrence relative to the other routes in the system. Route 17 is the only route which surpasses this threshold.

Figure 3.5

\section{Accident Frequency Distribution by Route}

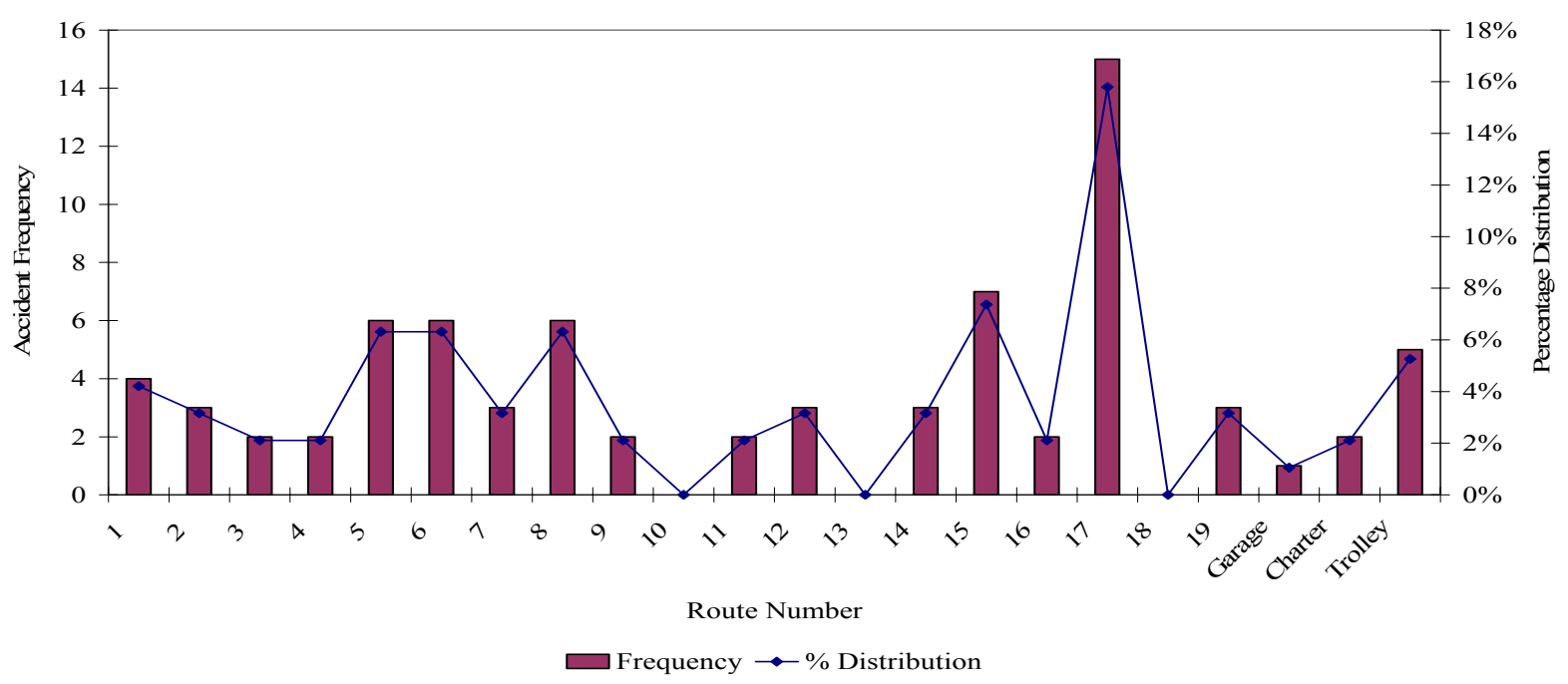




\subsubsection{Accident Occurrence by Type of Involvement}

The frequency distribution for bus accident occurrence by type of involvement is presented in Table 3.5. The data clearly indicates that of the 6 categories of accident types, the majority involved a motor vehicle (81 percent), followed by collisions with fixed objects (19 percent).

Table 3.5

Frequency Distribution for Type of Involvement

\begin{tabular}{|l|c|c|}
\hline Type of Involvement & Frequency & Percent Distribution \\
\hline Motor Vehicle & 77 & 81 \\
\hline Fixed Object & 18 & 19 \\
\hline Pedestrian & 0 & 0 \\
\hline Another SCAT Bus & 0 & 0 \\
\hline Parked vehicle & 0 & 0 \\
\hline Miscellaneous & 0 & 0 \\
\hline Total & $\mathbf{9 5}$ & $\mathbf{1 0 0}$ \\
\hline
\end{tabular}

Very few accidents occurred on SCAT property. Other studies have shown that accidents involving vehicles from the same transit company tend to occur on the property of the transit company. In these cases, individuals other than regular operators, e.g. mechanics and feelers operate the buses.

\subsubsection{Type of Accident according to Time of Day}

A review of the time periods with the highest number of accidents according to type (Table 3.6) reveals that:

- Rear end accidents (5) occurred during the time period 10:00 a.m. to 10:59 a.m.

- Sideswipe accidents (2) occurred during the time periods 2:00 p.m. to 2:59 p.m. and 3:00 p.m. to 3:59 p.m.

- Angle accidents (5) occurred during the time period 3:00p.m to 3:59p.m.

- 3 other types of accidents (e.g. hitting a fixed object) occurred during the time period 2:00 p.m. to 2:59p.m.

Overall, rear end accidents accounted for 31 percent of all accidents, sideswipe accounted for 15 percent; angle in 38 percent of accidents and other types comprised of 16 percent. 
Table 3.6

Time Day by Type of Accident

\begin{tabular}{|c|c|c|c|c|c|}
\hline Time of Day & Rear End & Sideswipe & Angle & Other & Total \\
\hline 6:00 a.m. to 6:59a.m. & 2 & 1 & 2 & - & 5 \\
\hline 7:00 a.m. to 7:59a.m. & 2 & - & 2 & - & 4 \\
\hline 8:00 a.m. to 8:59a.m. & 3 & 1 & 2 & 1 & 7 \\
\hline 9:00a.m. to 9:59a.m & 2 & - & 1 & - & 3 \\
\hline 10:00 a.m. to $10: 59$ a.m. & 5 & - & 1 & - & 6 \\
\hline 11:00 a.m. to $11: 59$ a.m. & - & 1 & 4 & 1 & 6 \\
\hline 12:00 p.m. to $12: 59$ p.m. & 3 & 1 & - & 2 & 6 \\
\hline 1:00 p.m. to $1: 59$ p.m. & 1 & 1 & 2 & 1 & 5 \\
\hline 2:00 p.m. to $2: 59$ p.m. & 4 & 2 & 2 & 3 & 11 \\
\hline 3:00 p.m. to 3:59 p.m. & - & 2 & 5 & 1 & 8 \\
\hline 4:00 p.m. to 4:59 p.m. & 2 & 1 & 4 & 2 & 9 \\
\hline 5:00 p.m. to 5:59 p.m. & 1 & - & 1 & - & 2 \\
\hline 6:00 p.m. to $6: 59$ p.m. & - & 1 & 1 & 1 & 3 \\
\hline 7:00 p.m. to 7:59 p.m. & - & 1 & 3 & - & 4 \\
\hline 8:00 p.m. to $8: 59$ p.m. & - & - & - & - & 0 \\
\hline 9:00 p.m. to 9:59 p.m. & - & - & - & - & 0 \\
\hline 10:00 p.m. to $10: 59$ p.m. & - & - & - & - & 0 \\
\hline 11:00 p.m. to $11: 59$ p.m. & - & - & - & - & 0 \\
\hline 12:00 a.m. to 5:59 a.m. & - & - & 1 & 1 & 2 \\
\hline Unknown & 5 & 2 & 5 & 2 & 14 \\
\hline Total & 30 & 14 & 36 & 15 & 95 \\
\hline
\end{tabular}

\subsubsection{Type of Accident according to Bus Route}

Table 3.7 presents SCAT bus routes and accident type (ranked according to frequency). On Route 17, the majority of accidents were rear end. On Route 15 rear end accidents accounted for more than 50 percent of all accidents. Routes with the highest accident frequency are 17, 15, 5, 6 and 8. Route 17 was the only route involved in all four accident type categories (e.g. rear end, sideswipe, angle and other). The four other routes were involved in a maximum of three of the four accident type categories. These 5 routes combined were involved in total of 40 accidents, of which 75 percent were rear end and angle type of accidents. 
Table 3.7

Accident Occurrence by Route and Type (Ranked)

\begin{tabular}{|c|c|c|c|c|c|}
\hline Route & Rear End & Sideswipe & Angle & Other & Total \\
\hline 17 & 7 & 1 & 5 & 2 & 15 \\
\hline 15 & 4 & 1 & 1 & 1 & 7 \\
\hline 5 & 1 & 1 & 4 & & 6 \\
\hline 6 & 4 & & 1 & 1 & 6 \\
\hline 8 & & 1 & 3 & 2 & 6 \\
\hline Trolley & 1 & 2 & 1 & 1 & 5 \\
\hline 1 & 1 & & 2 & 1 & 4 \\
\hline 2 & & 1 & 2 & & 3 \\
\hline 7 & 1 & & 1 & 1 & 3 \\
\hline 12 & 1 & 1 & 1 & & 3 \\
\hline 14 & 1 & & 1 & 1 & 3 \\
\hline 19 & 1 & & 1 & 1 & 3 \\
\hline 3 & & 2 & & & 2 \\
\hline 4 & & 1 & 1 & & 2 \\
\hline 9 & 1 & & 1 & & 2 \\
\hline 11 & & 1 & 1 & & 2 \\
\hline 16 & 1 & & 1 & & 2 \\
\hline Charter & & & 2 & & 2 \\
\hline Garage & & & 1 & & 1 \\
\hline 10 & & & & & 0 \\
\hline 13 & & & & & 0 \\
\hline 18 & & & & & 0 \\
\hline Missing & 6 & 2 & 6 & 4 & 18 \\
\hline TOTAL & 30 & 14 & 36 & 15 & 95 \\
\hline
\end{tabular}

\subsubsection{Accident Occurrence by Type of Weather and Road Condition}

The frequency distribution of prevailing weather and road conditions at the time of the accident is presented in Table 3.8 and Figure 3.6 The majority of accidents (62 percent) occurred in clear weather. 
Table 3.8

Accident Occurrence by Type of Weather and Road Condition

\begin{tabular}{|c|c|c|c|}
\hline Weather & Road Condition & Frequency & \% Distribution \\
\hline \multirow[t]{2}{*}{ Clear } & Dry & 62 & $65.3 \%$ \\
\hline & Wet & - & - \\
\hline \multirow[t]{2}{*}{ Rain } & Dry & - & - \\
\hline & Wet & 5 & $5.3 \%$ \\
\hline \multirow[t]{2}{*}{ Dark/Night } & Dry & 1 & $1.1 \%$ \\
\hline & Wet & - & - \\
\hline \multirow[t]{2}{*}{ Dusk/Semi Dark } & Dry & 1 & $1.1 \%$ \\
\hline & Wet & - & - \\
\hline \multirow[t]{2}{*}{ Cloudy } & Dry & 5 & $5.3 \%$ \\
\hline & Wet & 2 & $2.1 \%$ \\
\hline \multirow[t]{2}{*}{ Fog } & Dry & - & - \\
\hline & Wet & 2 & $2.1 \%$ \\
\hline \multirow[t]{2}{*}{ Dark \& Clear } & Dry & 1 & $1.1 \%$ \\
\hline & Wet & - & $0.0 \%$ \\
\hline Missing & na & 16 & $16.8 \%$ \\
\hline Total & & 95 & \\
\hline
\end{tabular}

Figure 3.6

Accident Frequency Distribution by Type of Weather

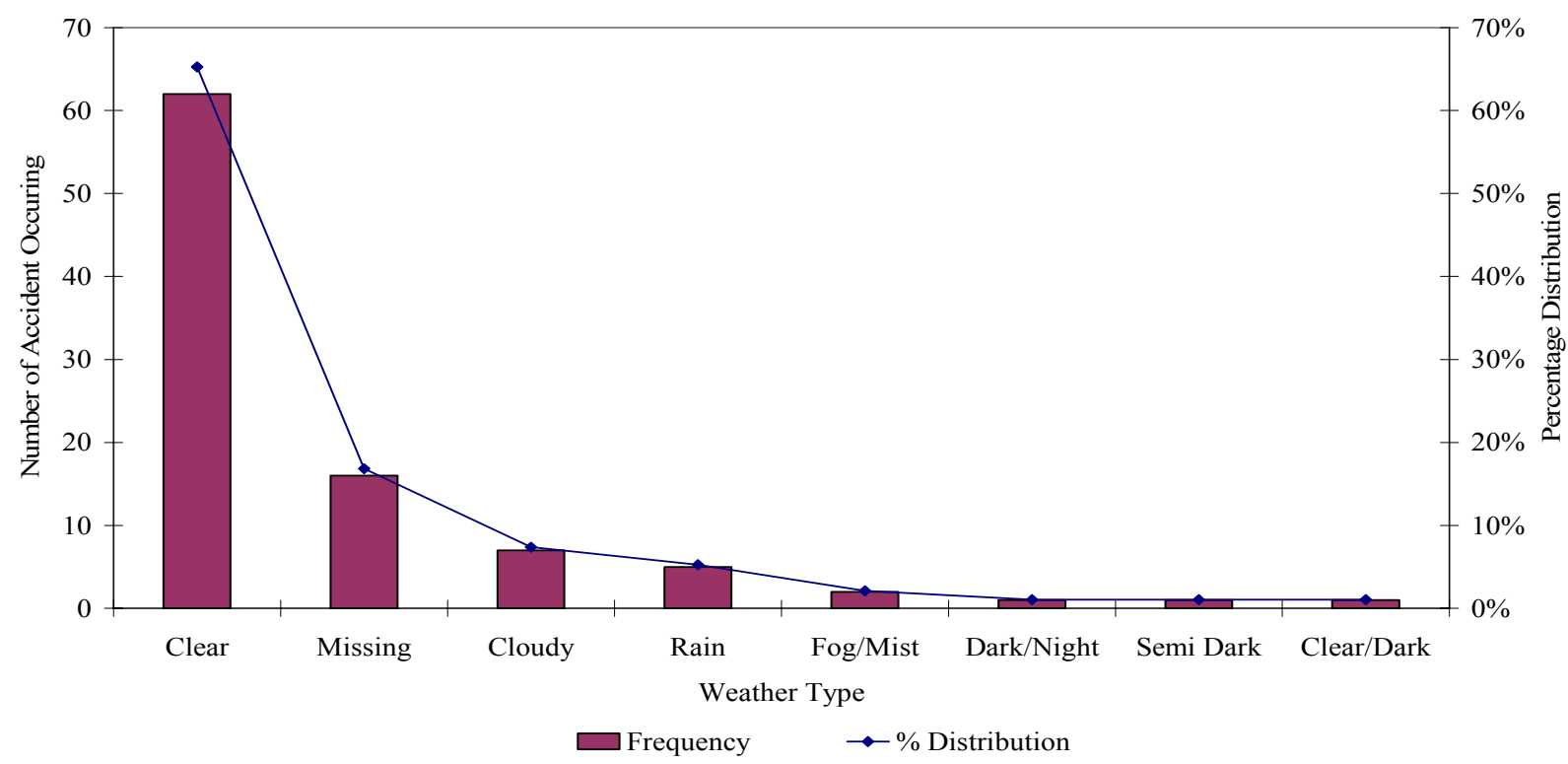




\subsubsection{Accident Occurrence Identified By Preventability Status}

SCAT did not record an indication of the preventable versus non-preventable on their accident records.

\subsubsection{Crash Occurrence by Years of Operator Experience}

Accident data collected by SCAT indicates the date of hire of the bus operator involved. From this information it is possible to calculate the of years of driving experience the operator had at the time of the accident and if there is any relationship between length of driving operation and accident potential. Table 3.9 presents frequency distributions of accidents with respect to length of service at the time of accident. The first two columns present the distribution of all collision occurrences by the operator experience categories. The final column illustrates the distribution of SCAT operator by level of experience based on August 2003 data.

Table 3.9

Frequency Distribution of Accidents According to Years of Operator Experience

\begin{tabular}{|c|c|c|}
\hline Years of Experience at SCAT & Frequency (All) & Valid \% Distribution \\
\hline$<1$ yr & 17 & 18 \\
\hline 1 & 13 & 14 \\
\hline 2 & 7 & 7 \\
\hline 3 & 12 & 4 \\
\hline 4 & 4 & 3 \\
\hline 5 & 3 & 3 \\
\hline 6 & 3 & 3 \\
\hline 7 & 3 & 0 \\
\hline 8 & 0 & 2 \\
\hline 9 & 2 & 1 \\
\hline 10 & 1 & 2 \\
\hline 11 & 2 & 1 \\
\hline 12 & 1 & 3 \\
\hline 13 & 3 & 1 \\
\hline 14 & 1 & 4 \\
\hline 15 or more & 4 & 20 \\
\hline Missing & 19 & $\mathbf{1 0 0}$ \\
\hline Total & $\mathbf{9 5}$ & \\
\hline & & 13 \\
\hline
\end{tabular}

Operators with less than one years experience were responsible for 18 percent of the accidents in the study period. This group was followed by those with 1 year (14 percent) and 3 years (13 percent). Operators with 3 years or less of bus operations for SCAT accounted for just over half (52 percent) of all accidents in the study period. 


\subsection{Accidents per Service Mile}

The monthly totals of revenue service miles supplied by SCAT and the corresponding number of bus accidents are illustrated in Figure 3.7. This graphic clearly shows the peak and trough nature of bus accidents per 100,000 revenue service miles. Data on revenue service miles supplied was provided by SCAT for the FY 2003. Monthly totals in the FY 2001 and FY 2002 were estimated using the yearly totals from the National Transit Database (1.5 million and 1.6 million miles) and by proportioning these figures according to the monthly amounts of the 2003 data. Figure 3.8 illustrates the accident totals per 100,000 revenue miles by month.

Figure 3.7

Revenue Miles per Month Supplied versus Number of Accidents

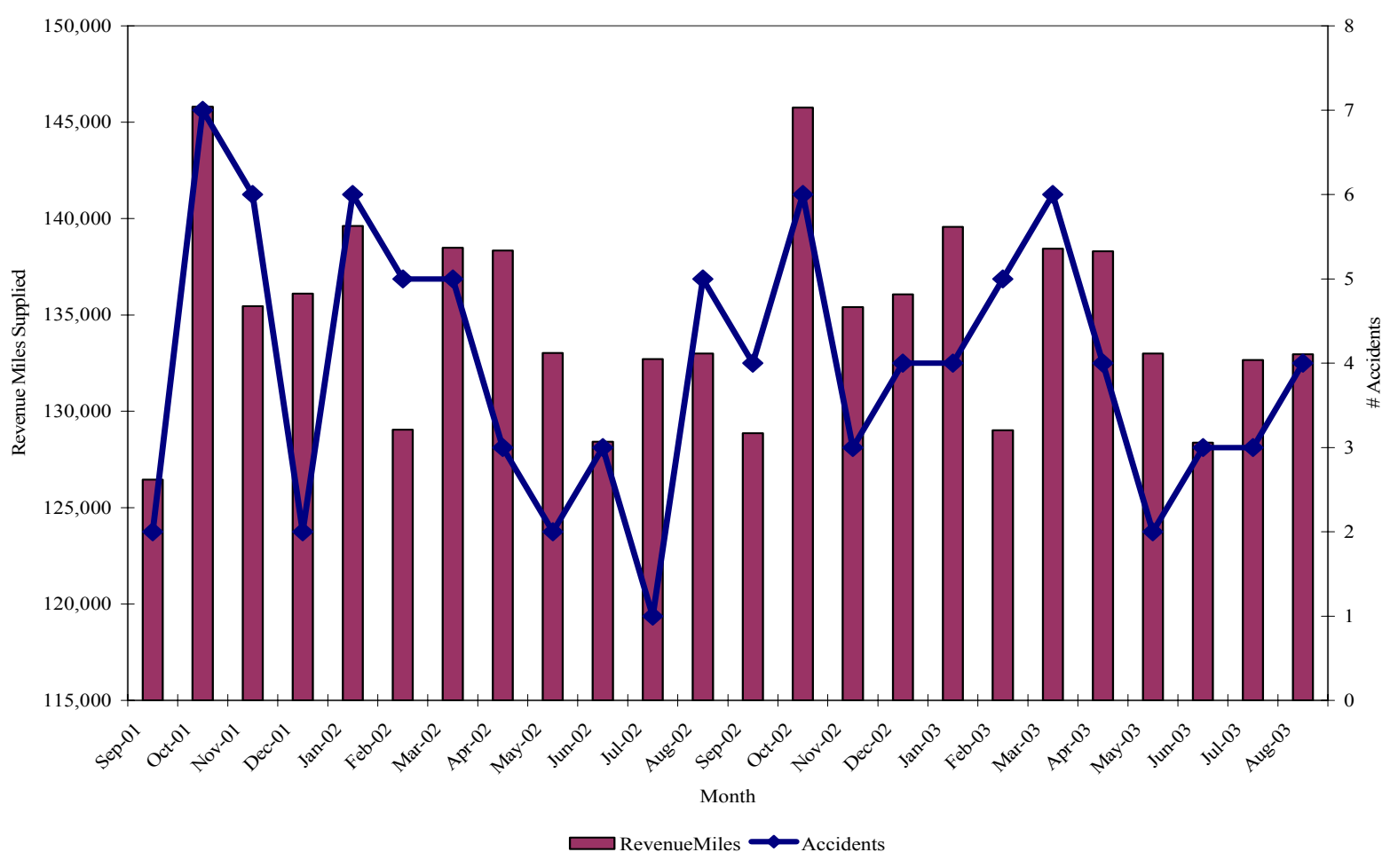


Figure 3.8

Accidents per 100,000 Revenue Miles by Month

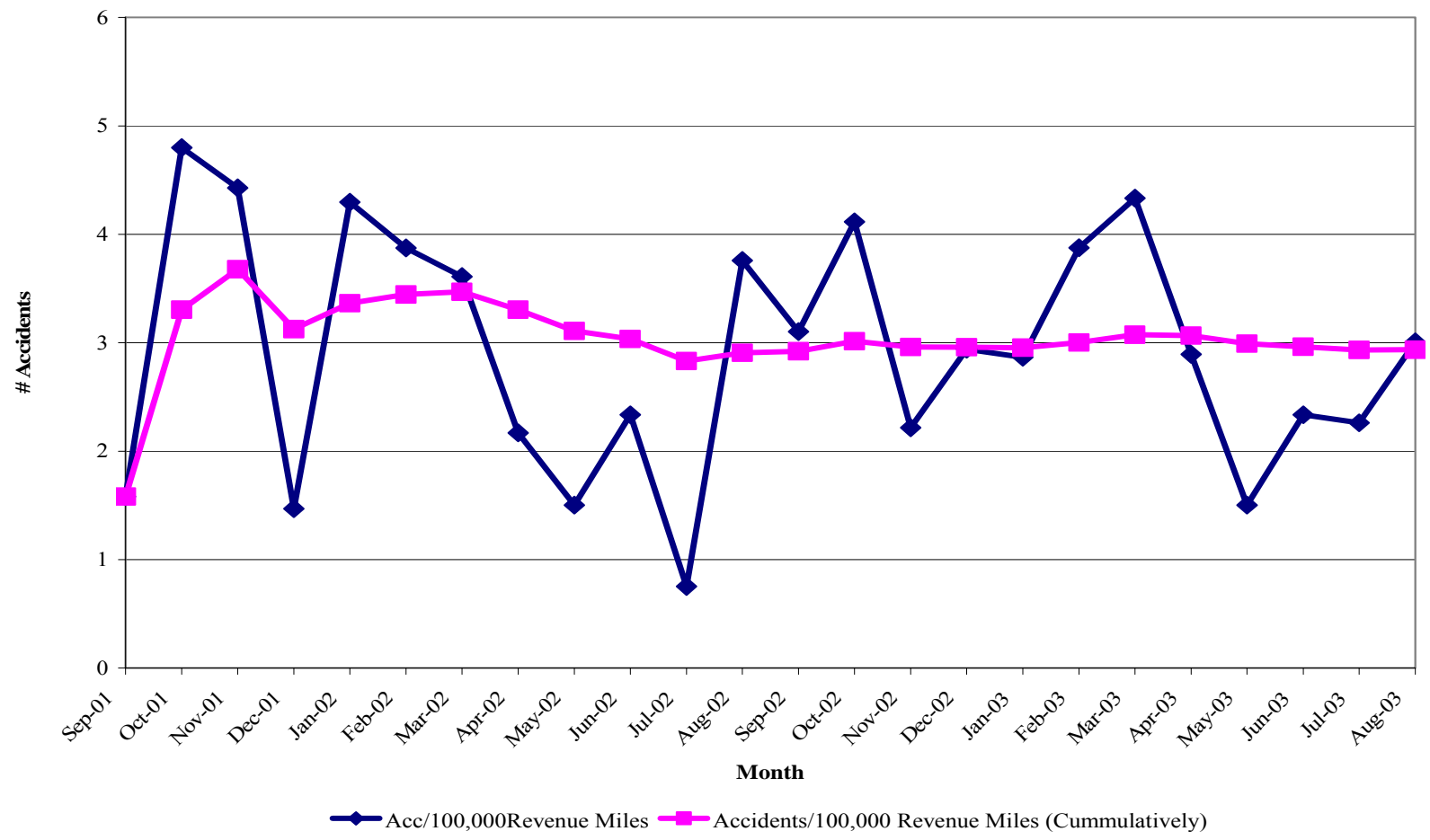

\subsection{Summary of General Occurrence Characteristics}

Based on a review of the frequency distributions as contained in the preceding sections, a 'typical' accident for a SCAT bus operator during the study period:

- Occurred during the month October

- Occurred on a Monday or Thursday

- Occurred between 2:00 p.m. to 3:00 p.m.

- Occurred in clear weather

- Occurred on Route 17

- Involved another motor vehicle

- Was an angle type of accident and

- Involved an operator with less than 3 years experience

\subsection{Other Factors Influencing Accident Potential}

Discussions with SCAT officials revealed the following additional information which has impacted the accident potential of SCAT bus operators. 


\section{- New Bus Operators}

New bus operators having to operate under a new operating routine when compared to their previous employer may increase accident potential in the initial transitional phase. New operators, operating new routes in new areas, may be subjected initially to unfamiliar roads and driving conditions, which in turn can impact on accident potential.

\section{- Operator Fatigue}

Many new SCAT bus operators take advantage of overtime and may work up to a maximum of 98 hours per pay period. Operators may drive a 13 hour day, 6 days a week, some of whom start their day very early in the morning. Route expansion or changes, as well as driver absenteeism, provide opportunities for overtime, which newly hired operators may take a greater propensity to advantage of these opportunities.

\subsubsection{Accident Location by Geographic Area}

Geo-coding of accident allows the identification of problem location on the SCAT Route Network. Figure 3.90 is an example of 25 accidents that have been manually geo-coded to a base map. This tool could be used to identify patterns in accident location that could be a result of roadway configuration and signalization, traffic congestion, and bus stop location. 
Figure 3.9

\section{Bus Accident Locations- Sarasota County}

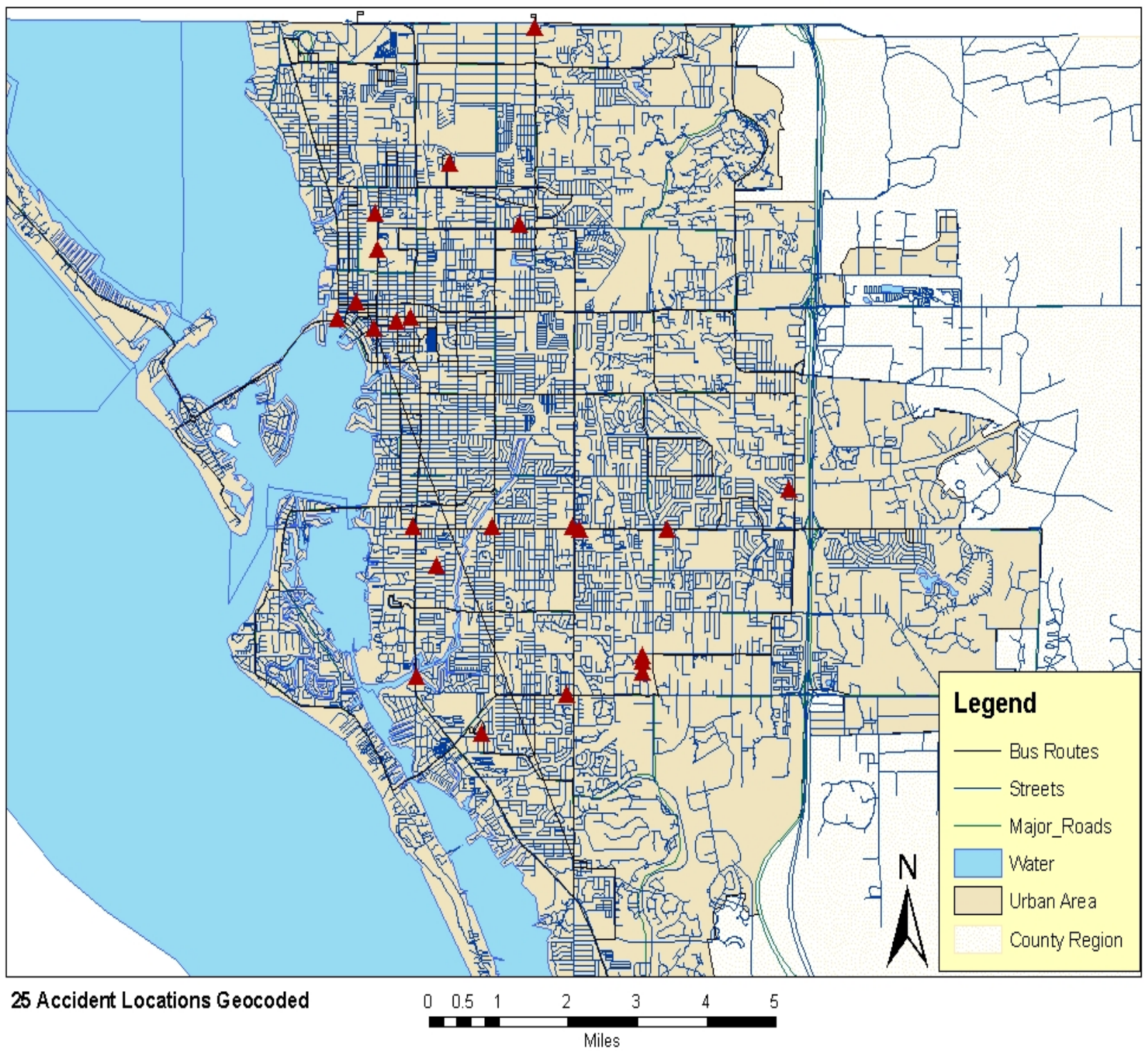




\section{CHAPTER 4 VOLUSIA COUNTY PUBLIC TRANSIT SYSTEM}

According to the Census 2003 population estimate, more than 465, 000 people call Volusia County home. Volusia County is situated on the east coast of Central Florida and has 47 miles of Atlantic Ocean coastline. Volusia County includes the cities of Daytona Beach (famous for motor racing), Ormond Beach and New Smyrna Beach. The 2003 population estimate ranked Volusia County as the $11^{\text {th }}$ most populous county in Florida.

County of Volusia, dba: VOTRAN is a county-wide tax-supported public transit system. According to the 2002 National Transit Database, VOTRAN had a fleet of 60 revenue-producing fixed route buses operating over a route network of 645 miles, with additional vehicles leased or contracted to satisfy transportation demand. In 1993, VOTRAN received the American Public Transit Association's (APTA) award for the "Outstanding Transit System in North America." During the first six months of 1995, VOTRAN was ranked seventh in growth among all U.S. public transit systems by APTA. VOTRAN received the Florida Department of Transportation's top safety award in 1992-94, 1996-97, 2000, and placed second in 1998 and 1999. In 2002, VOTRAN provided 2,963,000 unlinked passenger trips, a 22 percent decrease from 2001 ridership level $(3,817,000)$ as shown in Figure 41.

Figure 4.1

VOTRAN Ridership Trends

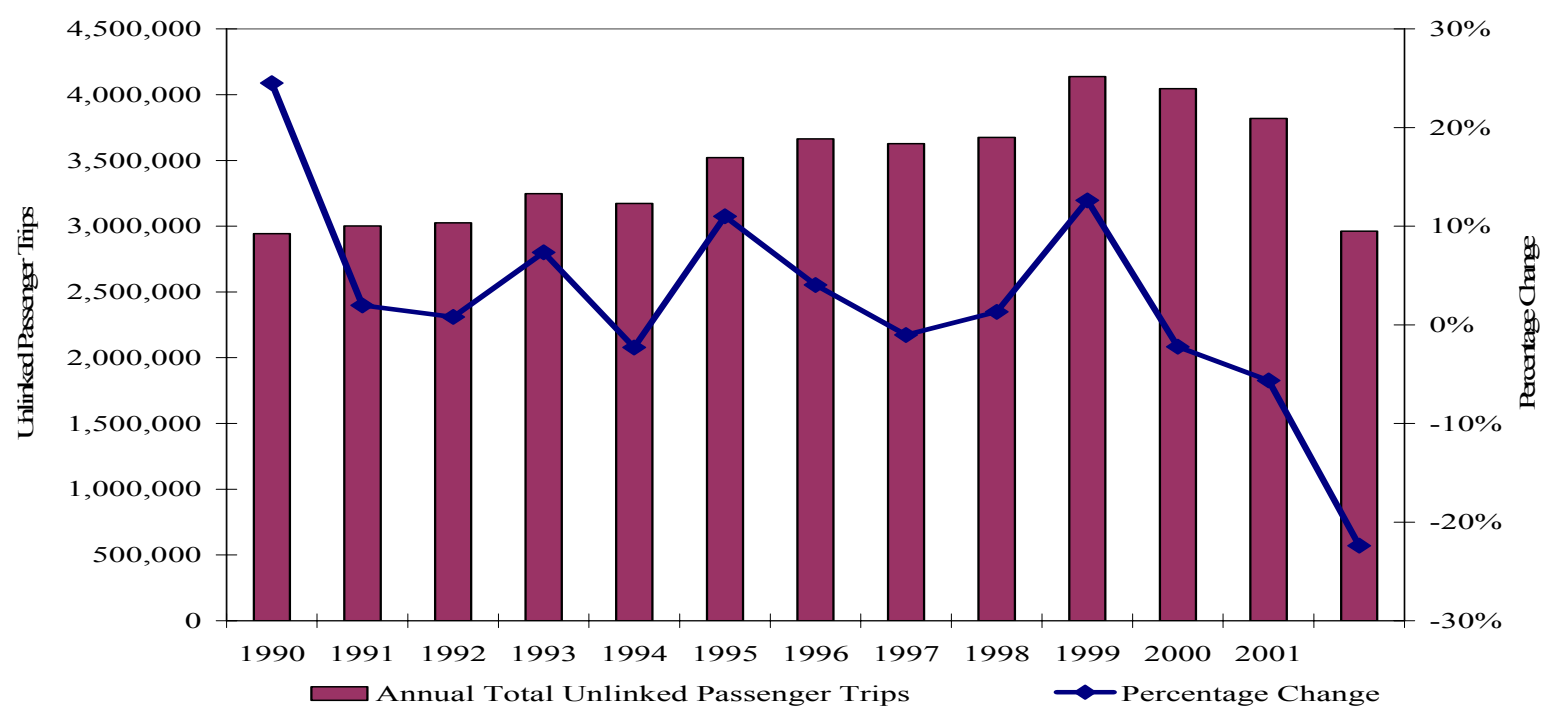

\subsection{VOTRAN Safety Training}

The VOTRAN Safety Manager is tasked with training operators in safety techniques of bus driving and operations. The Safety Manager is certified by the Transportation Safety Institute and is assisted by other safety staff (certified defensive driving instructors) when training is needed. All new operators joining VOTRAN are required to complete the Commercial Drivers License (CDL) course. 


\subsection{VOTRAN Safety Programs}

According to information received from VOTRAN, a safety training course is conducted at least once every two years (preferably on an annual basis). All bus operators are required to participate in this course. The course is conducted during the month of October which is typically a 'down' month with respect to VOTRAN bus operations. October Fest and Daytona Motor Racing which impact public transit demands in the county are over.

The safety training course is typically a two to four hour class offering training on defensive driving techniques. The chief instructor is assisted by up to five supervisors (when necessary). Trained personnel within VOTRAN permit the course to be given in-house rather that using contracted professional training service providers. Safety classes range in size from 12 - 45 students, but class size is usually kept to 30 or less students. Currently, VOTRAN has approximately 170 bus operators to put through the program.

In order to make the syllabus directly relevant to VOTRAN's bus operator's needs, the safety training manager does a preliminary assessment of all bus accidents occurring in the intervening period from the last training course. This enables identification of any accident trends, e.g. rear end or sideswipe, which allows the safety training program manager to concentrate on these types of accidents and minimize the potential of bus operators being involved in these types of accidents in the future. Accident trends that cause concern to the safety training manager are targeted objectives of the training program to correct the problem.

VOTRAN has in place a rolling-program of safety training. It is the requirement of every bus operator that has been involved in an accident to retake the defensive driving course that was initially given at the start of their hire at VOTRAN. Overall, the bus safety programs have paid dividends, as VOTRAN is highly ranked in Florida State rankings for the lowest number of bus accidents (taking into account property and fleet size).

\subsection{Accident Database}

All accidents involving any VOTRAN bus is recorded by VOTRAN, even when a third party may have been involved. Through such data collection, basic accident statistics are captured on a regular basis, which are subsequently used as management information. In-depth statistical analysis of the data is not performed (partly due to the low number of accidents).

\subsection{Accident Analysis and Period of Analysis}

Accident data used in this study was captured at the VOTRAN offices in South Daytona. VOTRAN staff collected and prepared the records while CUTR staff captured the data in MS Excel format. Any questions seeking clarification of records input were answered by VOTRAN staff either on site or by 
telephone. This analysis was done entirely in MS Excel, due to the small number of accident record. The total analysis time frame was from July 2001 to June 2003 (24 months).

\subsection{General Occurrence Characteristics}

A total of 124 accidents occurred during the 24 month period from July 2001 through June 2003 as shown in Table 4.1 and Figure 4.2. Column 2 of Table 4.1 presents the number of accidents per month. The percentage distribution of these accidents is determined by the monthly accidents divided by the total number of accidents in the study period. Average frequency (per year) is derived by the number of accidents divided by the number of years for which those accidents were submitted.

Table 4.1

Combined Frequency Distribution of Monthly Accidents

\begin{tabular}{|c|c|c|c|c|}
\hline Month & Number & \% Distribution & $\begin{array}{c}\text { Average } \\
\text { Frequency }\end{array}$ & Years of Data \\
\hline January & 7 & $5.6 \%$ & 3.5 & 2 \\
\hline February & 8 & $6.5 \%$ & 4.0 & 2 \\
\hline March & 20 & $16.1 \%$ & 10.0 & 2 \\
\hline April & 9 & $7.3 \%$ & 4.5 & 2 \\
\hline May & 8 & $6.5 \%$ & 4.0 & 2 \\
\hline June & 15 & $12.1 \%$ & 7.5 & 2 \\
\hline July & 10 & $8.1 \%$ & 5.0 & 2 \\
\hline August & 7 & $5.6 \%$ & 3.5 & 2 \\
\hline September & 5 & $4.0 \%$ & 2.5 & 2 \\
\hline October & 9 & $7.3 \%$ & 4.5 & 2 \\
\hline November & 15 & $12.1 \%$ & 7.5 & 2.5 \\
\hline December & 11 & $8.9 \%$ & & \\
\hline Total & $\mathbf{1 2 4}$ & $\mathbf{1 0 0 . 0 \%}$ & & 2 \\
\hline
\end{tabular}

The month of March experienced the highest number of accidents (based on average frequency), followed by June and November. 
Figure 4.2

\section{Combined Frequency Distribution of Monthly Accidents}

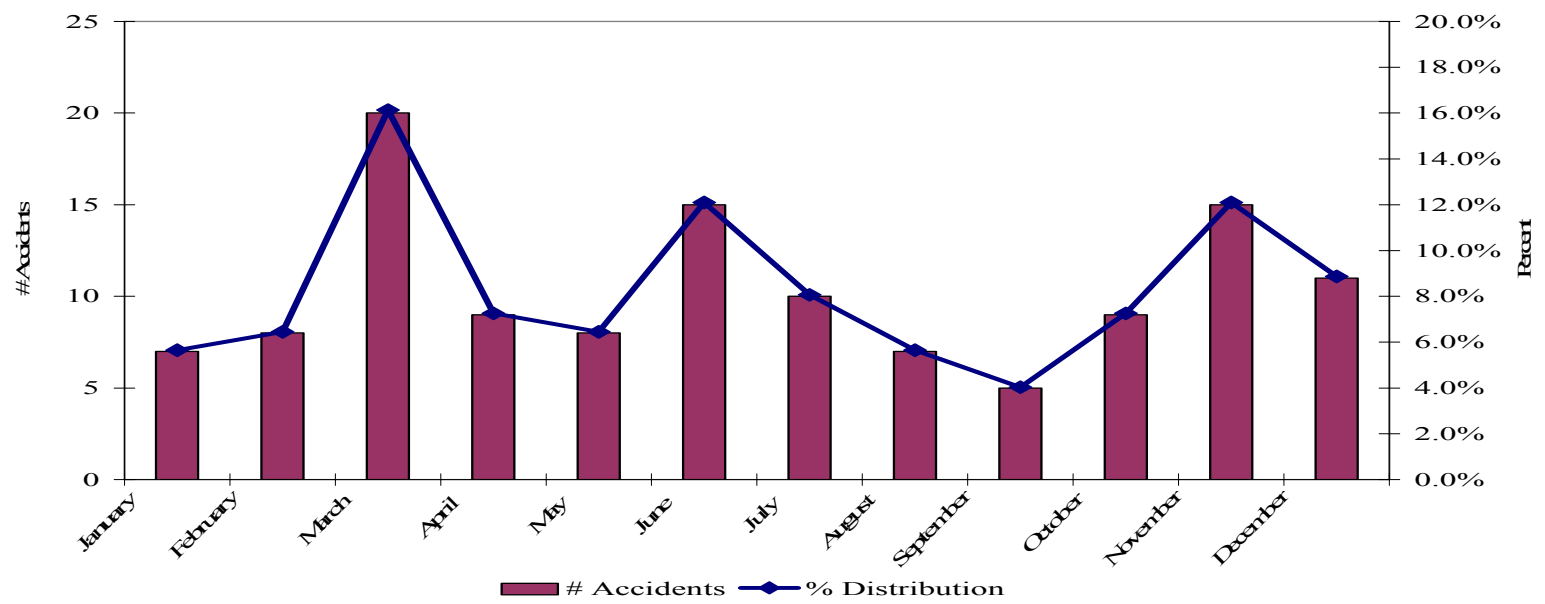

\subsubsection{Crash Occurrence by Day of Week}

Crash occurrence data by day of week is presented in Table 4.2 and in Figure 4.3. Table 4.2 also presents data as to the accident frequency by day of week. Overall, Wednesday and Friday were the days with the highest numbers of accidents (24 each). The reduced Sunday bus operation may account for the significantly lower numbers of accidents occurring on this day.

Table 4.2

Combined Frequency Distribution of Day of Week Accidents

\begin{tabular}{|c|c|c|c|c|}
\hline Month & Frequency & \% Distribution & Average Frequency & \# Years \\
\hline Sunday & 6 & $4.8 \%$ & 3.0 & 2.0 \\
\hline Monday & 22 & $17.7 \%$ & 7.3 & 3.0 \\
\hline Tuesday & 14 & $11.3 \%$ & 7.0 & 2.0 \\
\hline Wednesday & 24 & $19.4 \%$ & 12.0 & 2.0 \\
\hline Thursday & 14 & $11.3 \%$ & 7.0 & 2.0 \\
\hline Friday & 24 & $19.4 \%$ & 12.0 & 2.0 \\
\hline Saturday & 20 & $16.1 \%$ & 10.0 & 2.0 \\
\hline Total & $\mathbf{1 2 4}$ & $\mathbf{1 0 0 . 0 \%}$ & $\mathbf{4 1 . 3}$ & $\mathbf{3 . 0}$ \\
\hline
\end{tabular}


Figure 4.3

\section{Combined Frequency Distribution of Day of Week Accidents}

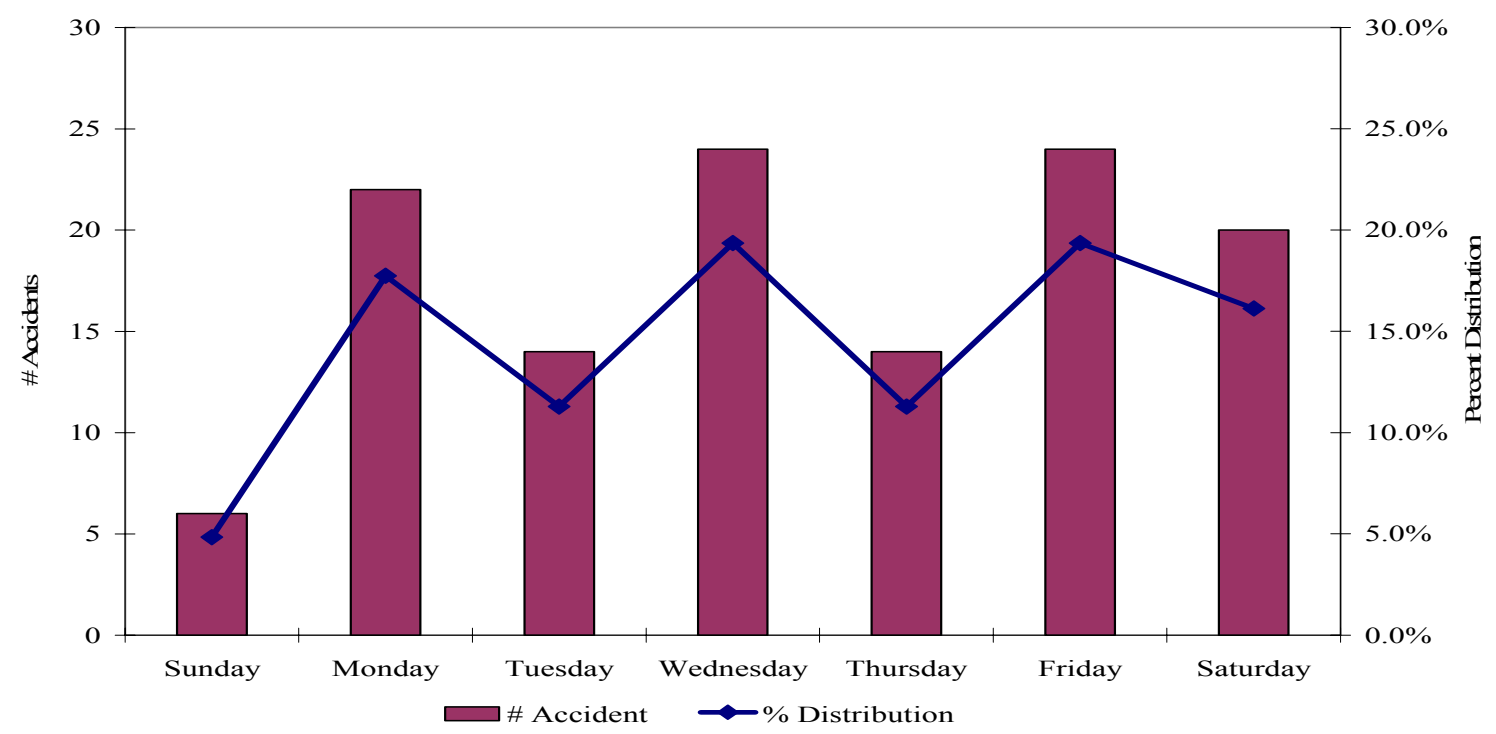

\subsubsection{Accident Occurrence by Time of Day}

Table 4.3 and Figure 4.4, presents the accident occurrence by time of day. The time periods with the highest number of accidents are during lunch hour and the late afternoon time periods from 11:00 a.m. 5:00 p.m. This five hour period accounted for 74 accidents or 59 percent of the total number of crashes. The hour between 1:00 p.m. - 1:59 p.m. experienced the highest accident frequency overall with 14 accidents. Table 4.4 presents data by time by type of accident.

Table 4.3

Combined Frequency Distribution by Time of Day Accidents

\begin{tabular}{|l|c|c|l|c|c|}
\hline Time of Day & Frequency & $\begin{array}{c}\text { \% } \\
\text { Distribution }\end{array}$ & Time of Day & Frequency & $\begin{array}{c}\% \\
\text { Distribution }\end{array}$ \\
\hline 6:00 a.m. to 6:59a.m. & 2 & $1.61 \%$ & $4: 00$ p.m. to $4: 59$ p.m. & 10 & $8.06 \%$ \\
\hline 7:00 a.m. to 7:59a.m. & 9 & $7.26 \%$ & $5: 00$ p.m. to 5:59 p.m. & 6 & $4.84 \%$ \\
\hline 8:00 a.m. to 8:59a.m. & 5 & $4.03 \%$ & $6: 00$ p.m. to 6:59 p.m. & 4 & $3.23 \%$ \\
\hline 9:00a.m. to 9:59a.m & 6 & $4.84 \%$ & $7: 00$ p.m. to 7:59 p.m. & 4 & $3.23 \%$ \\
\hline 10:00 a.m. to 10:59 a.m. & 8 & $6.45 \%$ & $8: 00$ p.m. to 8:59 p.m. & 0 & $0.00 \%$ \\
\hline 11:00 a.m. to 11:59a.m. & 12 & $9.68 \%$ & $9: 00$ p.m. to 9:59 p.m. & 0 & $0.00 \%$ \\
\hline 12:00 p.m. to 12:59p.m. & 13 & $10.48 \%$ & $10: 00$ p.m. to $10: 59$ p.m. & 2 & $1.61 \%$ \\
\hline 1:00 p.m. to 1:59 p.m. & 14 & $11.29 \%$ & $11: 00$ p.m. to $11: 59$ p.m. & 1 & $0.81 \%$ \\
\hline 2:00 p.m. to 2:59 p.m. & 13 & $10.48 \%$ & $12: 00$ a.m. to 5:59 a.m. & 2 & $1.61 \%$ \\
\hline 3:00 p.m. to 3:59 p.m. & 12 & $9.68 \%$ & Missing & 1 & $0.81 \%$ \\
\hline
\end{tabular}


Figure 4.4

Combined Frequency Distribution by Time of Day Accidents

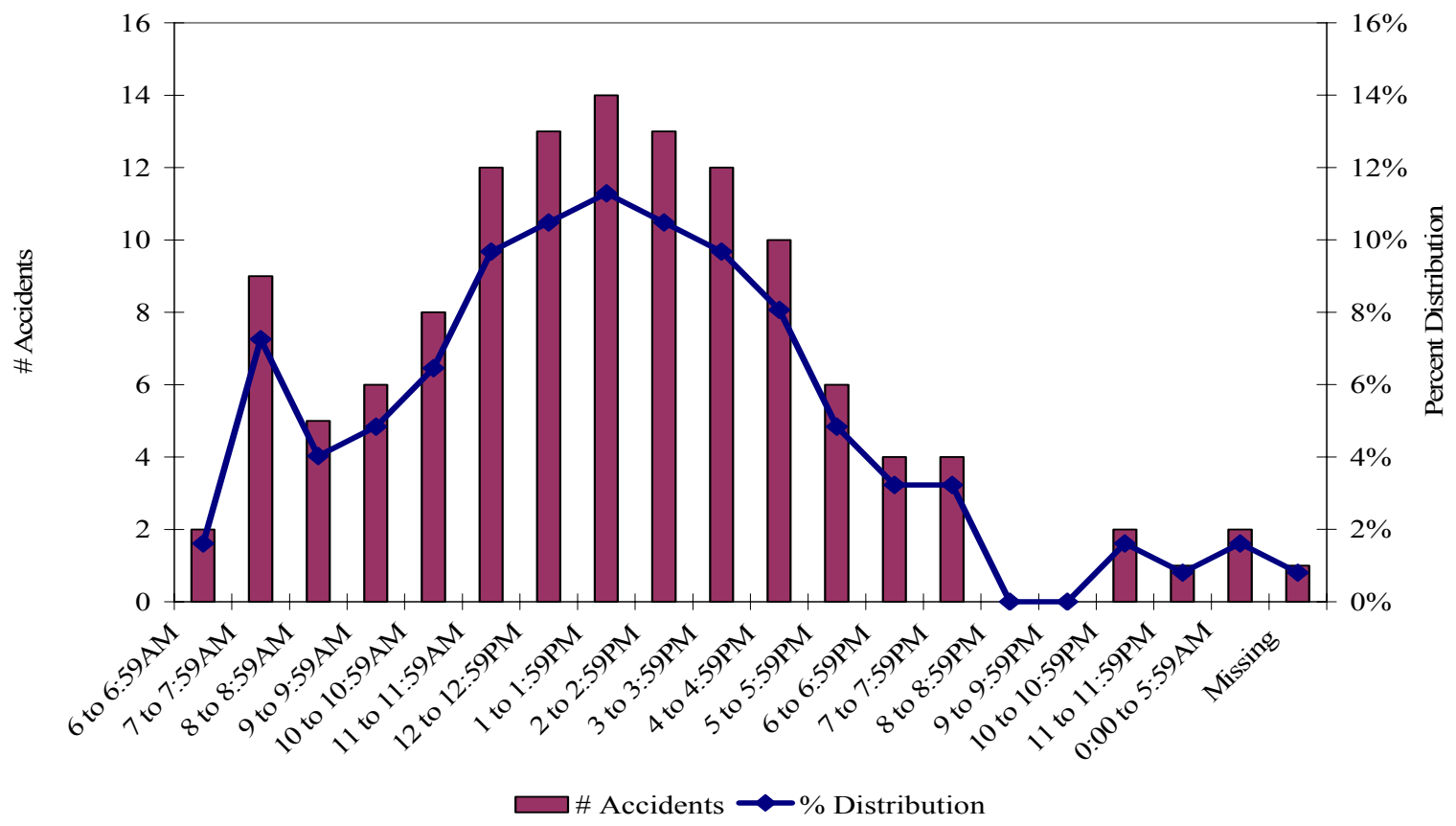

\subsubsection{Accident Occurrence by Type of Weather}

The frequency distribution for the weather conditions at the time of accident is presented in Table 4.4 and Figure 4.5. The majority ( 73 percent) of accidents occurred in clear weather.

Table 4.4

Accident Frequency Distribution by Type of Weather

\begin{tabular}{|l|c|c|}
\hline Weather & Frequency & \% Distribution \\
\hline Clear & 90 & $72.58 \%$ \\
\hline Rain & 20 & $16.13 \%$ \\
\hline Overcast & 14 & $11.29 \%$ \\
\hline Total & $\mathbf{1 2 4}$ & $\mathbf{1}$ \\
\hline
\end{tabular}


Figure 4.5

Accident Frequency Distribution by Type of Weather

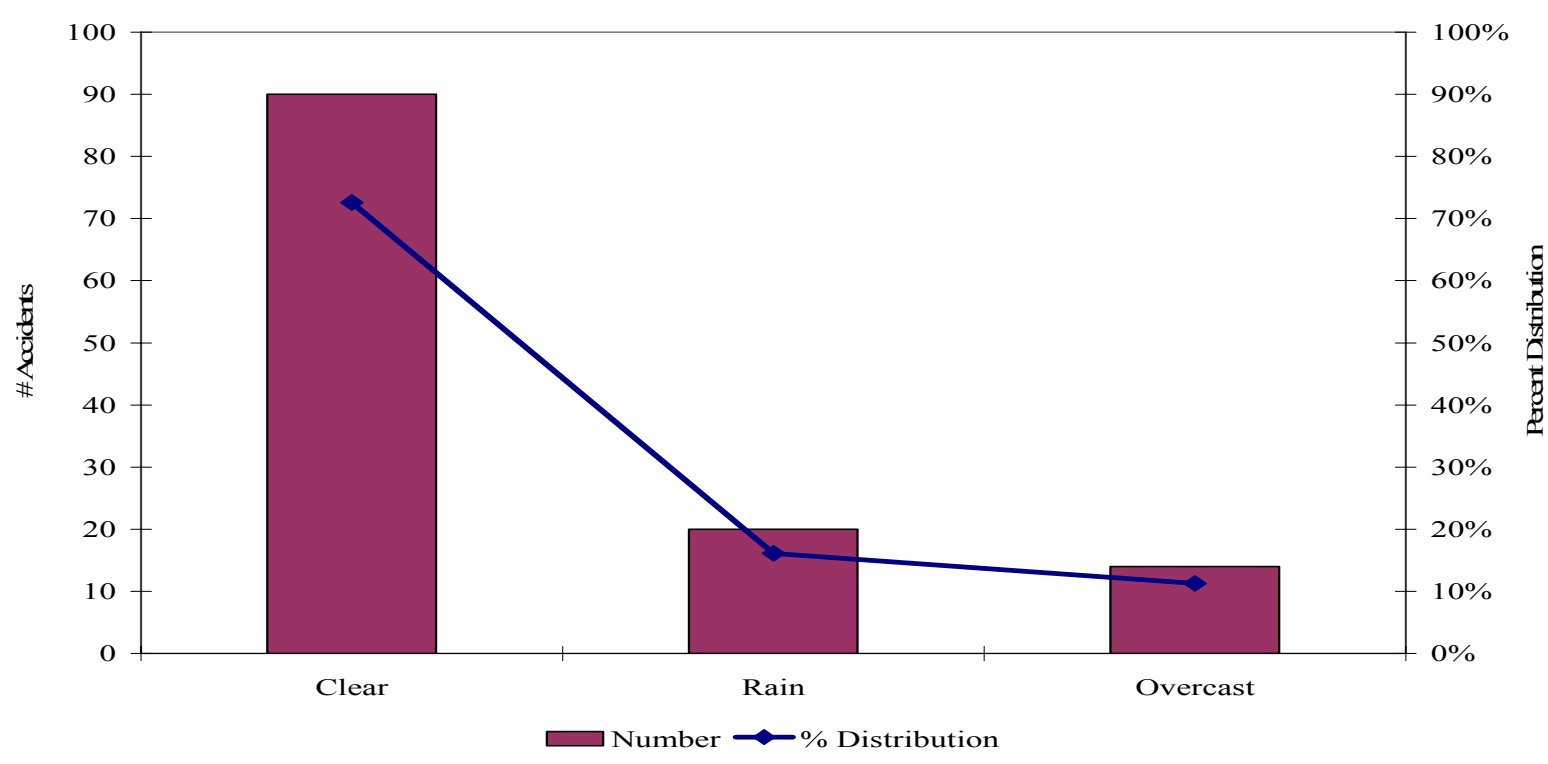

\subsubsection{Accident Occurrence by Road Condition}

The frequency distribution for the road conditions at the time of accident is presented in Table 4.6 and Figure 4.6. The majority ( 83 percent) of accidents occurred on dry road conditions.

Table 4.5

Accident Frequency Distribution by Road Condition

\begin{tabular}{|l|c|c|}
\hline Roadway Condition & Frequency & \% Distribution \\
\hline Dry & 104 & $83.87 \%$ \\
\hline Wet/Slippery & 0 & $16.13 \%$ \\
\hline Total & $\mathbf{1 2 4}$ & $\mathbf{1 0 0 . 0 \%}$ \\
\hline
\end{tabular}


Figure 4.6

Accident Frequency Distribution by Road Condition

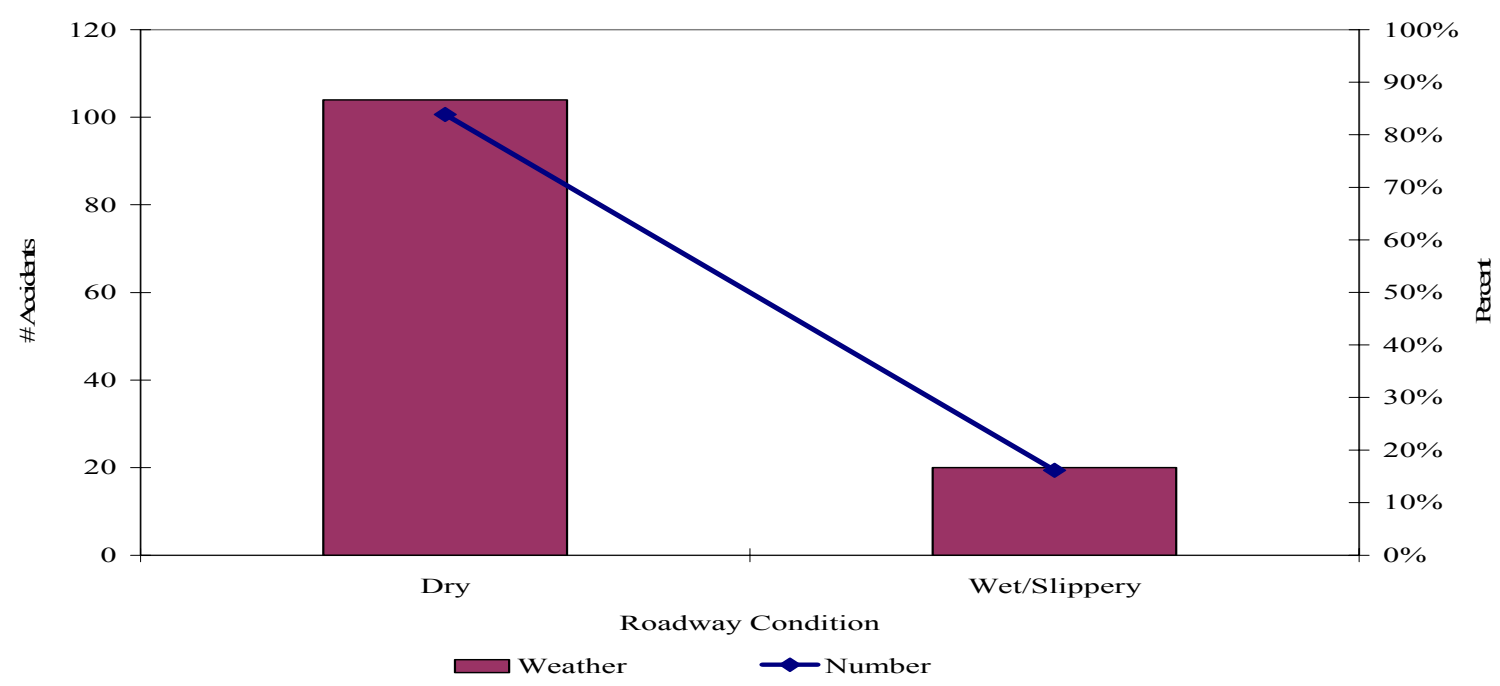

\subsubsection{Accident Occurrence by Route}

During the SCAT Fiscal Year ending 2002, VOTRAN operated a variety of routes with a fleet of 58 buses (NTD data). The number of routes operated does fluctuate on a month by month basis. Table 4.7 presents accident data by route.

Table 4.6

Accident Frequency Distribution by Route

\begin{tabular}{|c|c|c|c|c|c|c|c|}
\hline Route & Frequency & \% Distribution & Z-Statistic & Route & Frequency & \% Distribution & Z-Statistic \\
\hline $\mathbf{1 A}$ & 6 & $4.8 \%$ & 0.4429 & $\mathbf{1 7 A}$ & 2 & $1.6 \%$ & -0.8159 \\
\hline $\mathbf{1 B}$ & $\mathbf{1 1}$ & $\mathbf{8 . 9} \%$ & $\mathbf{2 . 0 1 6 5}$ & $\mathbf{1 7 B}$ & 3 & $2.4 \%$ & -0.5012 \\
\hline $\mathbf{3}$ & 9 & $7.3 \%$ & 1.3870 & $\mathbf{2 0}$ & 6 & $4.8 \%$ & 0.4429 \\
\hline $\mathbf{4}$ & $\mathbf{1 1}$ & $\mathbf{8 . 9} \%$ & $\mathbf{2 . 0 1 6 5}$ & $\mathbf{2 2}$ & 2 & $1.6 \%$ & -0.8159 \\
\hline $\mathbf{5}$ & 7 & $5.6 \%$ & 0.7576 & $\mathbf{4 0}$ & 2 & $1.6 \%$ & -0.8159 \\
\hline $\mathbf{6}$ & 8 & $6.5 \%$ & 1.0723 & $\mathbf{4 1}$ & 1 & $0.8 \%$ & -1.1306 \\
\hline $\mathbf{7}$ & 4 & $3.2 \%$ & -0.1865 & $\mathbf{4 2}$ & 1 & $0.8 \%$ & -1.1306 \\
\hline $\mathbf{8}$ & 3 & $2.4 \%$ & -0.5012 & $\mathbf{4 3}$ & 1 & $0.8 \%$ & -1.1306 \\
\hline $\mathbf{9}$ & 3 & $2.4 \%$ & -0.5012 & $\mathbf{6 0}$ & 4 & $3.2 \%$ & -0.1865 \\
\hline $\mathbf{1 0}$ & 6 & $4.8 \%$ & 0.4429 & Tram/Trolley & 4 & $3.2 \%$ & -0.1865 \\
\hline $\mathbf{1 1}$ & 4 & $3.2 \%$ & -0.1865 & Garage/Maint & 2 & $1.6 \%$ & -0.8159 \\
\hline $\mathbf{1 2}$ & 7 & $5.6 \%$ & 0.7576 & Other & 10 & $8.1 \%$ & 1.7018 \\
\hline $\mathbf{1 5}$ & 5 & $4.0 \%$ & 0.1282 & Missing & 0 & $0.0 \%$ & -1.4453 \\
\hline $\mathbf{1 7}$ & 2 & $1.6 \%$ & -0.8159 & Total & $\mathbf{1 2 4}$ & & \\
\hline
\end{tabular}


The routes which experienced the highest number of accidents were Route 1B and Route 4 (11 accidents each), followed by Route 3 with 9 accidents. These 3 routes accounted for a quarter of all the accidents in the study period. Table 4.7 also presents the Z-statistic for each route. A Z-statistic greater than 1.40 can be used to identify routes that are more prone to crash occurrence relative to the other routes in the system. This information can assist in identifying potential problem routes within the system. Figure 4.7 presents accident frequency by route.

Figure 4.7

\section{Accident Frequency Distribution by Route}

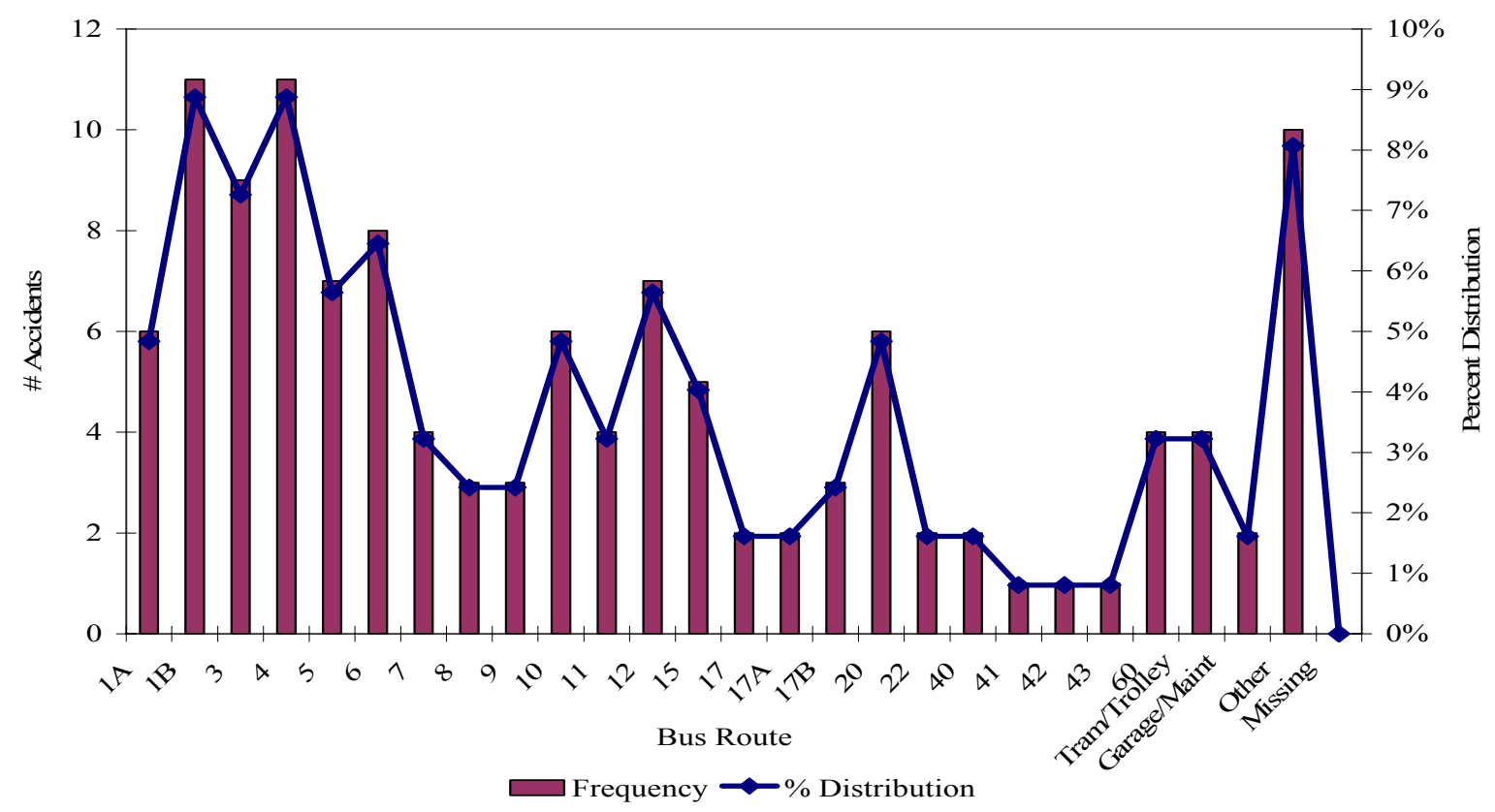

\subsubsection{Accident Occurrence by Type of Involvement}

The frequency distribution for accident occurrence by type of involvement is presented in Table 4.7. The data clearly show that the majority (68 percent) of accidents occurred with other motor vehicles. This was followed by accidents with fixed objects, (e.g. tree) at 25 percent. Accidents involving parked, other VOTRAN buses, and miscellaneous objects represented 6.5 percent of the total.

Table 4.7

Accident Occurrence by Type of Involvement

\begin{tabular}{|l|c|c|}
\hline Type of Involvement & Frequency & Percent Distribution \\
\hline Motor Vehicle & 85 & $68.5 \%$ \\
\hline Fixed Object & 31 & $25.0 \%$ \\
\hline Pedestrian & 0 & $0.0 \%$ \\
\hline Another VOTRAN Bus & 3 & $2.4 \%$ \\
\hline Parked vehicle & 4 & $3.2 \%$ \\
\hline Miscellaneous & 1 & $0.8 \%$ \\
\hline Total & $\mathbf{1 2 4}$ & $\mathbf{1 0 0 . 0} \%$ \\
\hline
\end{tabular}


Of the three accidents involving another VOTRAN bus, all three involved a parked bus. Other studies have shown that accidents involving vehicles from the same transit agency tend to occur on the property of the transit agency (e.g. maintenance facilities, etc.). In these cases, individuals other than regular operators operate the buses. The movement of buses within the confined spaces of maintenance facilities and by individuals other than the regular operators may increase the accident potential of buses according to this scenario.

Table 4.8

Time Day by Type of Accident

\begin{tabular}{|c|c|c|c|c|c|}
\hline Time of Day & Rear End & Sideswipe & Angle & Other & Total \\
\hline 6:00 a.m. to $6: 59$ a.m. & 0 & 1 & 0 & 1 & 2 \\
\hline 7:00 a.m. to 7:59a.m. & 3 & 1 & 5 & 0 & 9 \\
\hline 8:00 a.m. to $8: 59$ a.m. & 1 & 3 & 0 & 1 & 5 \\
\hline 9:00a.m. to 9:59a.m & 3 & 2 & 0 & 1 & 6 \\
\hline $10: 00$ a.m. to $10: 59$ a.m. & 1 & 4 & 3 & 0 & 8 \\
\hline 11:00 a.m. to $11: 59 \mathrm{a} . \mathrm{m}$. & 2 & 5 & 5 & 0 & 12 \\
\hline $12: 00$ p.m. to $12: 59$ p.m. & 2 & 5 & 5 & 1 & 13 \\
\hline 1:00 p.m. to 1:59 p.m. & 1 & 9 & 4 & 0 & 14 \\
\hline 2:00 p.m. to 2:59 p.m. & 1 & 6 & 3 & 3 & 13 \\
\hline 3:00 p.m. to 3:59 p.m. & 4 & 3 & 3 & 2 & 12 \\
\hline $4: 00$ p.m. to $4: 59$ p.m. & 2 & 6 & 2 & 0 & 10 \\
\hline 5:00 p.m. to 5:59 p.m. & 1 & 2 & 3 & 0 & 6 \\
\hline 6:00 p.m. to 6:59 p.m. & 1 & 0 & 1 & 2 & 4 \\
\hline 7:00 p.m. to 7:59 p.m. & 1 & 0 & 1 & 2 & 4 \\
\hline 8:00 p.m. to 8:59 p.m. & 0 & 0 & 0 & 0 & 0 \\
\hline 9:00 p.m. to 9:59 p.m. & 0 & 0 & 0 & 0 & 0 \\
\hline 10:00 p.m. to $10: 59$ p.m. & 1 & 1 & 0 & 0 & 2 \\
\hline 11:00 p.m. to $11: 59$ p.m. & 0 & 0 & 0 & 1 & 1 \\
\hline 12:00 a.m. to 5:59 a.m. & 0 & 2 & 0 & 0 & 2 \\
\hline Unknown & 0 & 0 & 0 & 1 & 1 \\
\hline Total & 24 & 50 & 35 & 15 & 124 \\
\hline
\end{tabular}

A review of the time periods with the highest number of accidents, as presented in table 4.8, reveals that:

- 9 sideswipe accidents occurred during the time period 1:00 p.m. to 1:59 p.m. which represented $64 \%$ of all accidents occurring during this time period.

- 4 rear end type accidents occurred in the time period between 3:00 p.m. and 3:59 p.m. This type of accident represented one third of accidents in this time period.

- 5 angle type accidents occurred during the time period between 7:00 a.m. to 7:59 a.m. These 5 accidents represented 56 percent of all accidents in this time period. 


\subsubsection{Accident Occurrence by Impact Dynamics}

Table 4.9 presents the three routes with the highest level of accidents according to accident type percentage. The data in the Table 4.9 indicates that Routes 1B, 3 and 4 had more than 50 percent of accidents of the sideswipe type, with Route 4 representing three quarters of bus accidents of this type. Angle type accidents represented the second highest percentage of accident type on Route 1B (27 percent) and Route 3 ( 34 percent). Route 4 had the highest percentage of rear end accidents. Routes $1 \mathrm{~B}$ and 4 experienced all three accident types according to categories in Table 4.9.

Table 4.9

Accident Occurrence by Impact Dynamics

\begin{tabular}{|l|c|c|c|c|}
\hline Route & \% Rear End & \% Sideswipe & \% Angle & \% Other \\
\hline $1 \mathrm{~B}$ & 9 & 55 & 27 & 9 \\
\hline 3 & - & 66 & 34 & - \\
\hline 4 & 18 & 73 & 9 & \\
\hline
\end{tabular}

\subsubsection{Accident Occurrence Identified by Preventability Status}

The frequency distribution for preventability status is presented in Table 4.10.Two categories were recorded by VOTRAN: preventable and non-preventable. The majority (60 percent) of accidents were non preventable.

Table 4.10

Accident Occurrence Identified by Preventability Status

\begin{tabular}{|l|c|c|}
\hline Preventability Status & Frequency & Percent Distribution \\
\hline Preventable & 50 & 40 \\
\hline Non Preventable & 74 & 60 \\
\hline Total & $\mathbf{1 2 4}$ & $\mathbf{1 0 0}$ \\
\hline
\end{tabular}

Table 4.11 presents the same information by the four general accident categories. From Table 4.11 it is evident that for three accident types: sideswipe, angle and other, the accidents were preventable. In the case of rear end accidents, the majority of these were non preventable.

Table 4.11

Accident Occurrence Identified by Preventability Status and Accident Type

\begin{tabular}{|l|c|c|c|c|}
\hline Preventability Status & \% Rear End & \% Sideswipe & \% Angle & \% Other \\
\hline Preventable & 18 & 66 & 57 & 60 \\
\hline Non Preventable & 82 & 34 & 43 & 40 \\
\hline Total & $\mathbf{1 0 0}$ & $\mathbf{1 0 0}$ & $\mathbf{1 0 0}$ & $\mathbf{1 0 0}$ \\
\hline
\end{tabular}




\subsubsection{Crash Occurrence by Years of Operator Experience}

Accident data collected by VOTRAN also indicates the date of hire of the operator involved. From this information it is possible to calculate the years of experience the operator had at the time of the accident and then determine if length of driving operation has some bearing on accident potential. Table 4.12 presents frequency distributions of accidents with respect to length of service at the time of accident. The first two columns present the distribution of all collision occurrences by the operator experience categories. Columns 3 and 4 present data for preventable crashes only. The final column illustrates the distribution of VOTRAN operator by level of experience based on June 2003 data.

From Table 4.12, operators with less than one year of experience were responsible for 31 percent of the accidents in the study period, followed by operators with 6 to 7 years of experience (8 percent each). Operators with 3 years or less VOTRAN experience accounted for more than 40 percent of the accidents in the study period. Assessing preventable accidents only those with less than 1 year experience accounted for 42 percent of the accidents followed by operators with 1, 6 and 15 years (10 percent each). In this case, operators with 3 years or less accounted for 60 percent of the preventable accidents.

Table 4.12

Crash Occurrence by Years of Operator Experience

\begin{tabular}{|l|c|c|c|c|}
\hline $\begin{array}{l}\text { Years of Experience } \\
\text { at VOTRAN }\end{array}$ & Frequency (All) & $\begin{array}{c}\text { Valid \% } \\
\text { Distribution }\end{array}$ & $\begin{array}{c}\text { Frequency } \\
\text { (Preventable) }\end{array}$ & $\begin{array}{c}\text { Valid \% } \\
\text { Distribution }\end{array}$ \\
\hline$<1 \mathrm{yr}$ & 38 & $30.6 \%$ & 21 & $42.0 \%$ \\
\hline 1 & 6 & $4.8 \%$ & 4 & $10.0 \%$ \\
\hline 2 & 6 & $4.8 \%$ & 0 & $8.0 \%$ \\
\hline 3 & 3 & $2.4 \%$ & 0 & $0.0 \%$ \\
\hline 4 & 4 & $3.2 \%$ & 1 & $0.0 \%$ \\
\hline 5 & 5 & $4.0 \%$ & 2 & $2.0 \%$ \\
\hline 6 & 10 & $8.1 \%$ & 5 & $4.0 \%$ \\
\hline 7 & 10 & $8.1 \%$ & 1 & $10.0 \%$ \\
\hline 8 & 6 & $4.8 \%$ & 1 & $2.0 \%$ \\
\hline 9 & 2 & $1.6 \%$ & 0 & $2.0 \%$ \\
\hline 10 & 3 & $2.4 \%$ & 1 & $0.0 \%$ \\
\hline 11 & 3 & $2.4 \%$ & 0 & $2.0 \%$ \\
\hline 12 & 4 & $3.2 \%$ & 0 & $0.0 \%$ \\
\hline 13 & 2 & $1.6 \%$ & 1 & $0.0 \%$ \\
\hline 14 & 4 & $3.2 \%$ & 5 & $2.0 \%$ \\
\hline 15 & 6 & $4.8 \%$ & 3 & $10.0 \%$ \\
\hline 16 or more & 12 & $9.7 \%$ & 0 & $6.0 \%$ \\
\hline Missing & 0 & $0.0 \%$ & $50.0 \%$ \\
\hline Total & $\mathbf{1 2 4}$ & $\mathbf{1 0 0 . 0 \%}$ & $\mathbf{1 0 0 . 0 \%}$ \\
\hline
\end{tabular}




\subsection{Summary of General Occurrence Characteristics}

Based on a review of the frequency distributions as contained in the preceding sections, it was determined that a 'typical' accident for a VOTRAN bus operator during the study period:

- Occurred during the month March

- Occurred on Wednesday or Friday

- Occurred between 1:00 p.m. - 2 p.m.

- Occurred in clear weather

- Occurred along Route 1B or Route 4

- Involved another motor vehicle

- Was a sideswipe type of accident

- Was non preventable and

- Involved an operator with less than 1 year of experience

\subsection{Other Factors Influencing Accident Potential}

Discussions with VOTRAN officials revealed a number of factors which have impacted on the accident potential of VOTRAN bus operators. Factors such as new bus operators and operator fatigue have impacted negatively in ways similar to the other transit properties studied (see RTS section 2.8). 


\section{CHAPTER 5 LEE COUNTY REGIONAL TRANSIT SYSTEM}

Lee County is located in southwest Florida and is bordered by Charlotte County to the North, Hendry County to the East, Collier County to the South, and the Gulf of Mexico to the West. The county is approximately 805 square miles of land area. According to the U.S. Census population estimates for 2003, Lee County has an estimated population of 492,210 (the $10^{\text {th }}$ most populous county in Florida). The largest city in Lee County is Cape Coral, which in 2003 had an estimated population of 120,439. Fort Myers, being the second-largest city and the County Seat has an estimated 2003 population of 52,527 .

Lee County Transit, known locally (and referred to in this report) as "LeeTran" is operated under the authority of the Lee County Government and the Lee County Board of Commissioners. LeeTran primarily operates a fixed-route, fixed-schedule type bus service. According to 2002 National Transit Database, LeeTran operated 20 regular fixed bus routes covering over 427 miles in Lee County and carried over 2.35 million passengers.

LeeTran provides a "Park and Ride" service to and from area beaches via a connecting replica trolley service. LeeTran also sponsors an ADA Paratransit service for disabled citizens who are not able to utilize the fixed route system. The paratransit service is contracted to a private provider who coordinates trips with operators specializing in transportation services for the disabled. Public transit services are available Monday through Saturday, from 5:00 a.m. to 9:45 p.m., with limited corridor service to the beach areas on Sundays operating from 6:00 a.m. until 9:45 p.m., as well as service to Southwest International Airport (SWI). LeeTran transit ridership levels are shown in Figure 5.1.

\subsection{LeeTran Safety Programs}

All operators joining LeeTran must complete an initial training program, which provides operators with a basic understanding of safety and security procedures of bus operation. With respect to other safety programs (apart from the induction course at their hiring) safety retraining is conducted with all operators during the summer months every year.

\subsection{Accident Database}

LeeTran records all accidents which involve their buses, even when a third party may have been involved. All accident and incident reports are scanned into LeeTran's computer system after the report is completed. Other divisions in Lee County perform accident data analysis which includes bus accidents. Currently, LeeTran does not perform in-house data analysis in relation to accidents involving its buses. 
Figure 5.1

\section{Lee County LeeTran Ridership Trends}

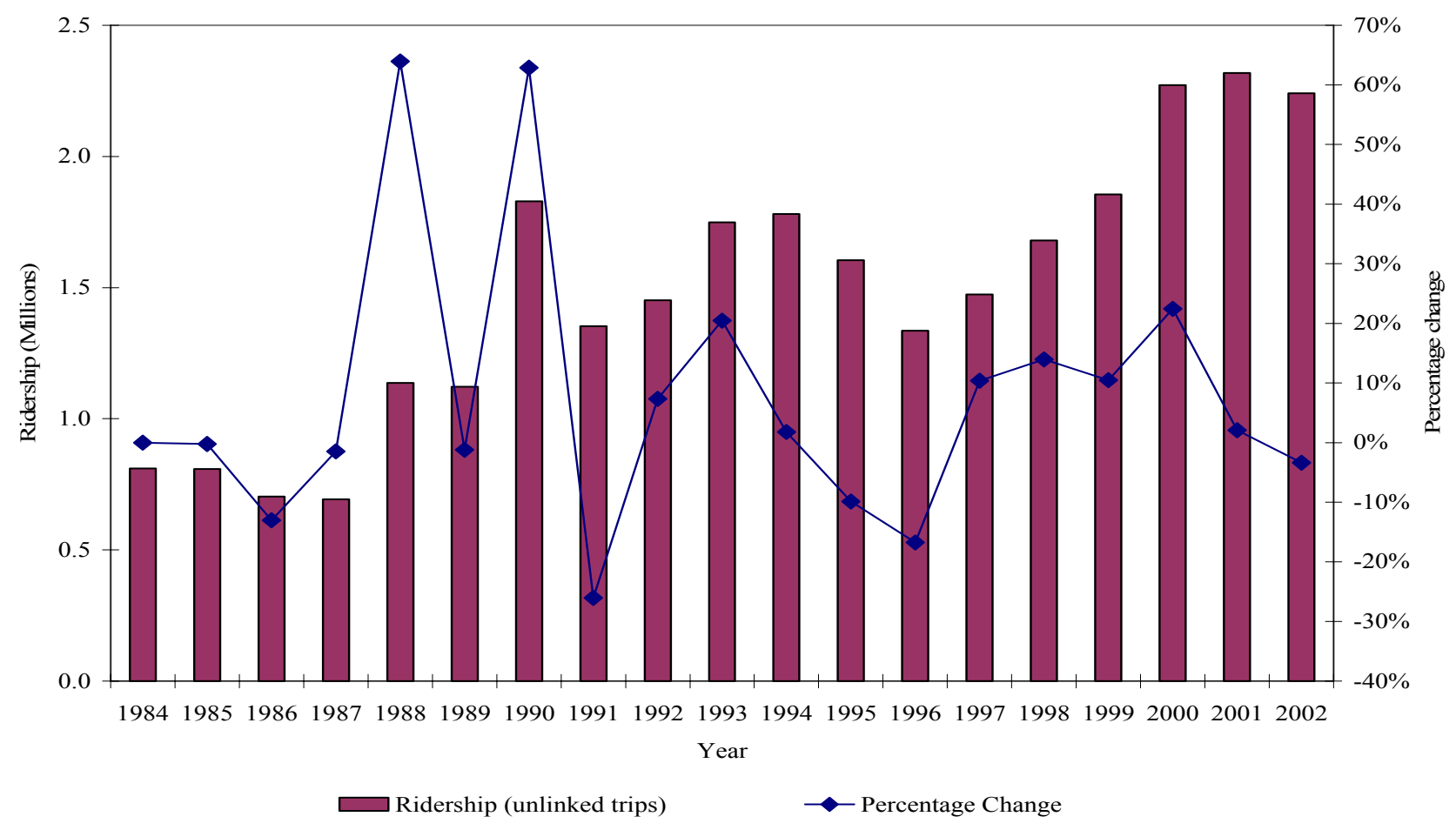

\subsection{Accident Analysis}

Accident data used in this study was submitted by LeeTran. LeeTran staff collected and prepared the records, while CUTR staff captured the data in MS Excel format. Any questions seeking clarification of records input were answered by LeeTran staff. Due to the small number of accident records, the analysis was conducted entirely in MS Excel.

\subsection{Analysis Period}

The analysis reported here covers a period of 24 months from October 2001 to September 2003. It should be noted that the fiscal year for LeeTran starts in October and ends in September the following year.

\subsection{General Occurrence Characteristics}

A total of 99 accidents occurred during the 24 month period of October 2001 through to September 2003, in Table 5.1 and Figure 5.2. Column 2 of Table 5.1 presents the number of accidents per month. The percentage distribution of these accidents is determined by the monthly accidents divided by the total number of accidents in the study period. Average frequency (per 
year) is derived by the number of accidents divided by the number of years for which those accidents were submitted.

Table 5.1

Combined Frequency Distribution of Monthly Accidents

\begin{tabular}{|c|c|c|c|c|}
\hline Month & Number & \% Distribution & Average Frequency & Years of Data \\
\hline January & 13 & $13.1 \%$ & 6.5 & 2 \\
\hline February & 16 & $16.2 \%$ & 8 & 2 \\
\hline March & 6 & $6.1 \%$ & 3 & 2 \\
\hline April & 8 & $8.1 \%$ & 4 & 2 \\
\hline May & 8 & $8.1 \%$ & 4 & 2 \\
\hline June & 8 & $8.1 \%$ & 4 & 2 \\
\hline July & 7 & $7.1 \%$ & 3.5 & 2 \\
\hline August & 7 & $7.1 \%$ & 3.5 & 2 \\
\hline September & 11 & $11.1 \%$ & 5.5 & 2 \\
\hline October & 7 & $7.1 \%$ & 3.5 & 2 \\
\hline November & 4 & $4.0 \%$ & 2 & 2 \\
\hline December & 4 & $4.0 \%$ & 2 & \\
\hline Total & $\mathbf{9 9}$ & $\mathbf{1 0 0 . 0 \%}$ & & \\
\hline
\end{tabular}

The months of February and January experienced the highest number of accidents (based on average frequency), followed by September, April, May and June. The months with the lowest average frequency of accidents are: November and December

Figure 5.2

\section{Combined Frequency Distribution of Monthly Accidents}

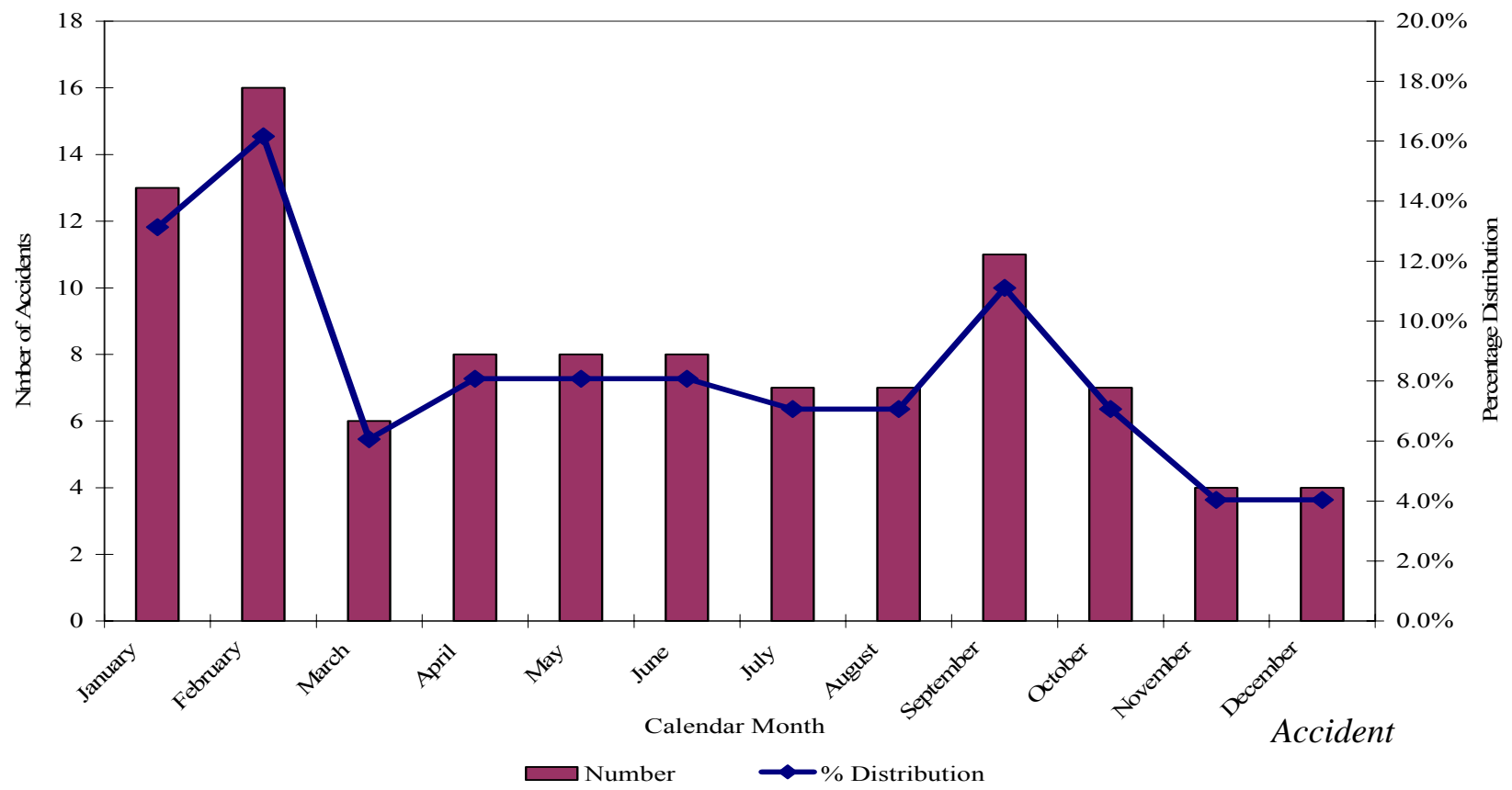




\subsubsection{Accident Occurrence by Day of Week}

Crash occurrence data by day of week is presented in Table 5.2 and in Figure 5.3. Table5.2 also shows accident frequency by day of week. Wednesdays had the highest number of accidents with 25 percent followed by Tuesdays with 18 percent. Reduced Sunday bus operation and less traffic may account for the significantly lower numbers of accidents occurring on this day.

Table 5.2

Crash Occurrence by Day of Week

\begin{tabular}{|c|c|c|}
\hline Month & Frequency & \% Distribution \\
\hline Sunday & 1 & $1.0 \%$ \\
\hline Monday & 13 & $13.1 \%$ \\
\hline Tuesday & 18 & $18.2 \%$ \\
\hline Wednesday & 25 & $25.3 \%$ \\
\hline Thursday & 13 & $16.2 \%$ \\
\hline Friday & 13 & $13.1 \%$ \\
\hline Saturday & 13 & $13.1 \%$ \\
\hline Total & $\mathbf{9 9}$ & $\mathbf{1 0 0 . 0 \%}$ \\
\hline
\end{tabular}

Figure 5.3

\section{Combined Frequency Distribution of Day of Week Accidents}

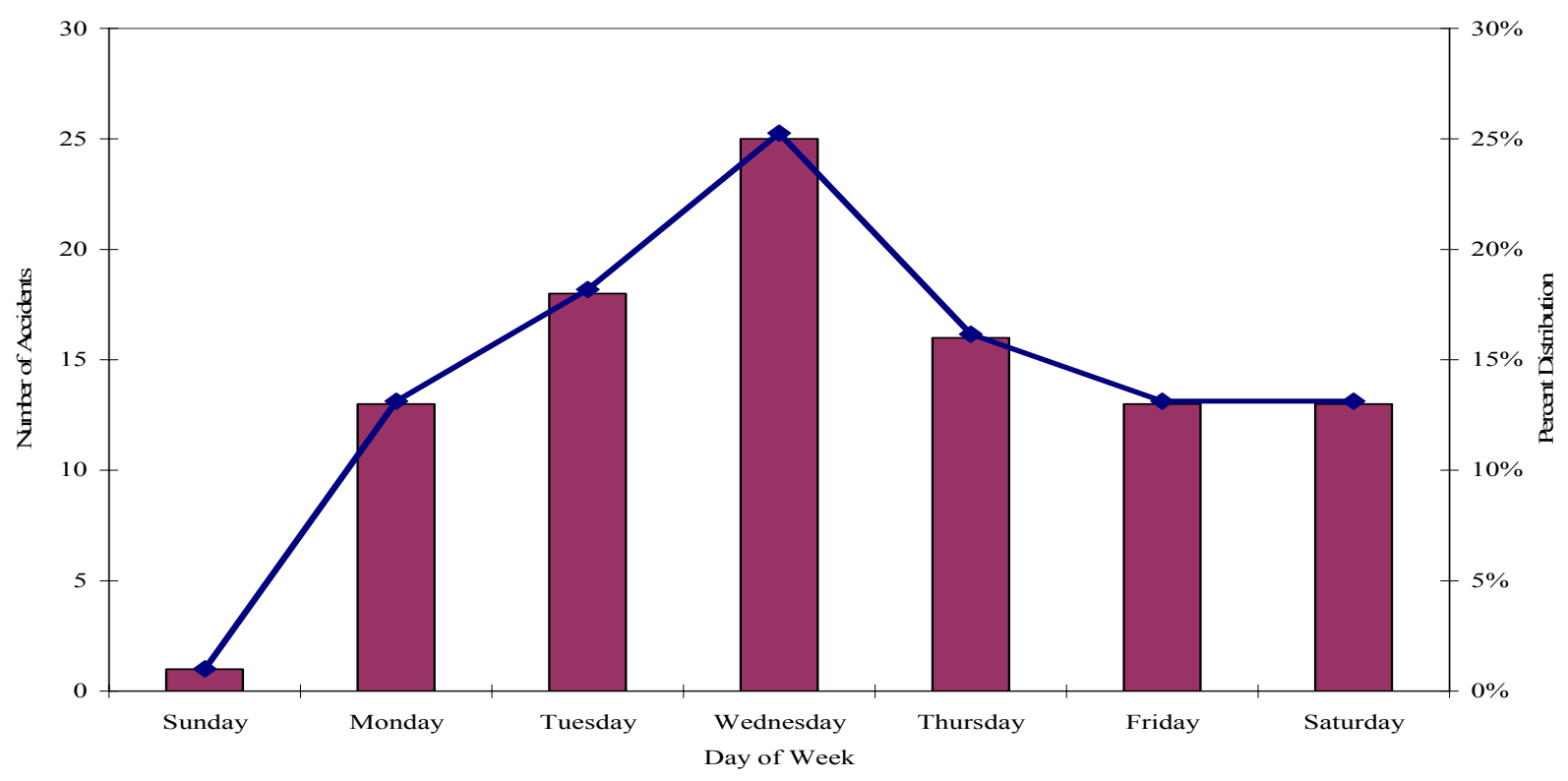

\subsubsection{Accident Occurrence by Time of Day}

Table 5.3 and Figure 5.4 indicate data on accident occurrence by time of day. The time period with the highest number of accidents (according to accident records where time was indicated) is 
between 2:00 p.m. - 2:59 p.m. This time segment marks LeeTran's PM peak ridership period as well as it being at the beginning of the PM traffic congestion period in Lee County. The second busiest period for accident occurrence is between 3:00 p.m. - 3:59 p.m. accidents occurring in this time period could be influenced by afternoon school traffic. The third highest period for bus accidents occurred during 10:00 p.m. - 10:59 p.m.

Table 5.3

Combined Frequency Distribution by Time of Day

\begin{tabular}{|l|c|c|l|c|c|}
\hline \multicolumn{1}{|c|}{ Time of Day } & Frequency & \% Distribution & Time of Day & $\begin{array}{c}\text { Frequency } \\
\text { Distribution }\end{array}$ \\
\hline 6:00 a.m. to 6:59a.m & 2 & $2.02 \%$ & $4: 00$ p.m. to $4: 59$ p.m. & 5 & $5.05 \%$ \\
\hline 7:00 a.m. to 7:59a.m. & 5 & $5.05 \%$ & $5: 00$ p.m. to 5:59 p.m. & 6 & $6.06 \%$ \\
\hline 8:00 a.m. to 8:59a.m & 5 & $5.05 \%$ & $6: 00$ p.m. to 6:59 p.m. & 5 & $5.05 \%$ \\
\hline 9:00am. to 9:59a.m. & 5 & $5.05 \%$ & $7: 00$ p.m. to 7:59 p.m. & 3 & $3.03 \%$ \\
\hline 10:00 a.m. to 10:59 a.m. & 8 & $8.08 \%$ & $8: 00$ p.m. to 8:59 p.m. & 2 & $2.02 \%$ \\
\hline 11:00 a.m. to 11:59a.m. & 5 & $5.05 \%$ & $9: 00$ p.m. to 9:59 p.m. & 3 & $3.03 \%$ \\
\hline 12:00 p.m. to 12:59 p.m. & 5 & $5.05 \%$ & $10: 00$ p.m. to $10: 59$ p.m. & & $0.00 \%$ \\
\hline 1:00 p.m. to 1:59 p.m. & 7 & $7.07 \%$ & $11: 00$ p.m. to $11: 59$ p.m. & & $0.00 \%$ \\
\hline 2:00 p.m. to 2:59 p.m. & 16 & $16.16 \%$ & $12: 00$ a.m. to 5:59a.m. & 1 & $1.01 \%$ \\
\hline 3:00 p.m. to 3:59 p.m. & 12 & $12.12 \%$ & Missing & 4 & $4.04 \%$ \\
\hline \multicolumn{2}{|c|}{ Total 99 } & & \\
\hline
\end{tabular}

Figure 5.4

\section{Combined Frequency Distribution by Time of Day}

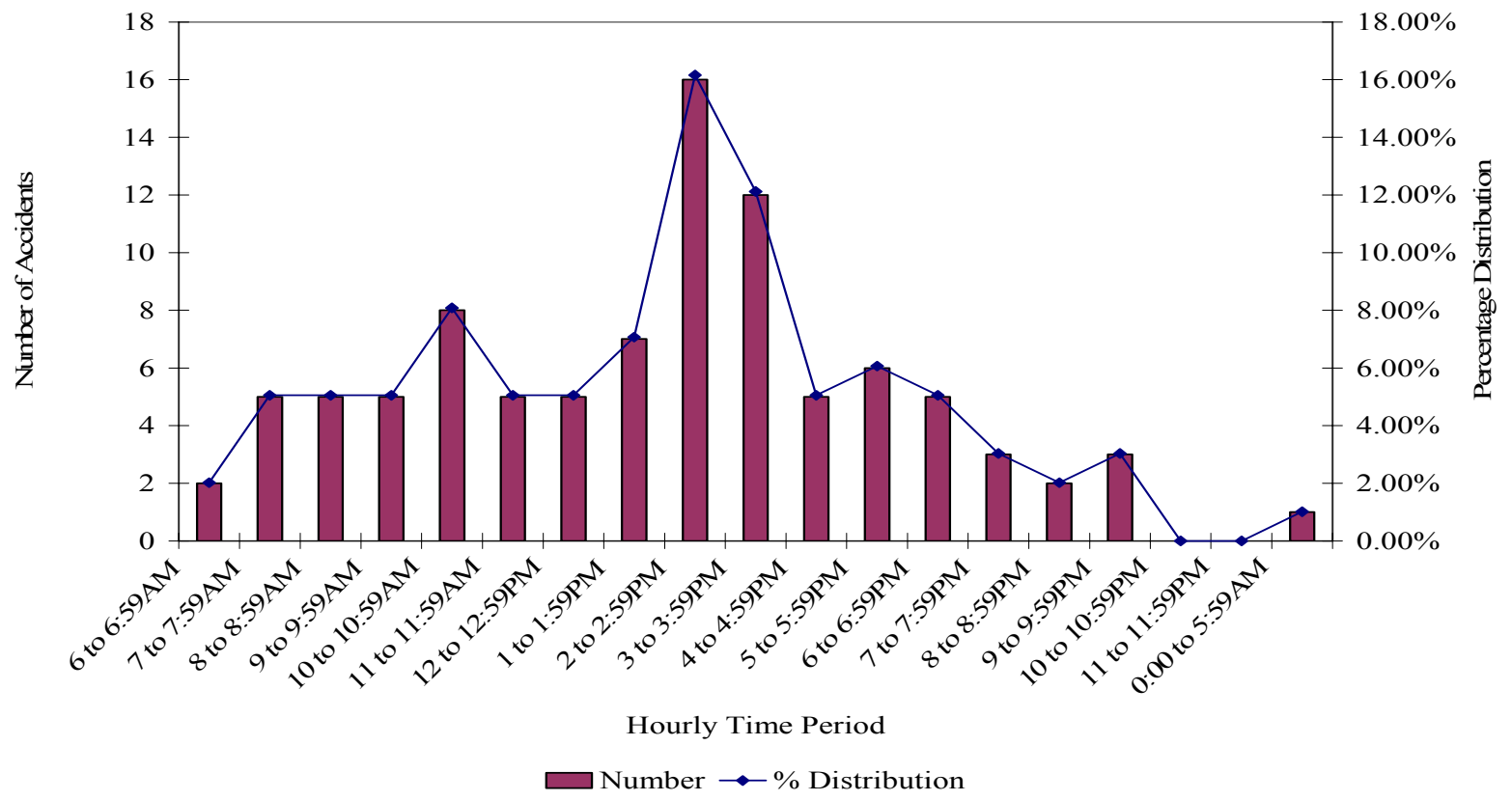

*Excludes missing records 


\subsubsection{Accident Occurrence by Type of Weather}

The frequency distribution for weather conditions at the time of accident is presented in Table 5.4 and Figure 5.5. LeeTran data only indicated two types of weather conditions, clear or rain. The majority of accident records did not indicate weather type at the time of accident. The 34 records where weather was given at the time of the accident, the majority ( 85 percent) of accidents occurred in clear/sunny weather.

Table 5.4

Combined Frequency Distribution by Type of Weather

\begin{tabular}{|l|c|c|c|}
\hline Weather & Frequency & $\begin{array}{c}\text { \% Distribution } \\
\text { (completed data) }\end{array}$ & $\begin{array}{c}\text { \% Distribution (all } \\
\text { data) }\end{array}$ \\
\hline Clear & 29 & $85.29 \%$ & $29.29 \%$ \\
\hline Rain & 5 & $14.71 \%$ & $5.05 \%$ \\
\hline Missing & 65 & $0.00 \%$ & $65.66 \%$ \\
\hline Total & $\mathbf{9 9}$ & $\mathbf{1}$ & $\mathbf{1}$ \\
\hline
\end{tabular}

Figure 5.5

Combined Frequency Distribution by Type of Weather

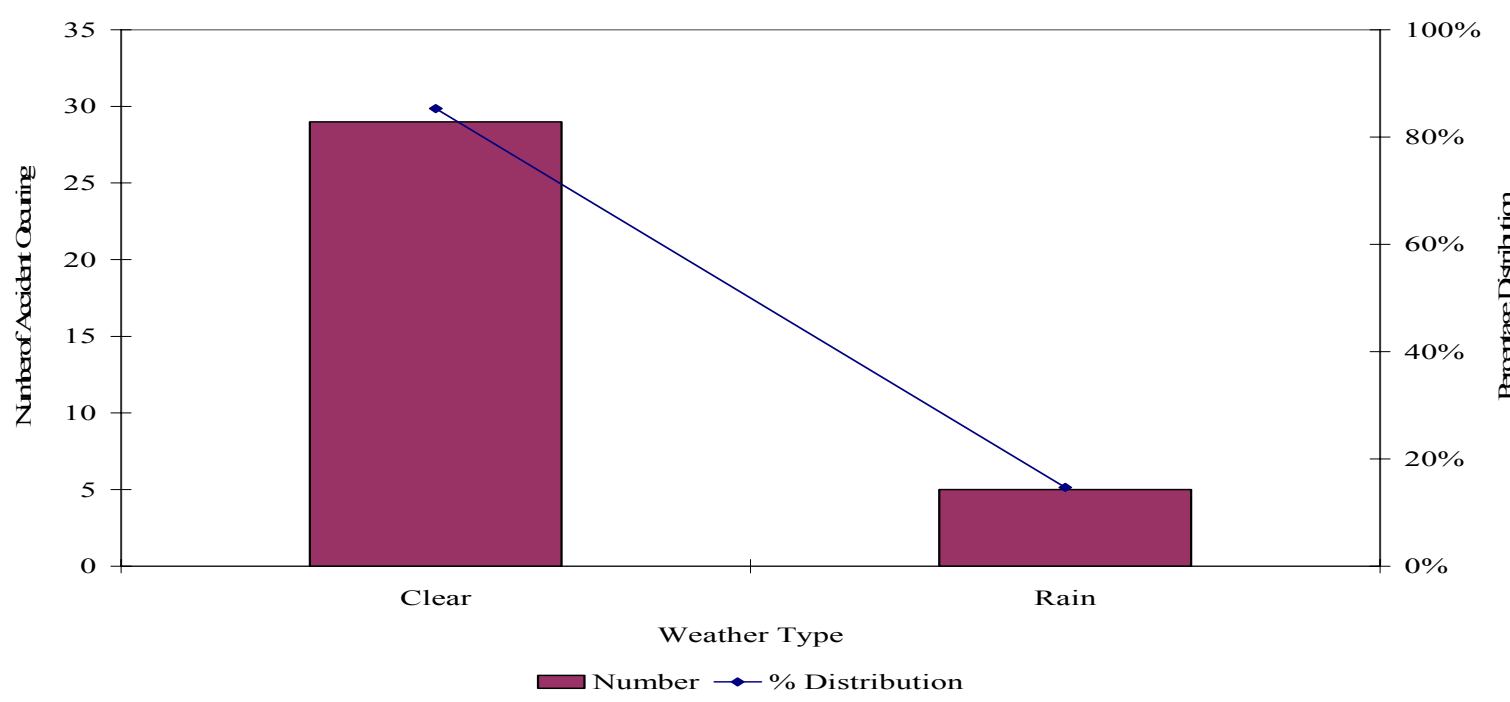

\subsubsection{Accident Occurrence by Route}

According to the 2002 National Transit Database (NTD) LeeTran operated a fleet of 70 buses. LeeTran increases the bus miles and hours of operation every year beginning in mid- to late December and going into or through the month of April. These extra miles and hours are primarily added to routes serving the beach communities to accommodate the winter visitors

Removing the accident records where the route numbers were missing, the route which experienced the highest number of accidents was Route 140 with 11 accidents, followed by Route 100 and Vans with 5 accidents each as shown in Table 5.5. These 3 routes accounted for a fifth 
of all accidents occurring in the study period. Table 5.5 also presents the Z-statistic for each route. A Z-statistic greater than 1.40 can be used to identify routes that are more prone to crash occurrence relative to the other routes in the system. This information can assist in identifying potential problem routes with the system.

Table 5.5

Accident Frequency Distribution by Route

\begin{tabular}{|c|c|c|c||c|c|c|c|}
\hline Route & Frequency & \% Distribution & Z-Statistic & Route & Frequency & \% Distribution & Z-Statistic \\
\hline $\mathbf{2 0}$ & 2 & $2.0 \%$ & -0.0788 & $\mathbf{3 2 1}$ & $\mathbf{2}$ & $2.0 \%$ & -0.0788 \\
\hline $\mathbf{3 0}$ & 2 & $2.0 \%$ & -0.0788 & $\mathbf{3 2 3}$ & 1 & $1.0 \%$ & -0.5964 \\
\hline $\mathbf{6 0}$ & 1 & $1.0 \%$ & -0.5964 & $\mathbf{3 2 5}$ & 2 & $2.0 \%$ & -0.0788 \\
\hline $\mathbf{7 0}$ & 4 & $4.0 \%$ & 0.9565 & $\mathbf{3 2 6}$ & 4 & $4.0 \%$ & 0.9565 \\
\hline $\mathbf{8 0}$ & 2 & $2.0 \%$ & -0.0788 & $\mathbf{3 2 8}$ & 1 & $1.0 \%$ & -0.5964 \\
\hline $\mathbf{9 0}$ & 1 & $1.0 \%$ & -0.5964 & $\mathbf{4 0 2}$ & 2 & $2.0 \%$ & -0.0788 \\
\hline $\mathbf{1 0 0}$ & 5 & $5.1 \%$ & 1.4742 & $\mathbf{4 0 3}$ & 3 & $3.0 \%$ & 0.4389 \\
\hline $\mathbf{1 1 0}$ & 1 & $1.0 \%$ & -0.5964 & $\mathbf{4 0 4}$ & 1 & $1.0 \%$ & -0.5964 \\
\hline $\mathbf{1 2 0}$ & 2 & $2.0 \%$ & -0.0788 & $\mathbf{4 0 5}$ & 1 & $1.0 \%$ & -0.5964 \\
\hline $\mathbf{1 4 0}$ & $\mathbf{1 1}$ & $\mathbf{1 1 . 1 \%}$ & 4.5801 & $\mathbf{4 1 0}$ & 3 & $3.0 \%$ & 0.4389 \\
\hline $\mathbf{3 0 1}$ & 2 & $2.0 \%$ & -0.0788 & $\mathbf{4 1 1}$ & 1 & $1.0 \%$ & -0.5964 \\
\hline $\mathbf{3 0 2}$ & 2 & $2.0 \%$ & -0.0788 & $\mathbf{4 1 2}$ & 1 & $1.0 \%$ & -0.5964 \\
\hline $\mathbf{3 0 4}$ & 1 & $1.0 \%$ & -0.5964 & $\mathbf{4 1 3}$ & 3 & $3.0 \%$ & 0.4389 \\
\hline $\mathbf{3 0 5}$ & 1 & $1.0 \%$ & -0.5964 & $\mathbf{4 1 4}$ & 1 & $1.0 \%$ & -0.5964 \\
\hline $\mathbf{3 0 6}$ & 1 & $1.0 \%$ & -0.5964 & $\mathbf{4 1 5}$ & 1 & $1.0 \%$ & -0.5964 \\
\hline $\mathbf{3 0 8}$ & 1 & $1.0 \%$ & -0.5964 & $\mathbf{4 1 6}$ & 1 & $1.0 \%$ & -0.5964 \\
\hline $\mathbf{3 1 1}$ & 2 & $2.0 \%$ & -0.0788 & $\mathbf{4 1 7}$ & 1 & $1.0 \%$ & -0.5964 \\
\hline $\mathbf{3 1 3}$ & 1 & $1.0 \%$ & -0.5964 & $\mathbf{9 0 9}$ & 1 & $1.0 \%$ & -0.5964 \\
\hline $\mathbf{3 1 4}$ & 3 & $3.0 \%$ & 0.4389 & $\mathbf{9 1 3}$ & 2 & $2.0 \%$ & -0.0788 \\
\hline $\mathbf{3 1 5}$ & 1 & $1.0 \%$ & -0.5964 & $\mathbf{9 1 4}$ & 2 & $2.0 \%$ & -0.0788 \\
\hline $\mathbf{3 1 7}$ & 1 & $1.0 \%$ & -0.5964 & Van & 5 & $5.1 \%$ & $\mathbf{1 . 4 7 4 2}$ \\
\hline $\mathbf{3 1 8}$ & 2 & $2.0 \%$ & -0.0788 & Shuttle & 1 & $1.0 \%$ & -0.5964 \\
\hline $\mathbf{3 2 0}$ & 2 & $2.0 \%$ & -0.0788 & $\mathbf{M i s s i n g}$ & 8 & $8.1 \%$ & 3.0271 \\
\hline & & & & Total & $\mathbf{9 9}$ & $\mathbf{1 0 0 . 0 0 \%}$ & \\
\hline
\end{tabular}


Figure 5.6

Accident Frequency Distribution by Route

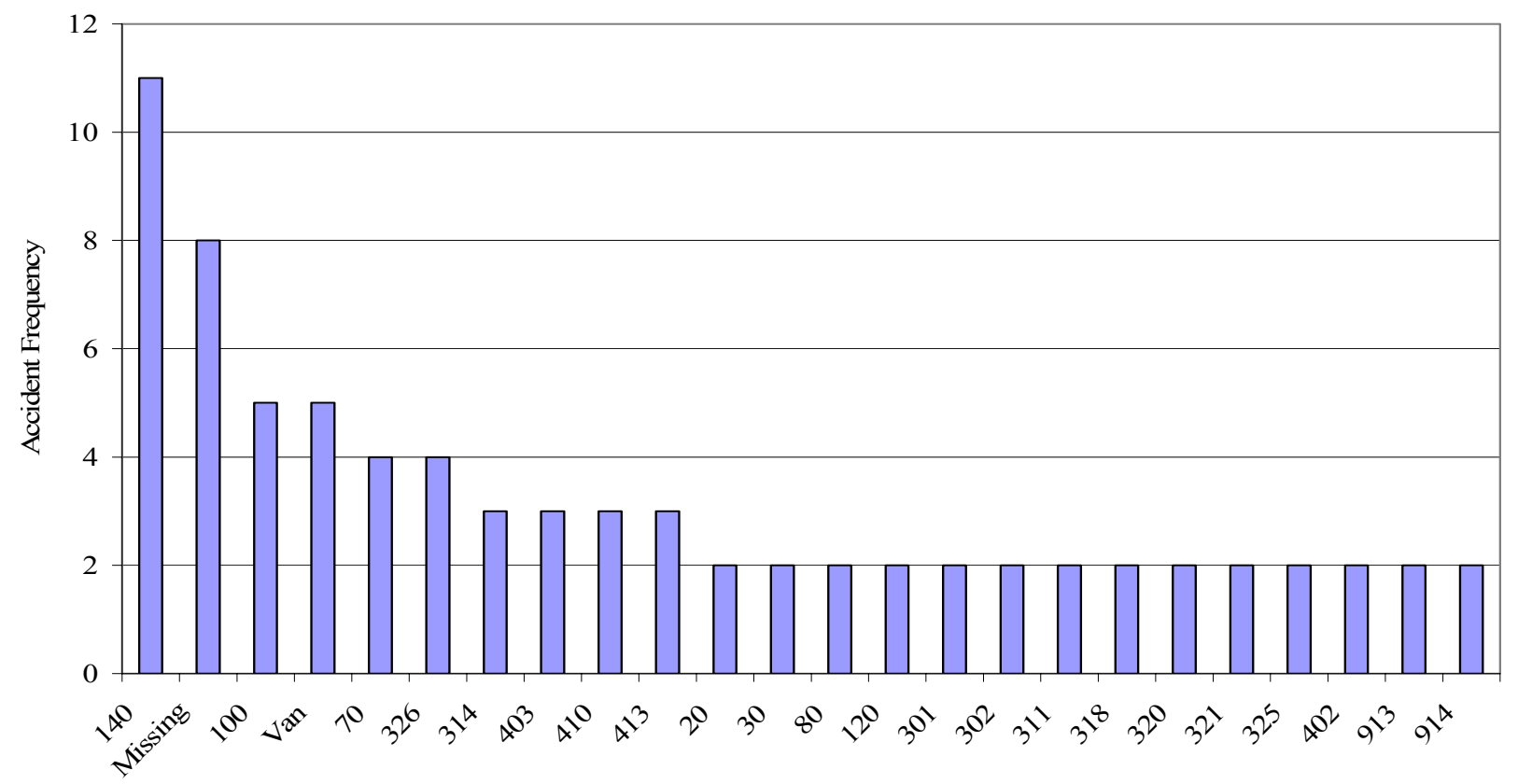

Route Number

Table 5.6 presents the three routes with the highest level of accidents according to their respective accident type percentage. From this analysis, it is apparent that for two of the routes, 140 and 100, 80 percent of accidents were either sideswipe or angle. In the case for Route 140, 45 percent were angle. Accident type was not recorded for any of the Van routes.

Table 5.6

Highest Level of Accidents by Type

\begin{tabular}{|l|c|c|c|c|}
\hline Route & \% Rear End & \% Sideswipe & \% Angle & Unknown \\
\hline 140 & 9 & 37 & 45 & 9 \\
\hline 100 & 20 & 40 & 40 & - \\
\hline Van & - & - & - & 100 \\
\hline
\end{tabular}

\subsubsection{Accident Occurrence by Impact Dynamics}

Table 5.7 presents LeeTran bus impact dynamics by time period. Taking the four categories of accidents, rear end accounted for 29 percent of accidents, sideswipe 34 percent, angle 34 percent and other 3 percent. Our analysis indicates that there was an even split between sideswipe and angle type of accidents. These two categories also had the highest number accidents 
Table 5.7

Accident according to Time of Day and Type

\begin{tabular}{|c|c|c|c|c|c|}
\hline Time of Day & Rear End & Sideswipe & Angle & Other & Total \\
\hline 6:00 a.m. to $6: 59$ a.m & & 1 & & & 1 \\
\hline 7:00 a.m. to 7:59a.m. & & & 2 & & 2 \\
\hline 8:00 a.m. to $8: 59$ a.m & 2 & & & & 2 \\
\hline 9:00am. to 9:59a.m. & 1 & 2 & 1 & & 4 \\
\hline $10: 00$ a.m. to $10: 59$ a.m. & 1 & 1 & 1 & & 3 \\
\hline 11:00 a.m. to $11: 59$ a.m. & & 2 & 2 & & 4 \\
\hline $12: 00$ p.m. to $12: 59$ p.m. & & 1 & 1 & 1 & 3 \\
\hline 1:00 p.m. to 1:59 p.m. & 3 & 1 & 2 & & 6 \\
\hline 2:00 p.m. to $2: 59$ p.m. & 3 & 1 & 1 & & 5 \\
\hline 3:00 p.m. to 3:59 p.m. & 1 & 1 & & & 2 \\
\hline 4:00 p.m. to 4:59 p.m. & & 2 & & & 2 \\
\hline 5:00 p.m. to 5:59 p.m. & & & 2 & & 2 \\
\hline 6:00 p.m. to $6: 59$ p.m. & & & & & 0 \\
\hline 7:00 p.m. to $7: 59$ p.m. & & & & & 0 \\
\hline 8:00 p.m. to $8: 59$ p.m. & & & & & 0 \\
\hline 9:00 p.m. to 9:59 p.m. & & & 1 & & 1 \\
\hline 10:00 p.m. to $10: 59$ p.m. & & & & & 0 \\
\hline 11:00 p.m. to $11: 59$ p.m. & & & & & 0 \\
\hline 12:00a.m. to 5:59a.m. & & 1 & & & 1 \\
\hline Total & 11 & 13 & 13 & 1 & 38 \\
\hline Unknown & & & & $2+59$ & \\
\hline
\end{tabular}

A cursory investigation of the time periods with the highest number of accidents according to type reveals (excluding the unknowns), that:

- Rear end (3 accidents) occurred during the time periods of 2:00p.m.-2.59 p.m. and 3:00p.m- 3.59 p.m., which were the time periods with the 1 st and 2 nd highest number of accidents overall (see Table 5.3).

- Sideswipe accidents occurred in the time periods, 10:00 a.m.-10:59 a.m. and 12:00 a.m. 12.59 a.m.

- Angle type accidents occurred in the time periods, 8:00 a.m. - 8:59 a.m. and 12:00 a.m.12.59 a.m.

\subsubsection{Accident Occurrence by Type of Involvement}

The frequency distribution for bus accident occurrence by type of involvement is presented in Table 5.8. The data clearly show that the majority ( 89 percent) of accidents occurred with other motor vehicles (assuming accident record fully completed, i.e. 38 records of the 99). This was 
followed by accidents involving fixed objects, (e.g. tree) at 10 percent. Accidents involving pedestrians amounted to zero.

Table 5.8

Frequency Distribution for Type of Involvement

\begin{tabular}{|l|c|c|c|c|c|c|}
\hline Type of Involvement & $\begin{array}{c}\text { Rear } \\
\text { End }\end{array}$ & Sideswipe & Angle & Other & $\begin{array}{c}\text { Total } \\
\text { Frequency }\end{array}$ & $\begin{array}{c}\text { Percent } \\
\text { Distribution }\end{array}$ \\
\hline Motor Vehicle & 12 & 9 & 13 & & 34 & $34.3 \%$ \\
\hline Fixed Object & & 4 & & & 4 & $4.0 \%$ \\
\hline Pedestrian & & & & & 0 & $0.0 \%$ \\
\hline Another LeeTran Bus & & & & & 0 & $0.0 \%$ \\
\hline Parked vehicle & & & & & 0 & $0.0 \%$ \\
\hline Miscellaneous/Unknown & & & & 61 & 61 & $61.6 \%$ \\
\hline Total & 12 & 13 & 13 & 61 & 99 & $\mathbf{1}$ \\
\hline
\end{tabular}

\subsubsection{Accident Occurrence Identified by Preventability Status}

The frequency distribution for preventability status is presented in Table 5.9. Only two categories of preventability were recorded by LeeTran: preventable and non-preventable.

Table 5.9

Accident Frequency and Distribution by Identified Preventability Status

\begin{tabular}{|l|c|c|}
\hline Preventability Status & Frequency & Percent Distribution \\
\hline Preventable & 32 & $32.3 \%$ \\
\hline Non Preventable & 65 & $65.7 \%$ \\
\hline Missing/Unknown & 2 & $2.0 \%$ \\
\hline Total & $\mathbf{9 9}$ & $\mathbf{1 0 0 \%}$ \\
\hline
\end{tabular}

The majority ( 66 percent) of accidents as indicated in Table 5.9 were non preventable. Table 5.10 presents the same information according to the four general accident categories. From Table 5.10 it is evident that the majority of rear end and angle type accidents were non preventable. In the case of sideswipe and other type of accidents, the opposite was true, i.e. the bus operator was at fault in the majority of cases in these two categories.

Table 5.10

Percentage of Accidents by Preventability Status by Accident Type

\begin{tabular}{|l|c|c|c|c|}
\hline Preventability Status & \% Rear End & \% Sideswipe & \% Angle & \% Other \\
\hline Preventable & $41.7 \%$ & $53.8 \%$ & $15.4 \%$ & $29.5 \%$ \\
\hline Non Preventable & $58.3 \%$ & $46.2 \%$ & $84.6 \%$ & $67.2 \%$ \\
\hline Other/Missing & $0.0 \%$ & $0.0 \%$ & $0.0 \%$ & $3.3 \%$ \\
\hline Total & $\mathbf{1 0 0 . 0} \%$ & $\mathbf{1 0 0 . 0} \%$ & $\mathbf{1 0 0 . 0} \%$ & $\mathbf{1 0 0 . 0 \%}$ \\
\hline
\end{tabular}




\subsubsection{Crash Occurrence by Years of Operator Experience}

Accident data collected by LeeTran also indicates the date of hire of the operator involved. From this information it is possible to calculate the years of experience the operator had at the time of the accident and then determine if length of driving operation has some bearing on accident potential. Table 5.11 presents frequency distributions of accidents with respect to length of service at the time of accident. The first two columns present the distribution of all collision occurrences by the operator experience categories. Columns 4 and 5 present data for preventable crashes only. The final column illustrates the distribution of LeeTran bus operators by length of time employed by LeeTran as at April 2003.

Table 5.11

Frequency Distribution of Crashes and Operators by Operator Experience

\begin{tabular}{|c|c|c|c|c|c|}
\hline $\begin{array}{l}\text { Years of } \\
\text { Experience at } \\
\text { LeeTran }\end{array}$ & $\begin{array}{l}\text { Frequency } \\
\text { (All) }\end{array}$ & $\begin{array}{c}\text { Valid \% } \\
\text { Distribution }\end{array}$ & $\begin{array}{c}\text { Frequency } \\
\text { (Preventable) }\end{array}$ & $\begin{array}{c}\text { Valid \% } \\
\text { Distribution }\end{array}$ & $\begin{array}{c}\text { Operator \% } \\
\text { Distribution } \\
\text { (2003) }\end{array}$ \\
\hline$<1 \mathrm{yr}$ & 5 & $5.1 \%$ & 3 & $9.4 \%$ & $13.2 \%$ \\
\hline 1 & 4 & $4.0 \%$ & 0 & & $6.6 \%$ \\
\hline 2 & 4 & $4.0 \%$ & 1 & $3.1 \%$ & $13.2 \%$ \\
\hline 3 & 3 & $3.0 \%$ & 3 & $9.4 \%$ & $8.5 \%$ \\
\hline 4 & 4 & $4.0 \%$ & 1 & $3.1 \%$ & $9.4 \%$ \\
\hline 5 & 7 & $7.1 \%$ & 1 & $3.1 \%$ & $11.3 \%$ \\
\hline 6 & & & 0 & & $16.0 \%$ \\
\hline 7 & & & 0 & & $0.9 \%$ \\
\hline 8 & 2 & $2.0 \%$ & 0 & & $2.8 \%$ \\
\hline 9 & 1 & $1.0 \%$ & 1 & $3.1 \%$ & $1.9 \%$ \\
\hline 10 & 2 & $2.0 \%$ & 1 & $3.1 \%$ & $3.8 \%$ \\
\hline 11 & & & & & $3.8 \%$ \\
\hline 12 & & & & & $0.9 \%$ \\
\hline 13 & & & & & $0.9 \%$ \\
\hline 14 & & & & & $0.9 \%$ \\
\hline 15 & & & & & $0.9 \%$ \\
\hline 16 or more & 3 & $3.0 \%$ & & & $4.7 \%$ \\
\hline Missing & 64 & $64.6 \%$ & 21 & $65.6 \%$ & \\
\hline Total & 99 & $100 \%$ & 32 & $100 \%$ & $100 \%$ \\
\hline
\end{tabular}

Due to the high number of accident records (64 percent) where the date of hire of the bus operator in question was omitted, an analysis of accidents based on length of service of the bus operator in question may not lead to any meaningful results. Nevertheless, based on the information that is available the following can be inferred. From Table 5.11, operators with up to 1 years experience were responsible for 25 percent of the accidents in the study period (where accident records were fully completed). Operators with 3 years or less LeeTran experience accounted for more than 45 
percent of the accidents in the study period. Assessing preventable accidents only, operators with less than 1 year of experience were responsible for 27 percent and operators with 3 years or less experience accounted for more than 60 percent of the preventable accidents.

Even with the available number of fully completed accident records, it is possible to conclude that the accident tendency of operators with 3 or less years of service was greater than that of their percentage makeup of LeeTran bus operators (45 percent to 41 percent). In the preventable accidents category, the statistics were 63 percent to 41 percent. From these cursory observations, it is evident that LeeTran bus operators with 3 years or less of service, were involved in the majority of accidents (of either non preventable or preventable) and may benefit from additional training with respect to accident mitigation and prevention.

\subsection{Summary of General Occurrence Characteristics}

Based on a review of the frequency distributions as contained in the preceding sections, it was determined that a 'typical' accident for a LeeTran bus operator during the study period:

- Occurred during the months of February or January

- Occurred on a Wednesday

- Occurred between the hour of 2:00 p.m. - 3:00p.m.

- Occurred in clear/sunny weather

- Occurred on Route 140

- Involved another motor vehicle

- Sideswipe or angle type of accident

- Non-preventable and

- Involved an operator with less than 3 years experience

\subsection{Accidents per Service Mile}

The lack of monthly service mile supplied information (for the study period) prohibited an analysis write respect to accidents per service mile provided to be undertaken.

\subsection{Other Factors Influencing Accident Potential}

Discussions with LeeTran officials revealed a number of factors which have impacted on the accident potential of LeeTran bus operators. A number of factors have impacted negatively in ways similar to the other transit properties studied (see RTS section 2.8). 


\subsubsection{Accident Location by Geographic Area}

Geo-coding of accident data allows the identification of problem location on the LeeTran Network. Figure 5.9 is an example 36 accidents that have been manually geo-coded to a base map. This tool could be use to identify patterns in accident location that could be a result of roadway configuration and signalization, traffic congestion, and bus stop location.

Figure 5.7

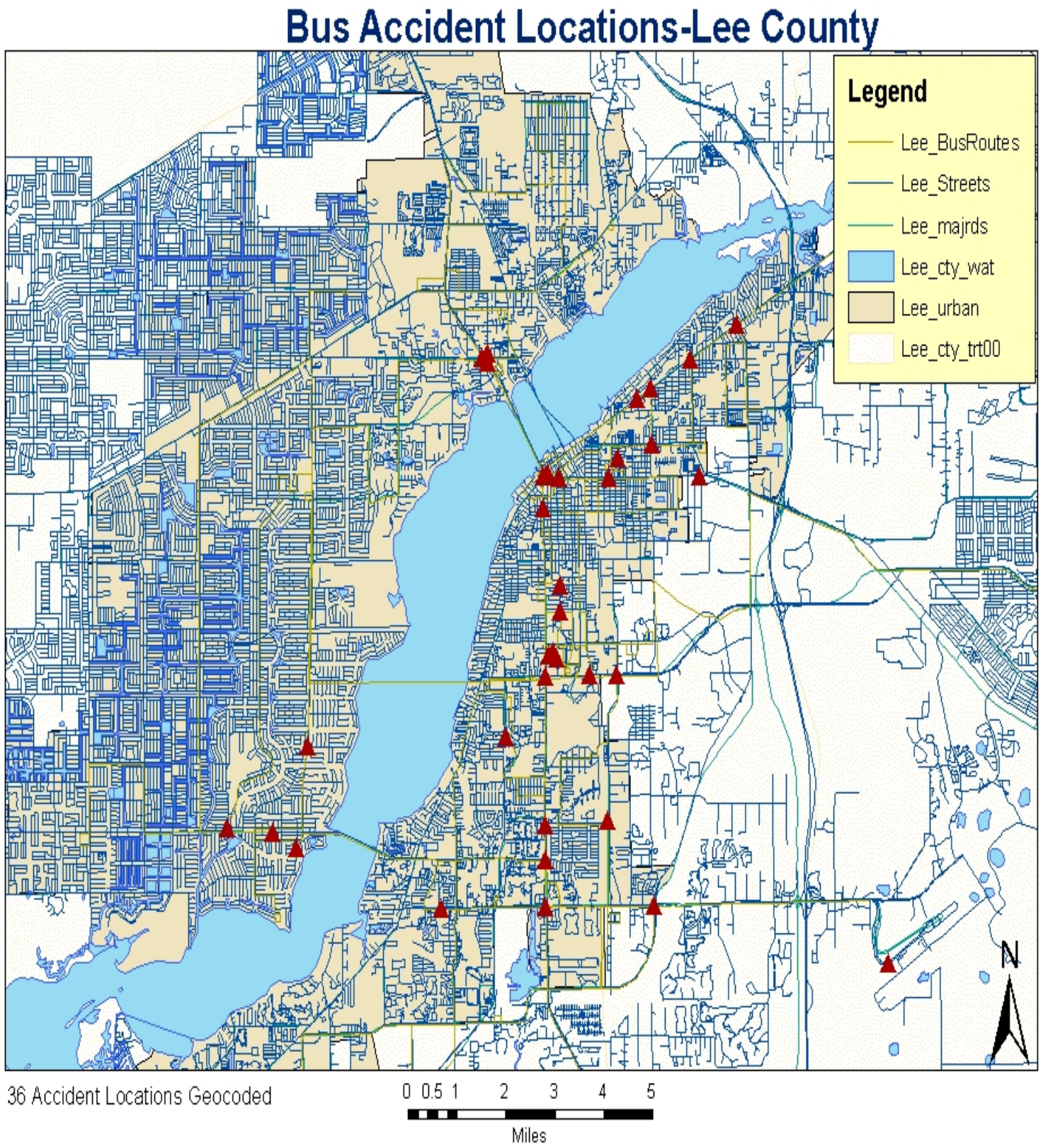




\section{CHAPTER 6 SUMMARY AND CONCLUSION}

\subsection{Summary}

In this project, transit bus accident data from four medium sized Florida transit systems was collected and analyzed in order to review changes in crash occurrence over time. The four systems selected were: RTS in Gainesville, VOTRAN in Volusia County, LeeTran in Lee County and SCAT in Sarasota. In all four cases, accident data for a minimum period of 24 months were collected from system records and analyzed.

Due to the low numbers of accidents affecting each of the four transit properties a detailed analysis of accident data was not done. The analysis as contained in this report can be seen as preliminary (based on the amount and detail of accident information available). Analysis of accidents per revenue service miles supplied (undertaken in the RTS case) can provide important information regarding bus operator levels of accident exposure. Such analysis could further be completed on a route by route basis, but the information required (i.e. revenue service miles supplied), has to be collected and disseminated on a regular basis. As this information is collected and validated, it should be incorporated into accident analysis reports, at least on a quarterly basis. The fact that detailed accident analysis is not regularly undertaken in the four transit companies, has led to the current situation where information that could be made available, e.g. monthly revenue service miles supplied, may not in the format that would make it user friendly, for the staff who may be tasked with the analyzing of bus accidents.

Consistency between each transit property with respect to recording specific aspects of each bus accident was another limitation faced during the data analysis process. It is known that bus accidents occurring at transit properties receiving Federal funds must be reported to the Federal Transit Administration, nevertheless, the non disclosure of accident information out of public sight has led to inconsistency in the amount and type of data that is collected by transit properties. For example, in the cases analyzed, some transit properties recorded the non-preventability or preventability status of each accident while others did not. In other cases, some transit properties, recorded the exact location where the accident occurred, with respect to the names of intersecting streets or prominent landmark adjacent to the accident site. The lack of a minimum requirement of accident data needs for each of the properties, resulted in the very limited level of comparative analysis that could be performed during this study. To attempt such a comparative analysis could prove problematic as each property had their own unique data needs and the resulting analysis would not be comparing 'apples' with 'apples.' Accepting that the number and type of bus accidents may be seen as a blemish on any transit property operations, the greater good that may result from comparative analysis (through data sharing) needs to be acknowledged and encouraged. 


\subsection{Conclusion}

In conclusion, based on the results of this analysis, it is apparent that a safety training program can have a positive influence on the number and type of bus accidents in the period following the program. The RTS case study showed this to be the case. Thus, the more training programs that can be held (at least on an annual basis) may improve the rate at which accidents occur at a bus agency.

One of the most enlightening aspects of this project was also encountered during an earlier study by CUTR, an 'Analysis of Florida Transit Bus Crashes' (published in June 2001), involved the process to acquire the data necessary to complete each evaluation. Thus, as mentioned earlier in the summary section, a major shortcoming of the data collection phase was that the transit properties only provided occurrence information that had been recorded in hard copy format (i.e. paper based records) or incorporated into a rudimentary electronic database. This meant that, in each case, a number of desirable variables could not be provided for analysis. It also made it necessary for CUTR to request supplementary information that was crucial to the analyses, such as, driver hire dates, or revenue service miles supplied (the latter variable enables account to be made for driver exposure). Even after requests had been made, some of this information was still not forthcoming.

Because of the data collection and analysis challenges faced during this project, it may be beneficial to reintroduce the major recommendation of the "Enhancing Safety in Florida Transit Systems" project that CUTR completed for FDOT in June 1998. In this project, a process to help Florida transit agencies track and analyze their bus crashes was developed to help the systems determine common causal factors and/or measure the success of their occurrence prevention efforts. The process involved five basic steps that should be followed by transit agencies when analyzing crash occurrence data and developing corrective action plans for addressing identified problem areas. The five steps are as follows:

\section{Collection of the data}

2. Preparation of the data for analysis

3. Analysis of the data

4. Interpretation of the results

5. Action plan to deal with identified issues/problems

Previous reports by CUTR on transit bus crashes, have recommended that the FDOT request that all of the Florida public transit systems collect the core set of crash occurrence characteristics that is detailed below. The reasoning for this recommendation was that the availability of this information on a system-by system basis would allow for not only similar analyses and comparisons between systems, but also for a comprehensive analysis of crash occurrence throughout the State. By FDOT requiring a minimum standard of accident reporting, future bus accident research, analysis and interventions can become more refined to suit the unique operating requirements of Florida Bus Transit properties. 
In the following list, those crash occurrence characteristics shown in bold are the key data elements that would be required for most safety campaign assessments. These key characteristics would be the minimum required data elements transit systems in creating a database from their occurrence records. The Access Database included in this report attempts to include these key data elements. The inclusion of the other crash data may not be necessary, it is up to the individual systems to decide on what other elements they wish to include. These supplemental data will only help to make any further analyses more thorough.

- Date, day of week, and time of day of occurrence

- Specific location of occurrence (on street and at street, longitude and latitude coordinates, intersection, cross street, plaza, mall, city, or other key location identifier)

- Location of stop (near-side, far-side, mid-block)

- Roadway surface type (concrete, asphalt, brick, gravel)

- Road way geometry (number of lanes, configuration, posted speed, traffic control)

- Roadway conditions (wet, dry, under repair, gravel, debris)

- Weather conditions (clear, cloudy, raining, foggy, other)

- Light conditions (daylight, glare, dawn, dusk, dark w/streetlights on, dark w/streetlights off, dark w/no streetlights)

- Traffic conditions (light, moderate, or heavy)

- Route number, Bus Number

- Vehicle type, manufacturer, and year of manufacture

- Observed vehicle defects at time of crash (steps, floors, seats, brakes, lights) and date of last scheduled preventative maintenance

- Operator hire and termination date (to be used to calculate years of experience at time of occurrence)

- Operator status (regular operator, regular relief, vacation relief, mini-run, extra board, mechanic, supervisor, service attend ant)

- Date of operator's last refresher training course

- Occurrence impact dynamic (head on, sideswipe, angle, rear end, backing, front)

- Type of involvement (fixed object, moving vehicle, parked vehicle, pedestrian, other bus, bike)

- Transit vehicle movement prior to/at time of occurrence (going straight, turning left, turning right, pulling into curb or loading zone, pulling away from curb or loading zone, passing, being passed, changing lanes, merging, sudden stop, slowing/braking, stopped in traffic lane, stopped in loading zone, parked, backing, starting, other)

- Movement(s) of other vehicle(s) involved prior to/at time of occurrence (going straight, turning left, turning right, pulling into curb or loading zone, pulling away from curb or loading zone, passing, being passed, changing lanes, sudden stop, slowing/braking, stopped in traffic lane, stopped in loading zone, parked, backing, starting, other) 
- Pedestrian/cyclist movement prior to/at time of occurrence (walking/running/riding with traffic, walking/running/riding against traffic, stationary, working in roadway, playing in roadway, unknown, other)

- Pedestrian/cyclist action related to location of occurrence

- At intersection (in crosswalk, not in cross walk, no crosswalk, with sign/signal, against sign/sign al, no sign/signal)

- Not at inter section (crossing diagonally, crossing in front of vehicle, crossing from behind vehicle, getting in/out of other vehicle, crossing from between park ed cars, other)

- Passenger movement prior to/at time of occurrence (waiting, boarding, alighting, standing in vehicle, moving in vehicle, sitting in vehicle, on lift, other)

- Observed condition of other driver/pedestrian/cyclist/passenger (influenced by alcohol/intoxicated, sober, sleepy/fatigued, infirmed, wearing glasses, carrying objects, with an observable disability, no observable disability, other)

- Contributory factors (vehicle double-parked, vehicle in crosswalk, pedestrian jaywalking, vehicle pulled out in front, vehicle parked at angle, vehicle parked in zone, other)

- Evasive action(s) taken b y driver (hard braking, swerve, other)

- Identified preventability status of occurrence

Though the above listing may be seen as exhaustive, it can mark the start of discussions between FDOT, bus transit systems and CUTR, as to what exactly should Florida bus transit properties collect with respect to bus accidents affecting their operations. 


\section{REFERENCES}

National Transit Database, 2001

http:/www.ntdprogram.com/NTD/ntdhome.nsf/Docs/NTDData?OpenDocument

University of Florida Facts and Rankings http://www.ufl.edu/facts.html

City of Lee County

http://www.cityofLee County.org/

City of Cape Coral

http://www.capecoral.net/

Florida Department of Community Affairs - Population Estimates

http://www.dca.state.fl.us/ffct/2003\%20Population\%20Estimates.htm

National Transit Database, 2001

http://www.ntdprogram.com/NTD/ntdhome.nsf/Docs/NTDData?OpenDocument

Votran News and General Information

http://volusia.org/votran/news.htm

National Transit Database, 2001

http://www.ntdprogram.com/NTD/ntdhome.nsf/Docs/NTDData?OpenDocument

University of Florida Facts and Rankings http://www.ufl.edu/facts.html

City of Gainesville

http://www.cityofgainesville.org/

Census 2000, Population Estimates 2000 - 2003

http://eire.census.gov/popest/estimates_dataset.php

Division of Colleges \& Universities Facts and Figures

http://www.fldcu.org/factbook/quickfacts.asp

National Transit Database, 2001

http://www.ntdprogram.com/NTD/ntdhome.nsf/Docs/NTDData?OpenDocument

Sarasota Government Network

http://www.co.sarasota.fl.us

\section{ACKNOWLEDGEMENTS}

Dorothy Nelson - Acting Operations Manager

Mike Horsting - Transit Planner

Anthony DeFuria - Transit Manager

Dr. Steve Polzin - Director Transit, Center for Urban Transportation Research

Jerry G Walker - Transit Supervisor

Harry Howell - Training Supervisor

Phil Lieberman - SCAT

George Kuyper - SCAT 


\section{APPENDIX A}




\section{Accident Database Manual}

\section{Getting Started}

To install the application from the $\mathrm{CD}$ on to your computer follow these steps:

- Insert the $\mathrm{CD}$ in the CD Drive.

- Go to My Compute or -> X drive (Where X is the name of your CD Drive)

- Double Click CD drive on the icon. This will take you to the contents of the CD.

- The file to be copied is the Access Database is called Accident.mdb.

Single click on Accident.mdb. Go to Edit->Copy and then go to the destination drive/folder where you want to store the database on your computer. Then Click Edit->Paste.

Follow the same procedure for user's guide.

Click on: Start-> Programs->Microsoft Office-> Microsoft Office Access.

Click on File -> Open

Locate the access program file on your computer and

Click on the access “Accident” program-> Click on Open.

A dialog box appears, Click on Open

\section{If a warning dialog box appears after clicking on open, ignore it and continue to open the program.}

\section{The Main Screen}

From the main screen two operations can be preformed: Data Entry, and Running Queries and Reports.

\section{To Start Data Entry}

Click On "Open AccidentsForm" button and the accident database form will open. You are now ready to start entering your accident data in to the database. The Accidents Form can be used to add, delete, or modify accident records.

\section{Note: Access automatically saves your data after you enter it into a field.}

\section{Adding a New Record}

To add a new record to the existing database, click Add record button on the bottom right corner of the form. Enter the data, and click exit. Your data is now saved.

\section{Navigating Through Records}

Each accident record will be displayed individually, and can be viewed sequentially using the navigation buttons at the left bottom corner of the form.

\section{Deleting a Record}

To delete an accident record, click on the "Delete" button at bottom right corner of the form. This will delete the current record, and take you to the next record in the sequence. 


\section{Changing Data in a Record}

To change data in a field go to that record using the navigation buttons. The changes you made will be auto saved.

\section{Exit Form}

The "Exit" Button on the form will close the form, and bring you back to the main Screen.

\section{Running Reports}

On the main switchboard, click on the button "Run Queries and Reports".

This takes you to the "Database Analysis and Report Page."

Click on a "Report" button, the report is displayed in the "print preview" mode, ready to be printed.

\section{Printing Report}

To print the report, Click on the "Print" button on the toolbar, or click File -> Print. To close the report click "Quit" button the Report Screen or "Close” button on the toolbar.

\section{Closing the Reports Screen}

To close reports screen, click on the "Exit" button" at the bottom right corner. This will take you back to the main screen.

\section{Fields on the Form}

\section{Employee Number}

This is the only way that the database can identify the employee, since all of the data is anonymous with regard to the individuals involved in the reported incidents.

\section{Hire Date}

Employee's date of hire. The format of the hire is: 09/02/1977 (mm/dd/yyyy).

\section{Accident Number}

Number assigned to the accident.

\section{Month}

Pull down menu that shows the month of the accident.

\section{Date}

Date of the accident. Example: 7

\section{Year}

Pull down menu of the year of the accident.

\section{Day of Week}

Pull down menu of the days of the week.

\section{Time}

This is time of the accident. The format is "HR: MM AM/PM (11:14 AM)

\section{On Street}

The Street the accident occurred on. 


\section{At Street}

The closes intersection or land mark to accident location.

\section{City}

The city the accident occurred in.

\section{Weather}

A pull down menu of weather conditions at the time of the accident. Pick the selection that most closely matches the accident conditions.

\section{Light}

This is a pull down menu of light conditions at the time of the accident. Pick the selection that most closely matches the accident conditions.

\section{Impact}

This is a pull down menu of impact types. Pick the selection that most closely matches the accident circumstances.

\section{Bus Route}

Enter the name or number of the system route on which the incident occurred.

\section{Bus Number}

Enter the number of the system vehicle involved in the incident.

\section{Road Type}

Pull down menu. Pick the selection that most closely matches the road type of the accident.

\section{Roadway Condition}

This is a pull down menu. Pick the selection that most closely matches the roadway condition at the time of the accident.

\section{Involvement Type}

Pull down menu. Pick the selection that most closely matches the involvement type.

\section{Manufacture}

Pull down menu. Pick the manufacture of the vehicle involved in the accident.

\section{Year}

Pull down menu. Pick the manufacture year of bus involved in the accident.

\section{Traffic}

Pull down menu of congestion level at time of accident.

\section{Preventable Status}

This is a pull down menu. If the accident was preventable, the box should say "PREV." If the accident was not preventable, the box should say "NP."

\section{Post Accident Testing}

This is a pull down menu. If the driver was tested for drugs or alcohol as a result of the accident, the box should say "Yes". If driver was not tested for drugs or alcohol as a result of the accident, the box should read say "No". 


\section{Last Training}

This is the date of the last training.

Training Type

Last training taken my employee. (Defensive driving, CDL etc;.)

\section{Accident Description}

Enter a description of the accident.

\section{Questions}

For question or assistance with Analysis of Florida Transit Bus Accidents Database contact:

Deborah Sapper

Center of Urban Transportation Research (CUTR) University of South Florida at: sapper@cutr.usf.edu or by phone at 813.974.1446 
